\title{
(The) Margin(s) Speak! A Multifaceted Examination of Practising 'Men who have Sex with Men' Development in Bangkok
}

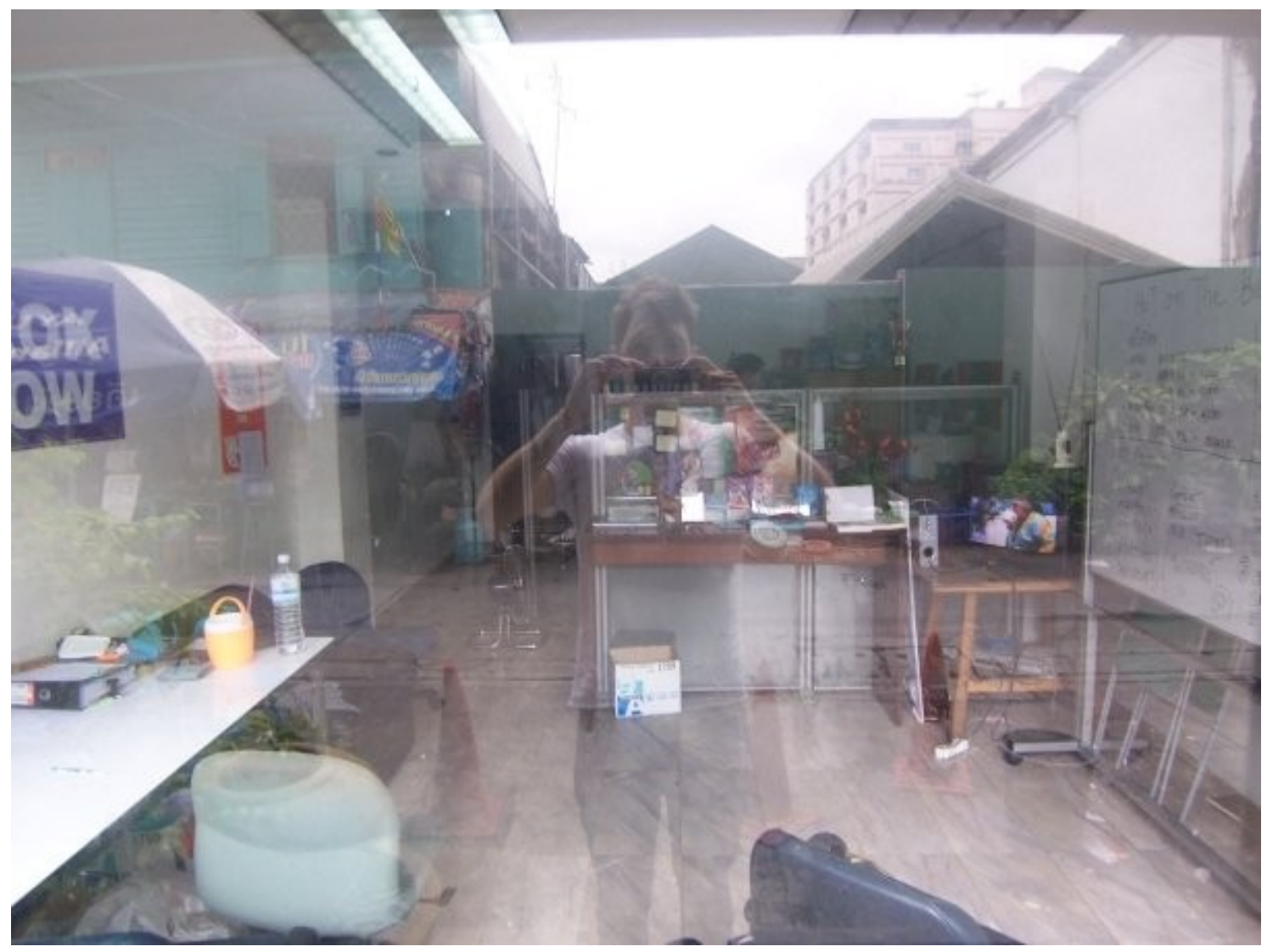

A thesis submitted to Victoria University of Wellington in partial fulfilment of the requirements for the degree of Master's in Development Studies

By James (Jamie) Burford 2010

Te Kura Tatāi Aro Whenua

School of Geography, Environment and Earth Sciences

Te Whare Wānanga o te Ūpoko o te Ika a Māui Victoria University of Wellington

Aotearoa-New Zealand 
[The photograph on the cover is my own. It was taken during one of many visits to Bangkok Rainbow during my field study. The camera captures a blurry image of the inside of a humble working office in one of Bangkok's gayer suburbs, saphan-kwai. Within the picture I can barely see traces of queerness. The rainbow wig on the mannequin that stands in the corner, and the final letters of the purple 'Bangkok Rainbow' sign. The photograph illustrates the size of the office I spent many months visiting. A small partitioned room, with a bathroom and storage out the back. Also seen is my image reflected in the glass as I make my study. I appear shimmery, floating in the middle of a liminal space, the space between inside and outside. In making my study, I am always present, 'contaminating' what I see. I have chosen this as the opening text of my thesis as a way of introducing its spirit. I act as a vulnerable author (Behar, 1996); placing myself on the page in an effort to draw attention to the important issues into which my re-search inquires.] 


\begin{abstract}
In this study, I explore the experiences and understandings of twenty-seven participants involved with 'men who have sex with men' (MSM) development interventions in Bangkok, seeking to better understand the complex realities that emerge in practising MSM development. I endeavor to interrogate the development field's limited understandings of sexuality as well as the discourses present (and absent) in existing Queering Development research. By acknowledging my personal journey in and through this re-search, I also examine authentic ways-of-being a queeresearcher, noting the challenges I faced and power I discovered in re-searching and re-presenting my own work. Ultimately, I explore the link between the paucity of local developing queer narratives in Queering Development and the limited space students have, to be visibly queer in mainstream theses - to do this I use the metaphor of 'the margins'.
\end{abstract}

In framing this re-search, I draw nourishment from queer, critical, poststructural and Participatory Action Research epistemologies. Methodologically, I carried out semistructured interviews and focus groups, as well as using other tools such as mapping and story writing. I also spent time 'hanging out' at both Rainbow Sky and Bangkok Rainbow, enabling both a deeper appreciation of the work carried out by the organisations as well as providing an opportunity to gather materials. The generation of data did not cease once I left 'the field'; I continued to produce autoethnographic texts including poetry and a research performance which I used both as a method of enquiry and re-presentation of this study. This multifaceted approach enabled diverse questions (emerging across disciplines) to be addressed in my work.

To re-present my analyses of participants' accounts I have celebrated different ways-ofknowing re-search. I have used poetry and consciously performative writing, visual art (including graffiti) and performance alongside traditional scholarly prose. This approach enables multiple voices to emerge all over the page, questioning the hegemony of the bound, straight-lined thesis and the 'legitimate' knowledges it generally contains. I argue that queer postgraduate students may be able to open spaces to produce authentic work, despite pressures to perform straight research texts. Yet, pressures to conform to 
traditional understandings of theses may be painful reminders of their own positions in academia and society.

Overall, my study offers intimate, multifaceted perspectives on the agency of MSM development practitioners in Bangkok and my own experience of finding power through queeresearch. I hope it will contribute to more nuanced understandings of local practitioners of MSM development in Queering Development literature, and to scholarship on queer postgraduate students' experience of re-search more generally.

\section{Key Words}

Development, Queering Development, MSM, Thailand, agency, power, queer research representation, arts-informed methodologies, performative writing, alternative theses. 


\section{Acknowledgements}

To the people who participated in this re-search, who generously gave their accounts, despite their hectic schedules and the sensitive nature of our discussions - I thank you. The testimonies present in this re-search certainly speak of a thoughtful 'sexually diverse' community in Bangkok. I express my gratitude to representatives of both Rainbow Sky Association of Thailand and Bangkok Rainbow for their permission to study alongside their organisations. I also thank Victoria University and Education New Zealand for making this project financially viable with a VUW Master's Thesis Scholarship and an Education NZ Travel Grant. I thank my supervisor Sara Kindon for acting as a gentle guide and encouraging me to innovate, create and feel my way through this re-search.

Special thanks must go to several people who played active roles in Thailand. First, Timo for his willingness to interpret and explain the complexities of Thai sexual and gender cultures to a relative newcomer, and for his later role as fact-checker. Thanks also to Hua for her patience and ability to create opportunities for me to deepen my knowledge, Paisarn for embarking with me on challenging conversations and $\mathrm{P}^{\prime} \mathrm{OW}$ for his friendship and encouragement. I must also thank Monique and P'Jang for the hilarious Thai lessons. There are many other friends who requested I do not name them in this work; I thank you all for your courage and support.

To Mon, Tom and Matilda I thank you for accompanying me along this long and emotionally tumultuous journey. To my fabulous dyossas (goddesses) Eunica, Kate and Sarah for nourishing my mind and spirit, and reminding me what theses can be. To Carl and Chloe for asking questions and giving it to me blunt. To Chris and Nins for leading the way. It takes a community to raise a thesis, thanks here go to my queer whānau in Dunedin, Joey, Sam, Pip, Hana, Ros, Heidi, and Leigh, thanks for reminding me to make time for this, alongside my other duties, for laughing and crying when each was necessary. To the Otago University Students Association Student Support Centre Staff for supporting me in moonlighting as OUSA Queer Support Coordinator and sometime thesis student. To Rhona and JC for the proofing. To Larry for reading my poems. To Mum'n'Dad for the financial, emotional and nutritional sustenance. Finally to Aun for reminding me that this is both an end and a beginning. 


\section{Table of Contents}

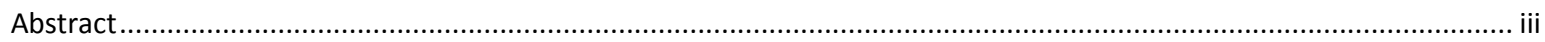

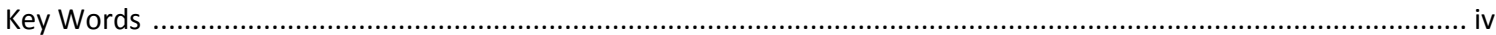

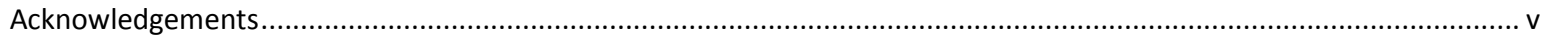

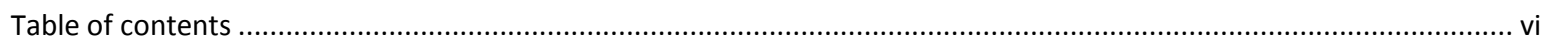

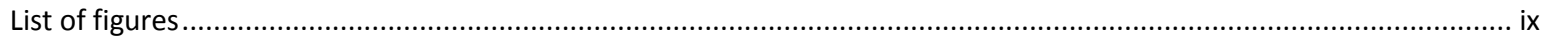

Map of Thailand

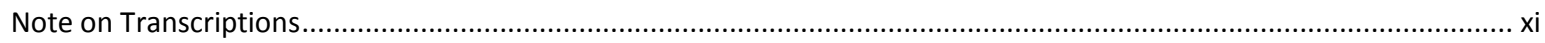

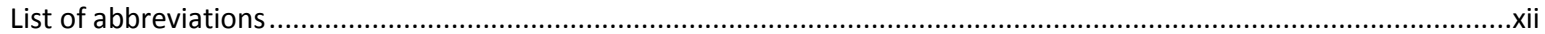

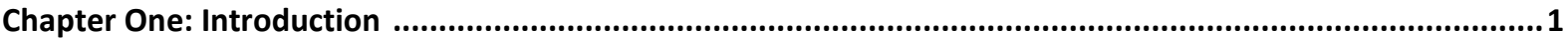

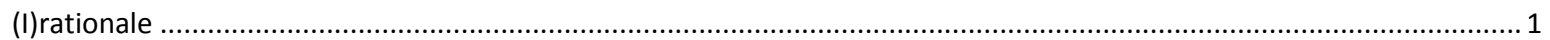

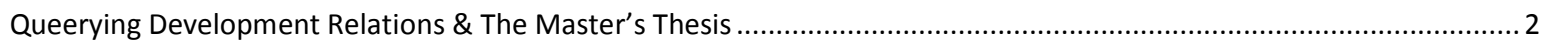

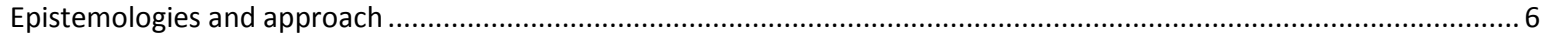

Thesis Structure

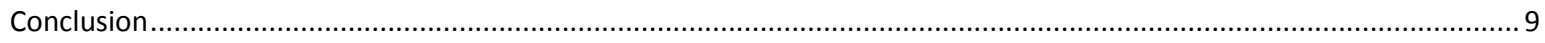

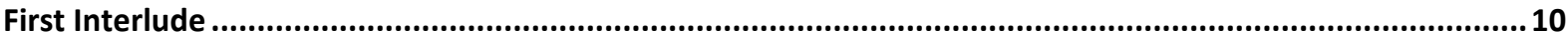

Foregrounding Background: A Personal Introduction to the Inquiry ...................................................................... 10

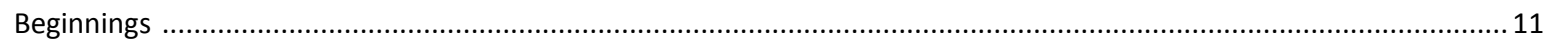

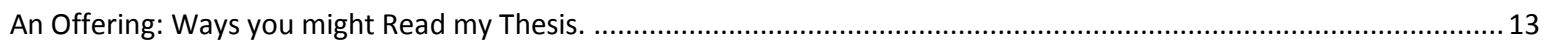

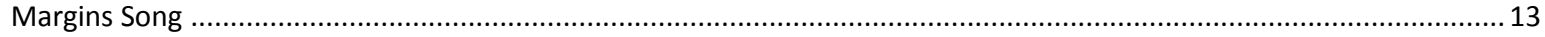

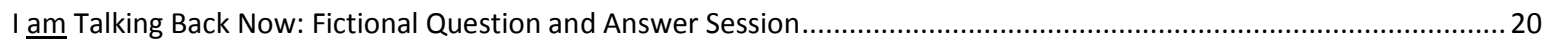

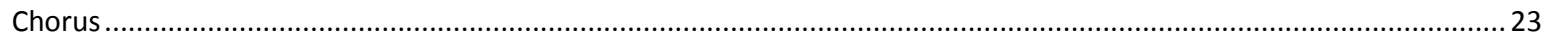

Mantras

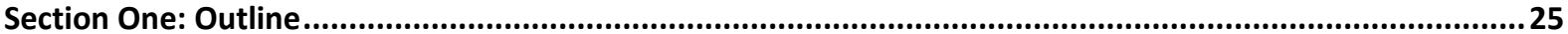

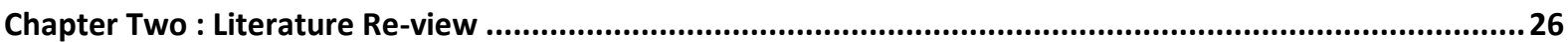

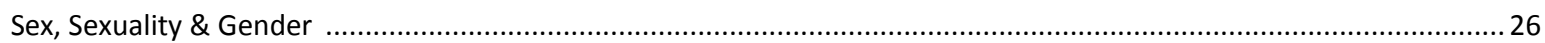

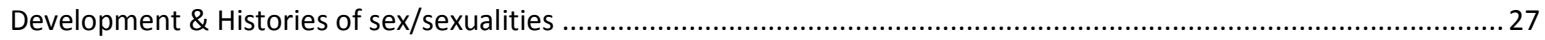

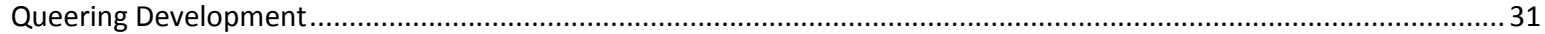

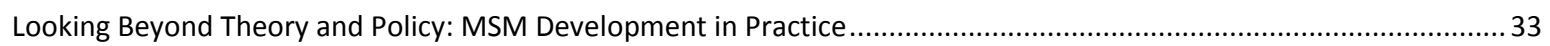

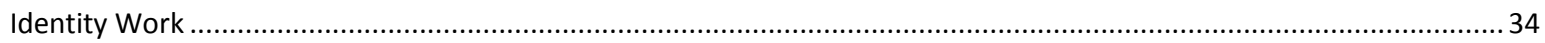

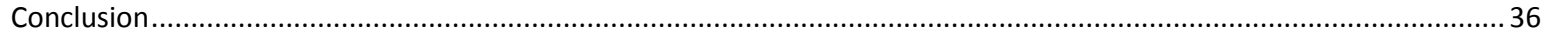

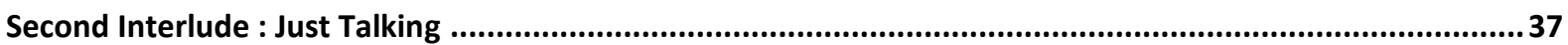

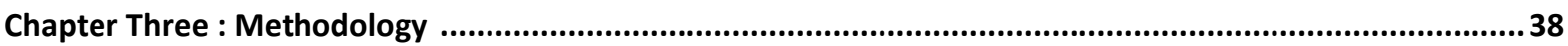

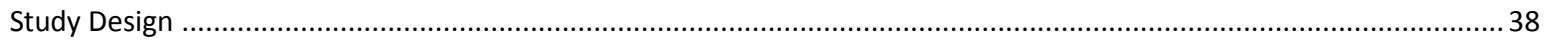

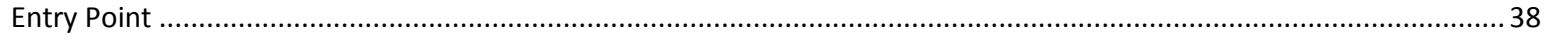

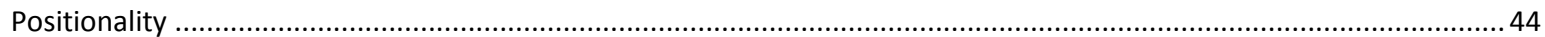

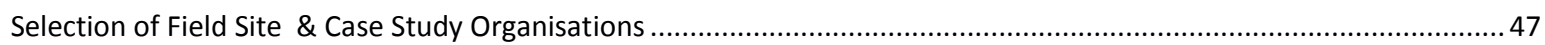

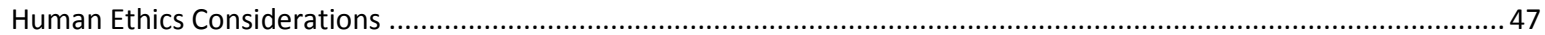




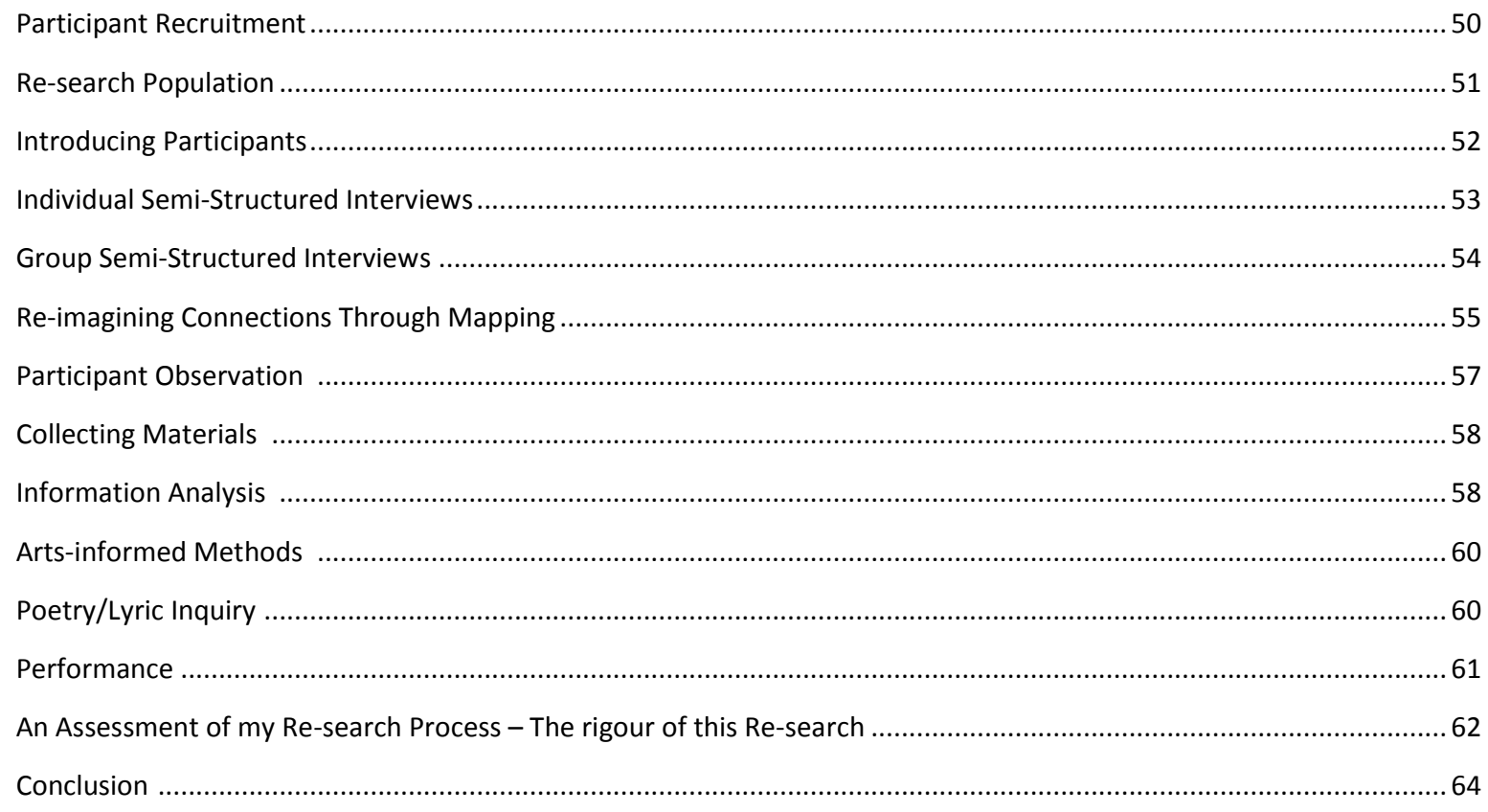

Third Interlude: Re-membering the Re-searchers Body ...............................................................65

Chapter Four : Rainbow Organisations - Establishing Context ........................................................66

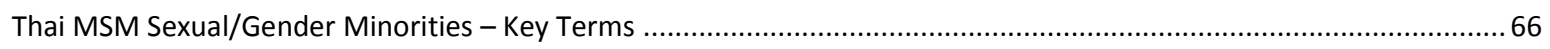

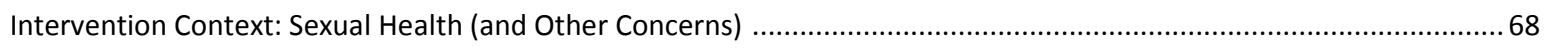

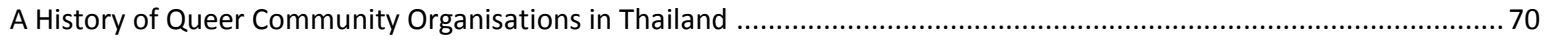

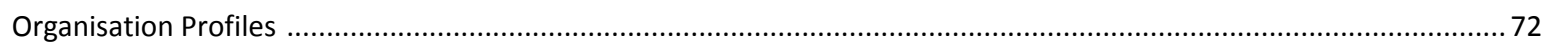

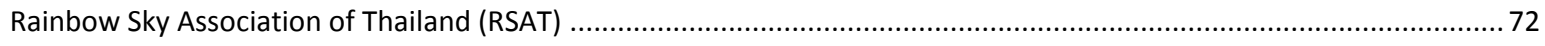

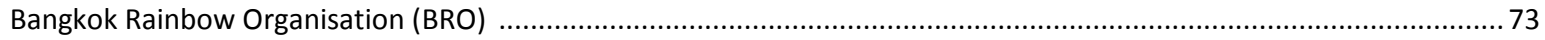

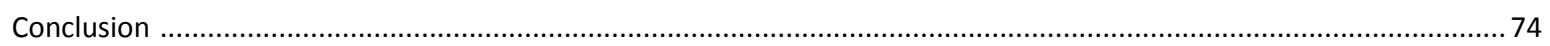

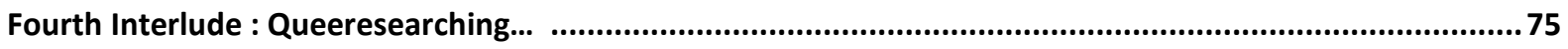

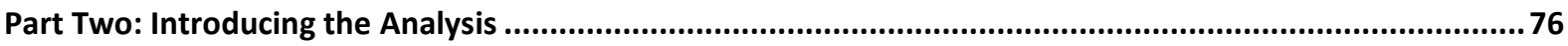

Chapter Five : "It's More Complex than that!" MSM CBO-Donor Relationships in Bangkok...........................77

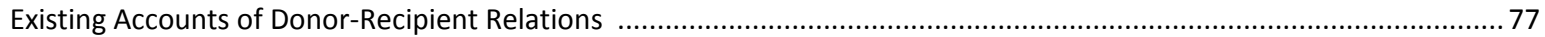

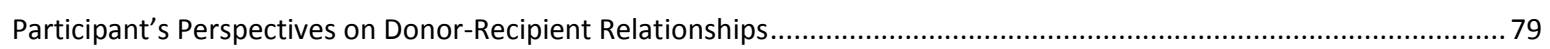

Participant's Perspectives on Donor Priorities - Well Intentioned 'Condom Mania'? ................................................... 84

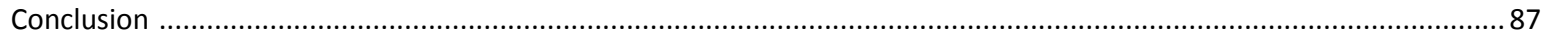

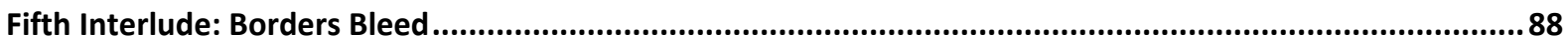

Chapter Six : Fields of Power/Knowledge - Structural Limitations to Practitioner Agency............................89

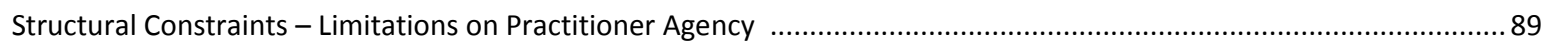

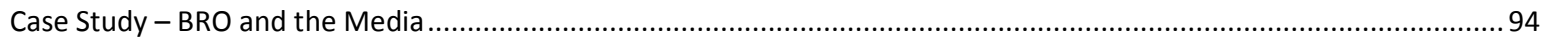

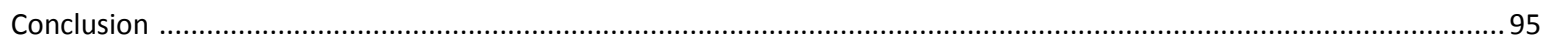

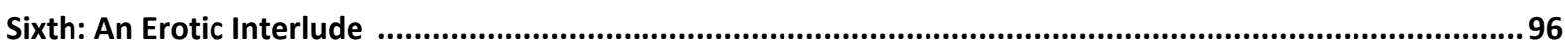

Chapter Seven : Re-searching Hidden Spaces - Collateral Benefits of MSM Interventions in Bangkok .........97

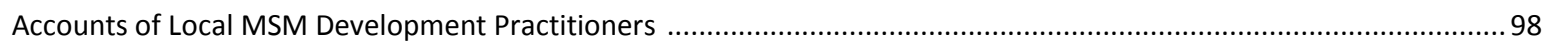

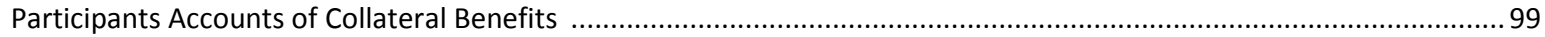




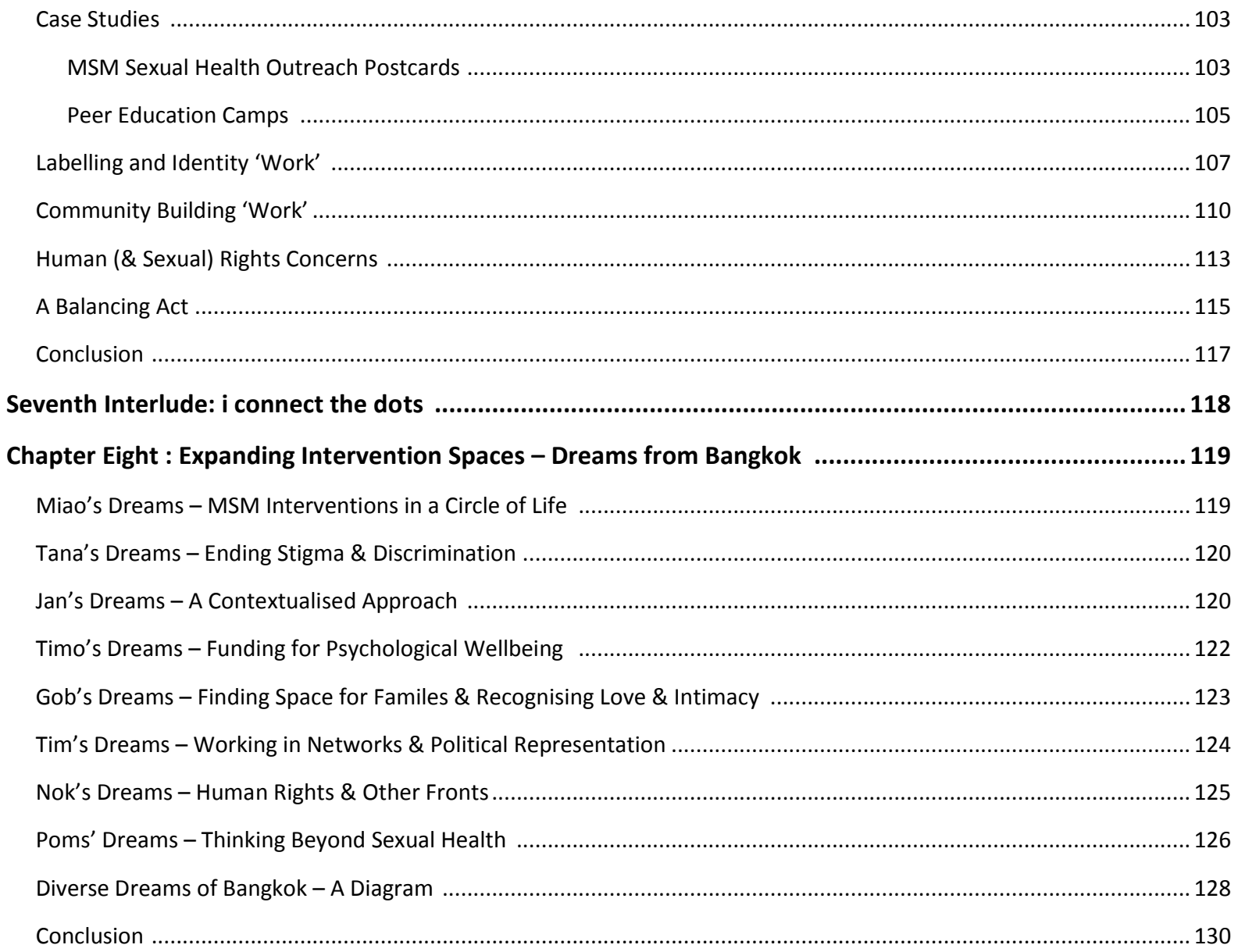




\section{List of Figures}

Figure 0.1 Map of Thailand ...

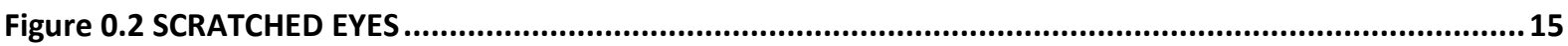

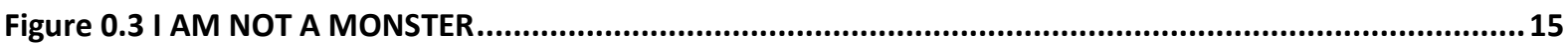

Figure 3.1 Jet's Interpretation of the Organisations that work with MSM .................................................55

Figure 3.2 Gob's Interpretation of the Current Distribution of Funding ...................................................56

Figure 3.3 Gob's Ideal Re-configuration of Funded MSM Priorities .........................................................57

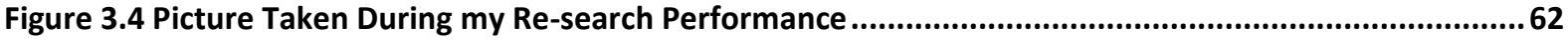

Figure 4.2 List of Organisations Which Target MSM in Thailand ..............................................................71

Figure 7.1 Diagram of Collateral Benefits of MSM Development Practice in Bangkok ..................................79

Figure 7.2 A 2007 Postcard Used for Outreach Activities .................................................................. 103

Figure 8.1 Diverse Dreams For Bangkok - A Diagram .......................................................................128 
Map of Thailand

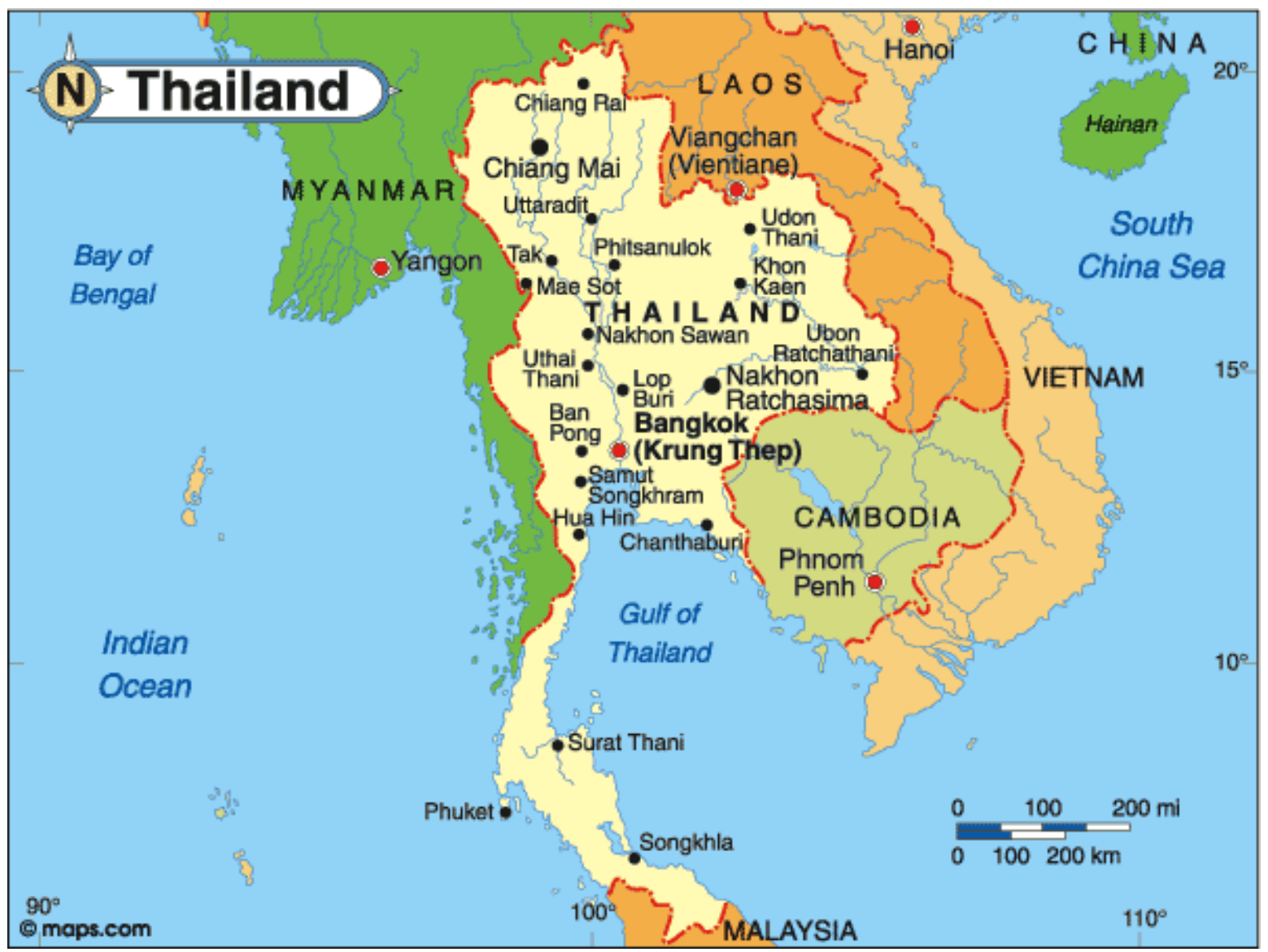

Figure 0.1 (2010 - Country Watch) 


\section{Note on Method of Transcription}

In my thesis I have elected to use the modified version of the Royal Thai General System of transcription (RTGS) used by Ojanen $(2009,2010)$. Ojanen $(2010)$ argues that RTGS fails to differentiate between certain important features of the Thai language, which have been accounted for through his adaptions.

Ojanen's changes enable short and long vowels to be distinguished through the use of a double vowel system. Excepted are Thai vowels that do not have a single-letter symbol in the Latin alphabet. Ojanen explains,

The two Thai o sounds ( and ), both of which roughly approximate the English oh but are differentiated sounds in Thai, are differentiated here by underlining the former in transcription (e.g., the underlined ŏo in mŏo refers to the sound; the not underlined oo in rôk refers to the sound). The sound represented by the letter is distinguished from the sound represented by the letters , and by using the Latin letter "j" for the former, and "ch" for the latter. (Ojanen, 2010, p. xvi)

Tones are indicated by marks placed on the vowel in each syllable. I have exempted English loan words such as gay, both, tom, versatile and bi, which are left in their original form. Direct quotations are also left in their original form. Names of people are transcribed in the preferred spelling of the person. 


\section{List of abbreviations}

MSM-

Men who have Sex with Men

HIV/AIDS -

Human Immunodeficiency Virus / Acquired Immune Deficiency Syndrome

$\mathrm{BRO}-$

Bangkok Rainbow Organisation

RSAT-

Rainbow Sky Association of Thailand

LGBT -

Lesbian, Gay, Bisexual, Transgender

PAR -

Participatory Action Research

NGO -

Non-Governmental Organisation

$\mathrm{CBO}-$

Community Based Organisation

RTGS -

Royal Thai General System of transcription

HEC -

Victoria University Human Ethics Committee

WSW -

Women who have Sex with Women

TG -

Transgender

MSW -

Men who have Sex with Women

CQR -

Critical Qualitative Research 


\section{Chapter One: Introduction}

Multifaceted scholarship turns and twists, stands to all sides, considers; it looks under and over, searches from top to bottom, ponders; it walks around, digs into, and tunnels before it acknowledges that it can never see it all. (Pelias, 2004, p. 12)

\section{(I)rationale}

The productive relationship between queers and the development ${ }^{1}$ industry is little theorised, swept to the margins of development theory and policy: "Mention the word, 'sexuality' to people involved in development policy and practice and the reaction is often one of puzzlement - what does sexuality have to do with development?" (Cornwall, Corrêa, \& Jolly, 2008, p. 5).

It is only in the last decade that significant discussions concerning this intersection have taken place (see Hunt, 2008). While small pockets of scholars, activists, and policy-makers are turning their minds to these connections, for many in the development industry 'sexuality' is a frivolous matter, a distraction from the real grunt work to uplift marginalised (and often assumed heterosexual) people.

My thesis builds on the gaps identified by Tan (2000), who questioned how development concerns (such as HIV/AIDS) affect discourses of sex and sexuality in 'developing' countries. By enquiring in this direction, I also take up Hunt's challenge to identify sexuality in development studies. Hunt explains "we all know what is unnamed is more likely to be unsupported, ignored and misunderstood" (Hunt, 2008, p. xi). My thesis represents my desire to name queerness in development. I have drawn on a series of texts: international literature and policy documents, texts generated from interactions with actors involved with MSM development in Bangkok including: regional representatives, practitioners, community activists, and the 'targets' of interventions, and finally autoethnographic texts I created myself.

\footnotetext{
${ }^{1}$ The single word of 'development' obscures a diversity of understandings. In thinking about 'development' I have made use of Corrêa and Jolly's (2008, p. 23) conception of the "cumulative improvement of human subjectivities and relations".
} 
Local MSM development practitioners are the focus of my re-search ${ }^{2} .1$ inquire into their experiences asking: how do these relationships work? What are the continuities and disjunctures of understanding between international theorists and policymakers and the practitioners of 'MSM' development in Bangkok? How would practitioners see the relationships constituted otherwise? I attempt to open up these questions, registering different and contradictory perspectives. By dispensing with monochrome modernity and its 'core truths', I enter the garish world of post-modernity, glimpsing "messes to smear around" (Gray, Ivonoffski, \& Sinding, 2002, p. 57), many truths. Starting from a position that sees MSM development interventions as constituting political and moral acts which alter the sexual meanings and practices of developments subjects, I view developing-MSM interventions as ethical encounters. Seeing these relationships in this way leads me to ask, are these interventions actually creating space for sexual subjectivity? Or, by objectifying queer sexualities as only a sexual health concern, do they simply obscure the need for change in wider socio-cultural contexts?

\section{Que(e)r(y)ing Development Relationships and The Master's Thesis}

My re-search explored the understandings and experiences of practitioners of Men who have Sex with Men (MSM${ }^{3}$ ) development in Bangkok. I depart from existing Queering Development accounts to reveal local practitioners as capable of exercising agency which enables them to work toward their priorities and passions. Like Queering Development authors I also recognised the limited room that practitioners have to manoeuvre yet, I offer something new by accounting for the collateral benefits of existing interventions with MSM.

My re-search revealed that MSM development practitioners in Bangkok do address the needs they identify as central to their purpose, often without explicit financial support from

\footnotetext{
2 I have deployed 're' as a "living prefix" (Bridgman, 2000, p. 3). In “working the hyphen" (Fine, 1994, p. 70) I bridge gaps between knowledges, "working in the creative spaces between our 'normal' lives.... [and] areas of transformation and possibility" (Bridgman, 2000, p. 16). Thus, for me 're-search' signifies my attempt to 'search' between mainstream research and alternative possibilities.

3 The label 'men who have sex with men' (MSM) was originally developed by epidemiologists as a way of describing sexual practices without necessarily understanding a persons' chosen sexual identity. It has been widely adopted in HIV/AIDS work. 'MSM' is widely critiqued for its focus on physical interactions while minimising love, emotions and desires (Gosine, 2006), and because it is often used to describe male to female transgender people who may understand and experience their gender as 'women' or a third sex rather than as 'men'.
} 
their international and domestic donors. I also ask whether the existing situation could be greatly improved if donors took a more humane approach to MSM subjects - seeing them as embodied and sensual beings. Informed by critical readings of development studies literature and drawing nourishment from poststructural and queer theories, I repeat calls for a politics of sexual embodiment in development interventions with queer subjects;

Adding sexuality takes us further, to reframe development itself as fundamentally concerned with the promotion of the well-being of whole people, not just in relation to their utility or capacities, their economic or social needs or their civil and political rights, but in terms of all that makes us fully human... we need to reclaim sexuality as an important area of human experience. (Cornwall, et al., 2008, p. 21)

I also attempt to expand the existing discursive space, by entering a field of play (Richardson, 1997) with my participants to dream up possibilities for future queer development.

Fructifying my project has necessitated that I investigate authentic possibilities (Four Arrows, 2008) for approaching this Master's Thesis. This particular work could not be created as scholarship-as-usual. To express my goal of articulating an embodied approach to queer subjectivity in development I also had to oppose the heterosexist hegemony of 'rational' scientism and its consoling and distanced writing in my thesis. I have attempted instead to craft embodied, multifaceted, proud, playful, subversive, elegant, pleasure-filled scholarship (see also Bingham, 2003, p. 161) with the hope that it will breathe life into the alternatives that are offered here for development interventions with queers ${ }^{4}$. My preference in choosing a queer re-search and re-presentation methodology represents my rejection of:

\footnotetext{
${ }^{4}$ In this study I use 'MSM' to describe males who are the 'developing' targets of the organisations with whom I studied. I use this term strategically because it enables for a more coherent examination of the international landscape within which queer people come to be 'developing/developed'. I do so with caution, conscious of the essentialism within the term 'men' and the objections raised by some of my participants that it privileges the 'sexual' over other dimensions of lived experience. I use 'queer' in a personal sense to describe my own experience of a fluid gender/sexuality. I also use it in a broader sense across cultures as a composite term for those with non-normative genders and sexualities. My use of the term is also political, in that it problematises unitary subjectivity.
} 
a minoritizing logic of toleration or simple political interest-representation in favour of a more thorough resistance to regimes of the normal...The insistence on 'queer' a term initially generated in the context of terror - has the effect of pointing out a wide field of normalization, rather than simple intolerance, as the site of violence. (Warner, 1993, p. xxvi)

Accordingly, I allow borders to bleed - socialscienceliteratureartspersonalacademic flow together, animating multiple meanings and dangling possibilities for re-thinking and refeeling. The ripe and ragged-edged words are consciously performative, intended to be coowned. This is new writing (Denzin, 1997), situating me in the seventh moment of qualitative research (Denzin, 1997, 2003). My work is a messy text (Denzin, 1997) comprising graffitied margins, poetry, as well as chapters of scholarly prose. The words of Wendell Berry's poem In Rain evoke my intellectual/spiritual/emotional journey:

The path I follow

I can hardly see

it is so faintly trod

and overgrown.

At times, looking,

I fail to find it

among dark trunks, leaves

living and dead. And then

I am alone, the woods

shapeless around me.

I look away, my gaze

at rest among leaves,

and then I see the path

again, a dark way of going on

through the light.

(Berry, 1987) 
Through my thesis, I invite the reader into a closer relationship, one which dispenses with the 'body building competition' approach to writing where the goal is to posture oneself to appear as strong as possible like "a human fucking penis" (Duggan, 1995, p. 176). Instead, I wish to reach out to ways of knowing and feeling that may be left untouched by mainstream approaches to writing theses. I value vulnerability, communication and sharing. While I attempt to extend an open hand to my readers, at times I crave provocation, never quite forgetting the trigger to my middle finger. I yearn to challenge the audience to imagine how development interventions with queers might be otherwise, and to induce self-critical reflection. My final aspiration is to craft a healing room ${ }^{5}$ for myself and the participants in this re-search, a creative space where we develop emotionally, spiritually and intellectually, fortifying compassion and strength.

With the above in mind, my study seeks to answer the following questions:

1. How is the domain of 'MSM/queer' sexuality understood in development theories and discourses?

2. How are development relationships experienced and understood by local MSM development practitioners in Bangkok?

3. What can the perspectives of MSM development practitioners in Bangkok offer to the development industry's understandings of, and interventions into queer sexualities more broadly?

4. What authentic and healing alternatives exist for approaching thesis re-search, writing and re-presentation?

Connected to the above questions, the key re-search objectives are:

1. To explore the histories of MSM/queers in development theory, policy and practice.

2. To share the empirical accounts of local people involved in the MSM development industry in Bangkok.

3. To explore, reflect on and evoke the experiences and understandings of MSM development related in these accounts.

\footnotetext{
${ }^{5}$ Thanks for this term go to Sinead O'Conner for the song "The Healing Room" released in 2000 on the album

"Faith and Courage".
} 
4. To examine the implications of these experiences and understandings in terms of existing accounts of MSM development practitioner agency.

5. To share my account of this re-search experience and examine how my queeresearcher ${ }^{6}$ subjectivity impacted upon the re-search process (and vice-versa), as well as offering alternative ways-of-knowing queeresearch and re-presentation.

In general, I hope that my re-search will contribute to the growth of multifaceted understandings of the outcomes of MSM development practice, and to wider conversations about the value of alternative forms of knowing and re-presenting re-search.

\section{Epistemologies and Approach}

According to Denzin and Lincoln (2000, p. 3), qualitative research concerns itself with "attempting to make sense of, or interpret, phenomena in terms of the meanings people bring to them". It is with this understanding that I attempt to be reflexive about my own understandings around what knowledge is, and how this has impacted on the decisions I have made throughout my re-search. In the above sentence the word attempt has been italicized to underline my belief that ways-of-knowing are neither fully knowable nor necessarily enduring. Indeed, I contend that throughout re-search journeys many ways-ofknowing and doing are called upon and developed. Bearing this in mind I share some of the ways-of-knowing that I can trace throughout my work.

Queer epistemologies (see Binnie, 1997) strongly influenced my work. I understand 'queer' as a reclaimed word, a "banner under which dishomogeneity and differences [can] be claimed" (Alsop, Fitzsimons, \& Lennon, 2002, p. 95). Queer theory emerged out of suspicions about identity politics which pivoted on the idea that homosexuality is 'natural' and deserves the respect that is accorded to heterosexuality. Queer activists and scholars argued that naturalising accounts of homosexuality require the maintenance of identities, creating borders which need policing. Instead, they conceptualised sexuality as slippery and transitional. Queerness encompasses a multiplicity of desires in which identity is seen as performative, something assembled from existing discursive practices (Kole, 2007). Queer

\footnotetext{
${ }^{6}$ This term foregrounds that for some queer researchers there is a struggle to align their overlapping queer and researcher identities. Sometimes ones supposed duty as a researcher feels inauthentic (Four Arrows, 2008) when it intersects with one's queer identity. This term signifies my desire to put my queerself at the center of my re-search, rather than compartmentalising the two.
} 
politics works to visibly challenge norms, to demonstrate their lack of naturalness and to celebrate transgressions from them. Engaging with queer theory and politics enabled me to question the stability of concepts such as identity, sex, gender and sexuality inside my study and personal and employment journeys. My work is consistent with a queer epistemological standpoint as it purposefully and performatively problematises normative regimes: in this case, the accounts of MSM in development studies and Queering Development accounts of MSM development practitioners. A queer worldview can also be seen in the interweaving, parallel themes throughout this work which question ways-of-being a queeresearcher, and ways-of-producing queeresearch.

Post-structural epistemologies also significantly impacted upon my writing of this work. These are ways of thinking about knowledge(s) which acknowledge a necessary plurality of standpoints. Poststructural epistemologies deconstruct the possibility of "pure [selves]" (Smith, 1999, p. 73). This recognition of multifaceted subjectivities was consistent with my approach, which did not centre on establishing a reality of the experiences of MSM development practitioners in Bangkok but rather on producing situated accounts which cast light on the understandings and experiences of particular subjects/agents of development at a particular time in Bangkok. To do this I resisted narratives that approach queers in development as a recipe, add L G B T, and stir... (Cornwall \& Jolly, 2009, p. 8), which are especially common in development policy (see Samelius \& Wagberg, 2005). Instead I sought to open the re-search to people who may hold subjectivities incoherent ${ }^{7}$ within existing narratives of MSM and development. Taking the perspectives of individual participants as a starting point for the re-search enabled me to generate more contextualised and nuanced accounts.

With the appreciation that knowledge is always situated by the knower (and knower's are always situated by knowledge) it has also been necessary to continually reflect upon my positionality throughout the re-search. I am an intersubjective being (Crossley, 1996), a researcher-come-queer-community-member. There are no easily contained realms of 'life' and 're-search', each continually informed and drew nourishment from the other. My

\footnotetext{
${ }^{7}$ I credit Joey Crofton (2010, pers. comm., August) for his use of the term 'incoherent subjectivities' which I adopted throughout this thesis to conceptualise people whose gender/sex/sexualities do not 'make sense' in existing mainstream narratives, but whose subjectivities may be affirmed within communities of incoherence.
} 
positionality vis-á-vis participants consisted of a complex mix of similarities and differences. Like most of my participants I self-identified as non-heterosexual and had an interest in MSM community development, but I was also of a different cultural and spiritual background, did not speak Thai fluently, and could access opportunities (including international travel and postgraduate education) - privileges that were unavailable to many of my participants. Thus, it has been crucial, both methodologically and ethically, to reflect on my personal understanding of my location and the locations of my participants and the bearing that my understanding may have had on the texts generated as a part of this research.

Throughout this study I have negotiated a balance between post modern re-search - which challenges the fixity of individuals identities, and their unique capacity to act as agents of change - and a queer and critical orientation which attempts to make visible hegemonic narratives and processes of oppression, emphasizing individual subjects agency to make change. This tension has been explored by a number of queer theorists (see Plummer, 2005) and resonates with Structuration Theory (Giddens, 1984) which advances a framework that sees individual agency and social construction as mutually constitutive. Using this approach I endeavored to identify not only the social structures that informed participants understandings of MSM development but also to better understand how participants actively constructed their own understandings. Attentiveness to the agency of participants was a crucial aspect of my work. It manifested as an awareness of the moments where participants identified or departed from existing socially structured realms. My awareness of the complexities of power and social change stems largely from my reading and experience (Burford, Clark, Hammonds, \& Morton, 2008) of Participatory Action Research (PAR), an approach to re-search that sees those often designated the 'objects' of re-search by 'expert' outsiders re-cast as active subjects who are the experts on their own experience. PAR problematises what knowledge is understood to be in research and the forms of subjectivity that research processes open. I have seen PAR as a radical departure from my former understandings of research, in that I felt both a responsibility to include participants in my work in a meaningful way, as well as a heightened sense of the opportunities for co-learning that this process could offer. The impact of PAR approaches on my work was significant, giving me cause to think about not only about involving participants in the data generation 
phase of my re-search, but inviting their participation throughout most phases; formulating the questions, the analyses of material, re-presentation and the interpretation of my text. My work was also significantly influenced by co-constructed storying ${ }^{8}$ (see Pavlenko, 2002) which emphasizes the productive relationship between the participant (storyteller) and the re-searcher (interlocutor) in the production of re-search data.

\section{Thesis Structure}

Following this Introduction, in a section entitled 'Interlude', I explore my personal motivations for undertaking this thesis, and the writing and life events that have influenced my attempts to produce radical (Schostak \& Schostak, 2008) re-search. This interlude offers answers to re-search question four. It is followed by a literature re-view which attempts to answer re-search question one, backgrounding the existing discursive space occupied by the intersection of development and sexuality. In Chapter Three I attend to the methods used to undertake the study. Chapter Four introduces the context of MSM organising in Thailand, before outlining the histories of the two organisations I studied with. This is followed by discussions of the major findings of the re-search what attend to key question two. Chapter Five re-positions donor-recipient relations as complex, messy and dynamic. Chapter Six examines the constrained field of power which governs donor-recipient relations. In Chapter Seven I contrast these constraints with the agency that local MSM practitioners display to leverage collateral benefits from existing funding. Chapter Eight departs from these analyses of what is, registering participants dreams of what could be, and in so doing takes up key question three. Chapter Nine draws the thesis to a close, and is followed by a list of references and appendices.

\section{Conclusion}

This chapter has introduced my re-search, located it epistemologically and outlined the structure of the thesis. The following chapter begins with an examination of my will to know, as well as sharing my personal journey through this re-search. By performing my attempt at an alternative and authentic (Four Arrows, 2008) queeresearch re-presentation, this chapter is an addition to the epistemological wanderings above.

\footnotetext{
${ }^{8}$ For a Kaupapa Māori re-search perspective see whakawhanaungatanga: Building a whānau of shared interest (Bishop, 1996).
} 


\section{First Interlude}

Foregrounding 'Background' - A Personal Introduction to the Inquiry

MY WORK CONSTITUTES A POLITICAL ACT

I cleave to the rainbow

Like a lover

dripping with cammmp

Listen:

Bitches please

I am NOT letting go

Let him run hiz sunny fingers through my hair

Taste his tongue

Liberate his hips on my dance floor

O000000000oooh Scandalzzzzzz

Coz you's my darls and my hons

I can tell you's truly

I don't want that other shit anyway

Want some DRAMA'S

and and and

!!!!!!!!!!!!!!!!!!!!!!!!!!!!! ROAR!!!!!!!!!!!!!!!!!!!!!!!!!!!!!!!!

and and and

All gawjussed up

I remember how good it feels

To sit'n' listen to Aretha

R.E.S.P.E.C.T.ING ME

Oh'n singing on the phone till it's sooooo late and I need my beauty sleep

But got to keep singing

Singing till my throat is sore and raspy

Singing cause I don't know the words and got to learn them

Singing cause it feels so good 


\section{Beginnings}

"No intellectual work is commenced without the prick of emotion, that particularly personal investment in a subject which moves somebody to write; however attempts to cover the self, to slough off this emotion, persevere..." (Munt \& Medhurst, 1997, p. 187)

Re-search journeys always have multiple starting points. Mine started with red lipstick and peachy powder borrowed from Nan's handbag, and miserable years spent on Canterbury's frost covered rugby fields for my Dad. It emerged in the classrooms of my rural high school, where I learned about the centring of heterosexuality and normative expressions of Pākehā masculinity. It started in a conference ${ }^{9}$ two years ago where I sat listening to speakers, finally hearing the absence of queer voices in development theory and policy:

This rained like a thick, dirty silence. It echoed in my head...

The beginnings of my re-search were manifested in feelings of difference, experienced as an ache, a pain. So, this journey starts with me as a wounded healer (see Denton, 2006; hooks, 1997), a person who is re-searching and re-stor(y)ing hiz ${ }^{10}$ own hiz-story, and attempting to fabricate a healing (see DeSalvo, 2000) room for himself and others.

I gingerly began this re-search in 2009. Back then, it focused on the marginal position of queer people in the international development imagination. I wished to challenge development theories and policies fantasies of 'functional' sexuality (functional being: heterosexual and reproductive) and the (de)positing of queers on the margins. I raged that interventions objectified queer sexualities ${ }^{11}$, without humanely or holistically 'developing' queer's capacities and freedoms (Sen, 1999). Developers appeared to deem interventions necessary to cease the spread of HIV/AIDS. Period. My re-search proposal highlighted the theoretical limitations of current paradigms and practices and counterposed these with the

\footnotetext{
${ }^{9}$ The conference I am referring to here was the 2008 New Zealand Geographical Society Conference held at Victoria University in Wellington. This was the first time I was exposed to discussions around the place of queer sexuality in geography. I found this an inspiring experience, one that has never been repeated in any development studies conference I have attended.

${ }^{10}$ The ' $z$ ' on hiz is a part of the queer vernacular that I grew up speaking with my gay/queer friends in Christchurch. I use it as an innovation on the terms his-story and her-story, simultaneously asserting a differentiated his-story as a genderqueer guy-not-man. It also represents a personal re-stor(y)ing of this space.

${ }^{11}$ I use sexualities in the plural to connote a diversity of erotic expressions and meanings.
} 
empowering potentialities for queer sexualities in development. My re-search proposal was strong. It was fortified by unyielding language. Yet, in reading back through it now, I seem hidden, almost apologizing for my role as author/creator. While calling for an embodied approach to sexuality in development, I was not forthcoming about those passionate rhythms of my own body. I never acknowledged that my re-search could not emerge from some 'clean' space in my brain; that it originated out of feelings of sadness, joy and excitement. What was not included in my re-search proposal was that I had begun a relationship with my partner, a man of Thai descent, that my motivations for this study were as much of the body and heart as of an inquiring mind. Before I had gone to Thailand I felt that I had to minimise my own journey, hide my sensuality from this process, consign, contain, and channel it (see also Cupples, 2002). I didn't want people to assume that my research was gay-sex-tourist-re-search. Unfortunately this unease lingered with me throughout my fieldwork. It wasn't until I returned home to Wellington that I realised what I had done, that in smothering the many reasons I went to Thailand, I was not only being intellectually dishonest, but I was replicating those practices that I went over Thailand to question - the pushing of sensuality and eroticism to the borderlands; to neatly defined territories.

I want to celebrate my story of (gender)queer ${ }^{12}$ masculinity which is complex: loving and patient, caring and respectful. The way I have chosen to write this thesis is a way of reworking and re-(w)ri(gh)ting my (gender)queer body back into my work. It is a means to reinforce my call for an embodied theorizing and practice of queer development interventions, as well as a radical (Schostak \& Schostak, 2008) and authentic (Four Arrows, 2008) approach to queering theses.

\footnotetext{
${ }^{12}$ To assist the reader I introduce Bulldagger's explanation of genderqueer as "pragmatic political identity that aspiring queer revolutionaries can use to explain who we are", it is a term that includes "all of us who fuck with gender, who have gender on the brain, and who never take gender for granted" (Bulldagger, 2006, p. 137). Yet, I am reluctant to offer this as a definition of genderqueerness because any articulation of a definition of genderqueer lends it an artificial coherence. This definition works for me, but I do not claim it can hope to define the unique positions that many self-identified genderqueers come from and inhabit.
} 


\section{Margins Song}

Warm up

We, find our voices for singing

Soft and fierce

Mane of lion and flash crocodilious teeth!!

We, sing the songz we know by heart

Creative and critical

Radical Expressionisms

Disrupting heterocentrisms

We, sing about many interpretations,

Of other ways of being

That we struggle for

We honour orthodox wayz of being

Masters-and-Mistresses

But we, know that our theses need music, poetry and autobiography,

We know our songz need singers,

Must be sung...

\section{An offering: Ways You Might Read My Thesis}

...we need to draw dirty pictures... do unruly things....un-ruly...against the rulers, against the rules. (Gergen \& Gergen, 2002, p. 21)

It is important to recognise that my thesis is an intentionally disruptive text. It establishes a desecr(e)ative ${ }^{13}$ space which foregrounds other ways of knowing, inviting the reader/audience to both understand and feel that the issues at the core of my thesis - MSM development and postgraduate queeresearch require attention. In my approach I join a lengthy list of scholar-artists (Denton, 2006; DeSalvo, 2000; Lorde, 1980; Leggo, 2006a, 2006b; Pelias, 1999, 2002, 2004, 2006) who use "heartful" (Sparkes, 2002, p. 210), avant-

\footnotetext{
${ }^{13}$ I created the term desecre(a)tive to register my understanding of the new sacred space that is created in theses when existing hegemonic spaces (which are held as sacrosanct) are disrupted through a myriad of creative practices. It also signals my interest in the provocative power of destruction and re-construction.
} 
garde forms to "interrupt status quo propaganda, which suggests all-is-well" (Weems, 2001, p. 4).

Choosing to register my discontent with hegemonic paradigms of knowing re-search and representing theses, I work in a queer spirit. Initially, I grieved at the thought of binding my queer work in a tidy book that would not reflect the performance of text that I knew that my re-search required. It also seemed counterintuitive to write straight prose (see Richardson, 1992) in this re-search, especially when I had learned myself, and been inspired by queer theorists to 'spoil' the oppressive practices of normativity, and to claim difference as a necessity in the world (Madison, 1999). Lost, I travelled to Christchurch to stay with my partner Adisorn, and we visited the Assume Nothing exhibition of Rebecca Swan's photography. I was moved to stillness by a film of Mani Bruce Mitchell, who explained the process of defacing a photo of herm ${ }^{14}$ naked self, scratching out herm own face much as New Zealand medical professionals had done to other intersex children who were featured in scientific journals in the not-so-distant past (see Figures 0.2-0.3). Reflecting on Swan's artwork, I noted similarities to my own experience of re-searching this work.

\footnotetext{
14 'Herm' is the personal pronoun used in 'Assume Nothing' text by Judith "Jack" Halberstam to make intersexual people and ways of living as an intersex person visible.
} 


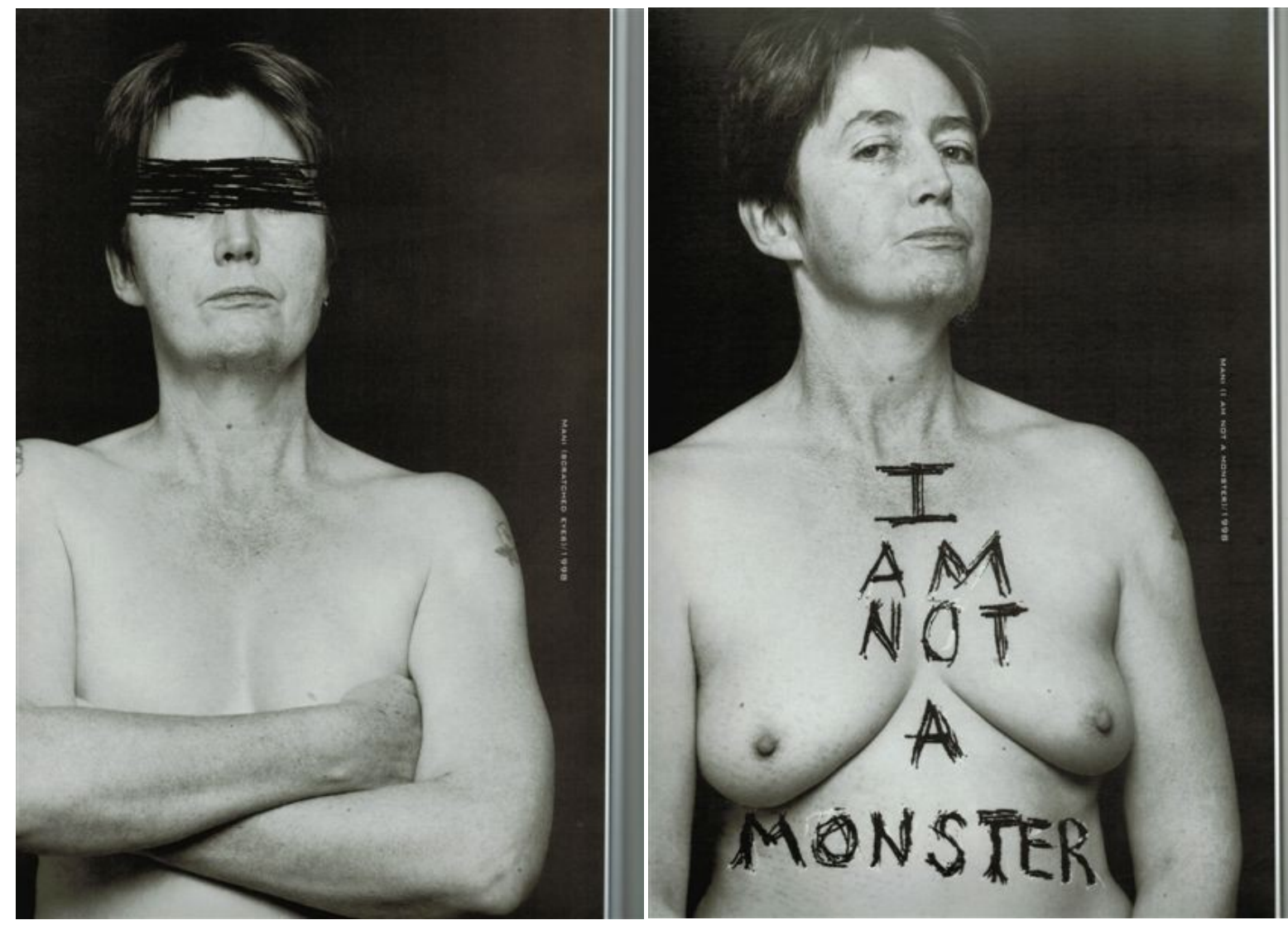

Figure 0.2 "SCRATCHED EYES" (1998) $)^{15}$

Figure 0.3 "I AM NOT MONSTER" (1998)

\section{[This space has been deliberately left blank]}

\footnotetext{
${ }^{15}$ These two photographs have been re-produced with the kind permission of both the artist, Rebecca Swan and the subject, Mani Bruce Mitchell. I thank both Rebecca and Mani for their permission to use the art-works. The graffiti on the page is my own response to the works.
} 
The photographs above connected to my own reading of scientific writing on gender/sexual minorities. I believed that graffiting my text would symbolically scribble on this scientific oppression (Halpin, 1989). It also connected to my own experience of feeling mislabelled and misunderstood. Reading through the experiences of other re-searchers, it has become apparent that this is a common feeling (see Chalmers, 2002; Richardson 2000b; Wagle \& Cantaffa, 2008).

Following Weems (2001) lead I decided to publish an excerpt of an email that I received when I was beginning my study in Bangkok from the administrative leader of my programme at Victoria University who handled Human Ethics Applications at that time:

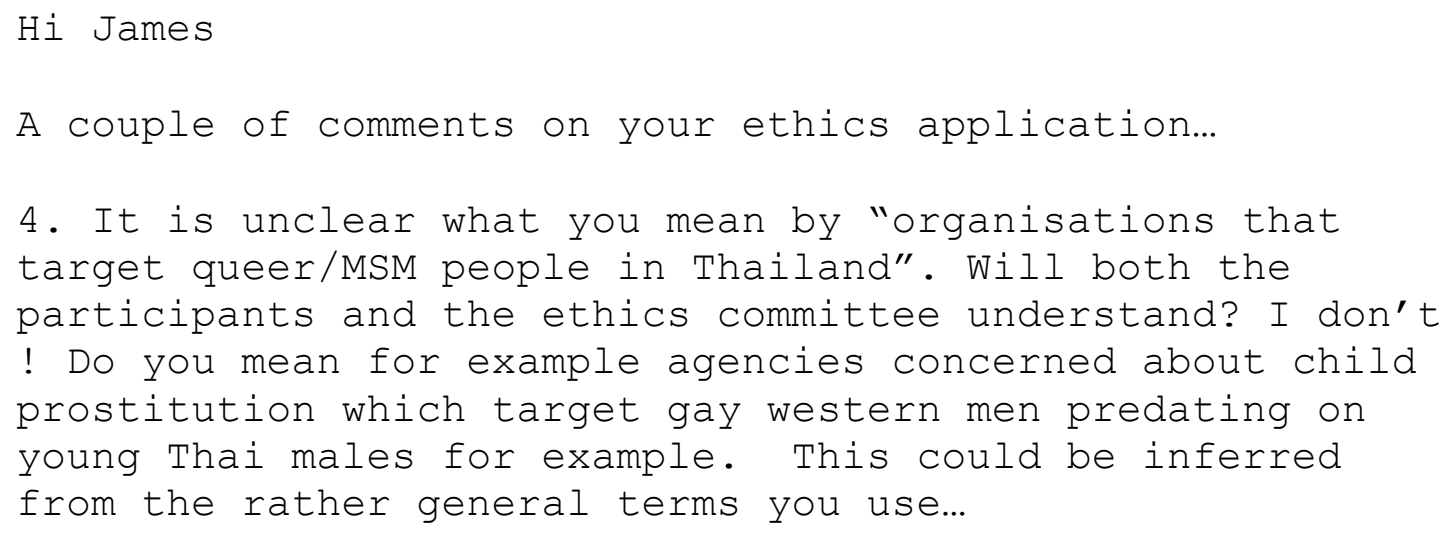

When I received this email from our resident "dealer in virtue" (Thrift, 2003, p. 115) I cried, tears of anger and frustration. Was it me? Was I unable to effectively communicate the purpose of my re-search? His message came as a brutal thump to my chest, a whack that I received both physically and emotionally through my adolescence in educational settings; the type of experience that made me both fearful and resilient. This email could be described as what Virginia Woolf called a "shock" (Woolf, 1985, p. 72); an intense episode which results in a compulsion to re-(w)ri(gh)te. With this email I realised that my work was being misinterpreted and failing to capture the positive focus on queer sexualities I held dear. Instead, it seemed to be understood through the negative, dangerous and destructive visions of sexuality upon which MSM development interventions themselves tend to focus.

After viewing Assume Nothing I came to know that I could reclaim the power of labelling my own work, through the performative act of 'defacing' my thesis. Thus, I write both on the 
page and in the margins ${ }^{16}$ of my thesis, defacing/graffiting my own text as an act of desecr(e)ation, a way of problematising a form of representation that is held as sacrosanct, and opening space for creative, re-flexive dialogue inside my text. It is also a way of questioning the containment of the spaces that social scientists generally have available to ponder their lived experiences, such as appendices and prefaces (see Richardson, 1992).

Writing with the margins is also writing with the undertones that are a part of the queer conversations I have with my queer whānau. It uses unspoken words; knowing glances. Defacing my thesis captures exaggeration - It is as silent as a queen screaming:

it is nail-polish or lip-gloss I used to try on with Christophe, purple or red from ballies (Ballantynes). we called it our 'rouge pulp' afternoons. hurried, covert, de-lish. applied under the unflattering department store lights, with the invariably evil-eyes of the sales attendant,

it

ran messily over nail edges, lips marking us queer. but that was the point. we never wanted it to be tidy... My thesis is as an intentionally messy text (Conquergood, 1991; Denzin, 1997; Ellis \& Bochner, 1992). Indeed parts are for speaking out loud, unable to be captured by a passive reader. They are brought alive on the breath. The poetry in my thesis is my own, unless otherwise acknowledged. It has been influenced by the funk-filled poems of Baraka, but my poems emphasise the voice I wish to re-claim. My poems speak camp. Sometimes this camp voice is cuter than cute and other times it is "Mad as Hell and refusing to be nice" (Duggan, 1995, p. 174).

I invite my reader to experience the re-presentation of the text as an exercise in critical reflexivity, one which holds my academic writing to account through a constant interruption of the performance of my scholarly prose. In privileging difference, and re-claiming silence as visible and readable (see Lorde, 1980) my defaced thesis asks back, in ways that

\footnotetext{
${ }^{16}$ For further analyses on writing from the margins see Richardson (1992).
} 
conventional academic discourse does not. My work engages the emotional, sensual, intuitive, visceral feelings of the audience. Purposefully disorientating, it provides oppositional counter-narratives and crafts non-linear text that might be read in multiple ways. My graffitied text complicates meanings rather than rendering them simple. It signifies my belief that re-search is not an object capable of closure that the meaning of my work is always under construction. And in dealing with dreams, it is a part of movements envisioning a social justice that is "not yet" (Weems, 2001, p. 7).

I understand this as a part of my queeresearcher duty, to foster subversive strategies of resistance to status quo. Graffiti, in inhabiting the space between word-art, connects to my thesis which bridges scholarship-art. In graffiting the margins and accessorizing the artifice of my thesis I am also symbolically que(e)r(y)ing the ontological assumptions of positivist research by registering more than one claim to truthful re-presentation. Rather than reprivilege scholarly prose, I choose to re-claim and celebrate the margins as spaces of truth and power (see Richardson, 1992). In the same spirit as my thesis, the act of graffiti is political, and produces a disruptive and disconcerting aesthetic experience and I hope that this orients readers toward critical reading. Graffiti is an act which amplifies my talking back and simultaneously questions the politics of voice. The literal margins of my thesis pages salute the subjugated knowledges that have informed my work; those perspectives that dwell in the gutter-margins, the oversized cocks and cell phone numbers that occupy toilet walls. My defaced margins metaphorically invoke images of playing with, and not surrendering to authority. In addition to Swan's work, I have also drawn inspiration from artists such as Jean-Michel Basquiat who brought the 'studio of the street' (Deitch, Sirmans, \& Vassell, 2007) into conversation with the mainstream art world.

As a queeresearcher I am simultaneously positioned in both a privileged location (as white, university educated, able-bodied, sexed and generally gendered male/man), and at the queer margins. Defacing my thesis enables me to de-centre my disembodied prose and attend to the politics of location with awareness of my-self as a subject becoming. I am defacing my work both to re-face it, to put my queerself back inside it, and to reflexively question the privileged position from which my academic prose emerges. Moreover, writing in the margins signifies my growing suspicion that the thesis does not serve our education system well as a vehicle for transgression, transformative learning and positive change. I am 
of the opinion that the thesis is more often experienced as a bureaucratic wrangle; a product-focused crusade rather than the attainment of any form of intellectual or creative mastery. My margin thoughts simultaneously signal my discontent, and mark my dreams for renovating the future of the thesis.

I invite the reader/audience into an intertextual space, concurring with Gergen and Gergen that "representation does far more than communicate about a subject; it simultaneously creates forms of relationship" (2002, p. 12). I seek to reduce alienating distance and hierarchy, welcoming the reader as a co-producer of its meaning. My writing outs itself as artifice, "...call[ing] attention to itself as an act that cannot be seen through" (Culler \& Lamb, 2003, p. 9). 


\section{I am Talking Back Now: Fictional Question and Answer Session}

(Scene: It's Thursday 4 PM -people are gathered inside the small partitioned seminar room that connects to a staff tea room at the university. Jamie stands at the front waiting to begin, wearing red jeans and mis-matched socks. His face is flushed, his hands feel cold. An audience, primarily older male social scientists in brown jackets is waiting, as well as some of his friends who sit in the middle smiling. Each wears a brightly coloured hat and scarf. The light is nauseatingly bright and artificial. The air is stale and smells faintly of budget instant coffee. He enters and gives his presentation.

Jamie: I would now be happy to take any questions or comments about my presentation.

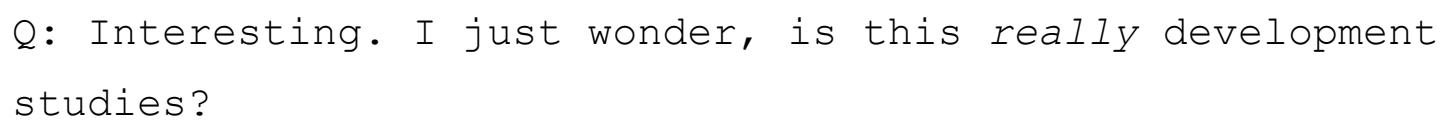

Jamie: It is high time we stopped disciplining queers and started queering disciplines (Gust, Lovaas, \& Elia, 2003). I understood my re-search as post-disciplinary in that it "refuses to be reduced to the confines of particular disciplines and refuses to keep the boundaries of disciplines intact..." (Schostak \& Schostak, 2008, p. 8).

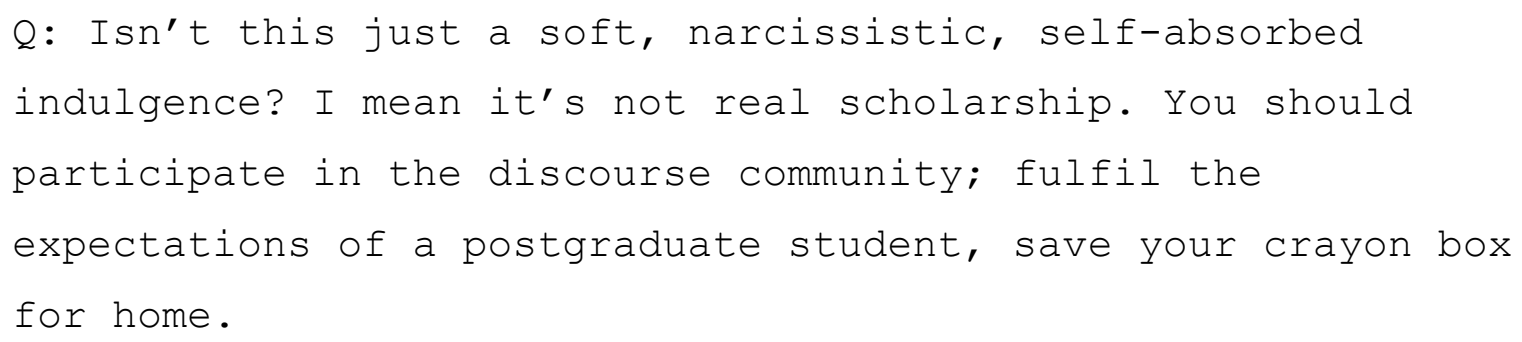

Jamie: Thank you for your comments [feeling bored that this question has resurfaced again...]. Rather than narcissistic or self-indulgent, I enjoy viewing my work as self-knowing and self-respectful. I also like Sparkes' (2002, p. 210) term "self-luminous". I have no problem with my work being described as soft; I see it as malleable, able to move between spaces that blunt-edged scholarship cannot. I find it unfortunate that creative and reflexive scholarship isn't often encouraged in Masters' Theses. While I acknowledge that students must participate in certain discourse communities, I also believe that the foundations of these communities require constant renovation, and sometimes this is achieved through 
redecoration. I understand the performance of my thesis text as way of doing this. I am a self-identified new writer which Denzin (1997) refers to, I interpret my work as that of an activist who is morally committed to positive social change directed toward a better world. Denzin's call to generate work that subverts traditional boundaries of scholarship resonated with me. I attempt to cast a critical eye on injustice, while inviting the reader/audience to enjoy the work as co-creators, co-performers and co-interpreters. As Culler and Lamb (2003) argue "The performative dimension of writing... does not simply transmit a thought or a content but performs an action... [it] takes up a stance" (2003, pp. 3-4). I am simply making the stance I take productive to the ends I hope to see realised.

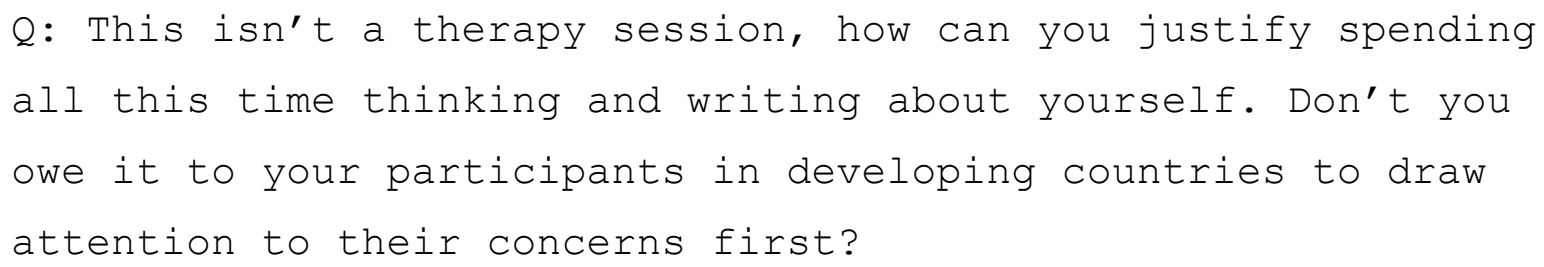

Jamie: "Post modern times are when the capacity for telling one's own story is reclaimed" (Frank, 1995, p. 7).

I also draw inspiration from Kirkland's words "Where is the I in the academy, which seems to be consumed with valid knowledge of the Self only through the other" (cited in Four Arrows, 2008, p. 164). This project has been prompted and mediated by my own experiences, therefore I do not intend to narrate it as a dispassionate, third person author who types with neutral fingers as if the task were not problematic. Pelias affirms this task is always problematic (Pelias, 1999). To re-present is to speak as a located self, one who is situated historically and culturally, who is invested in certain discursive practices that obscure, by privileging what is present and silencing what is absent (Pelias, 1999). With this knowledge I have written "vulnerably" (Behar, 1996). I use my own experiences to illuminate connections between myself and local practitioners to evoke feeling, and to create contextualised and rich knowledge for the reader to co-participate in the generation of meaning. Pelias taught me about the many layers of speaking, that one can speak by speaking under one's breath:

At such times, speech rides on the underbelly of breath to dodge the grind of angry teeth...to control speech is to control the speaker. Speaking under one's breath, one 
negotiates the space between silence and freedom. To speak under ones breath is to speak and keep on living. (Pelias, 2004, p. 32)

In writing in this manner I have also learned lessons from Behar - that if it doesn't "break your heart, it isn't worth doing" (Behar, 1996, p. 177). I discussed re-presenting my work with many of my participants in Bangkok. They continue to remind me that this is my research, and should be honestly guided by my vision. Despite your somewhat paternalistic concerns for them, I trust they are eminently capable of making their own decisions.

Q: This is attention seeking...

Jamie: All scholarship seeks attention. It wants to engage, to be heard. This is no different. To borrow Gergen and Gergen's evocative words I am a butterfly wing stroking in sweet rebellion (2002, p. 21)!

Q: It is too abstract. I don't get it. It is excessive and repetitive.

Jamie: Yes, at times my writing is difficult to grip on to. Rather than seeing myself as a member of an 'elite class' whose language is purposefully ensnarled and aloof, I see it as offering a different form of communication, one which pricks and prods. I am reminded of what Sedgewick has described as the epistemological privilege of unknowing whereby "obtuseness arms the powerful against their enemies" (1990, p. 7). I believe the role of critical scholarship is to challenge, and indeed to be challenging, entering into uncomfortable terrains of instability, carving pausing spaces for the reader to rest in, or tickling them with language which leaves their eyes watering. My thesis aims to shake out its unruly hair and revel in the sweetly incensed politics of excess. My thesis repeats. Some things bear reiterating. More than twice. 
Chorus:

Emerging from the margins

My words swoop and dive

Breathe white air

Strike black boxes

Like bowling pins.

Emerging from the margins

Feelings spiral

Deepen to depths

Puncture the superficial

Researchers' flesh.

Emerging from the margins

Ideas tumble in ink

And dry

My hand trembles

The pen hits paper. 


\section{Mantras $^{17}$}

My thesis is an alternative way of knowing re-search and representation

AND;

I do not feel duty-bound to write (a) 'rational', mono-vocal, derivative text

SO;

I dance with the multiple perspectives that I heard, read, felt

WHILE;

Refusing to silence the frustration - anger; honouring the politics that brought me here

SO;

I reach my fingers out because they have been burnt...

AND;

View "deconstruction without reconstruction as little more than a game of wit"

(Pelias, 1999, p. 165)

$\mathrm{SO}$;

I attune myself to the poetics of re-search, and the re-searcher's body

AND

Let colours clash

AND;

Stop punctuating *dreams*

Having engaged with some of the literature that has inspired my desecre(a)tive attempts at re-viewing authentic queeresearch re-presentation, as well as introducing myself as author, in the next chapter I explore the debates in related research in development studies and the cultural analysis of sexuality and identify the gaps that exist in these conversations.

\footnotetext{
${ }^{17}$ As many yoga teachers taught me, mantras are words or groups of words that are capable of creating spiritual transformation, providing liberation for the mind.
} 


\section{Section One: Outline}

Here, I aim to map the first section of my study. I hope this makes engaging with the material I present easier.

Chapter Two is my Literature Re-view. I start this chapter by examining the place of sexuality in the development industry, arguing that sexuality has generally been rendered heterosexuality by default. Next, I examine the emerging field of Queering Development, noting the valuable contribution these authors have made to understanding sexuality in the development industry. Following this, I examine the gap in which my study inquires: the positive benefits of local MSM development practice. I argue that Queering Development authors have generally failed to engage with the outcomes of local development practice, choosing to focus largely on theoretical and policy issues. I argue that authors working in the cultural analysis of sexuality have had more grounded examinations, but have still tended to focus on the negative outcomes of funding queer development, rather than positive impacts.

In Chapter Three I explore my methods and study design. I begin this chapter by examining the Heartful philosophical core of my thesis. Then, I address the ethical considerations of my study, followed by an outline of the methods I used to generate, analyse and re-present information. This is followed by a consideration of the rigour of my re-search.

The final piece of Section one is Chapter Four. In this chapter I introduce key Thai terms and concepts. Then, I summarise some of the key concerns for MSM development in Thailand. Next, I engage with the histories of MSM organising in Bangkok. This is followed by a detailed examination of the two organisations I studied alongside - BRO and RSAT. 


\section{Chapter Two: Literature Re-view ${ }^{18}$}

\section{Introduction}

“The poor simply can't be queer, sexual identities are...linked to being rich and privileged. The poor just reproduce" (Kleitz, 2000, p. 2).

My literature re-view offers a particular interpretation of the knowledge produced in the contemporary field of development studies that inquires into sexuality. It has two parts, which correspond to two key elements of my re-search: the understandings of sexuality in broader development theory and policy, and the limited engagement with perspectives of local MSM development practitioners within Queering Development theorising. Part one of my re-view briefly outlines theoretical developments in theories of sex, sexuality and gender before providing a critical overview of the literature in development studies concerning gender and sexuality broadly. In so doing, I begin to address re-search question one which seeks to understand the present mainstream invocation of sexuality in development theory and policy.

\section{Sex, Sexuality and Gender}

In recent years theories of sex and society have undergone a seismic shift. Early theorising about sex and sexuality is described as 'essentialist'. An essentialist standpoint views sex and sexuality as fixed traits which exist outside of social, cultural, and political structures, representing a "unified domain" of human experience (Weeks, 1985, p. 75). Essentialist understandings consider sex, sexuality and gender as coherent and biologically determined, those who exist outside of 'natural' identities have often been pathologised.

Social constructionists began to challenge essentialists from the mid $1970 \mathrm{~s}^{19}$ Constructionist debates were hastened by Foucault's work (1978) on discourse in social analysis which argued that sexuality was not an essential realm of human life; rather the creation of the object called 'sexuality' itself was seen as a social construct that emerged out of the re-

\footnotetext{
${ }^{18}$ Like my use of the word 're-search' I have deployed the prefix 're' to signify the new, and hopefully productive spirit with which I 'view' existing literature inquiring into sexuality in development.

${ }^{19}$ Although I would argue they are still absent from the mainstream development field's imagination of the subjectivities of 'developing' subjects.
} 
structuring of production and re-production under capitalism (Adams \& Pigg, 2005, p. 3). Rather than fixed, social constructionists see sexuality and gender as necessarily plastic and open for re-creation (Corrêa \& Jolly, 2008, p. 23). For constructionists, sexuality like all human activity is viewed as grounded in the body. Yet, as Vance has argued, the body's structure "do(es) not directly or simply determine the configuration or meaning of sexuality" (Vance, 1984, p. 8). Instead, a social constructionist approach sees "sexual identities, desires and practices [as] constituted through a complex and unstable weaving of biology, anatomy, intellect and discourses" (Corrêa \& Jolly, 2008, p. 23) as well as being transformed by economic and political processes (see Parker \& Aggleton, 1999; Parker \& Gagnon, 1995). Scholars working within the constructionist paradigm have further argued that sex taxonomies (and their intersection with other forms of stratification - race, class, and ability) articulated through institutional and social discourses translate into power differentials, socio-economic inequalities, discrimination and abuse (Corrêa \& Jolly, 2008, p. 23).

\section{Development and histories of sex/sexuality}

Why is it that challenging gender inequalities is seen as tampering with traditions or culture, and thus taboo, while challenging inequalities in terms of wealth and class is not? (Mehta, 1991, p. 268)

It has only been within the last decade that the meeting space between development and sexuality has received any significant attention in development studies (Hunt, 2008). Before this time the vast assumptions that informed the development field's bio-medical understandings of sex/sexuality had remained largely unchallenged, despite the "boom" in social research on sexuality (Parker \& Aggleton, 1999, p. 1). This long silence might be explained by a righteous conservatism which is present in development studies, a perception that it is unseemly to talk about something as trivial as sexuality, especially when one is confronted with serious (and presumably disconnected) problems of poverty and inequality. Vance is worth quoting at length here for her early contribution:

Some also believe that sexuality is a privileged topic, important only to affluent groups, so to talk of it betrays bad manners and bad politics on behalf of the sexual betters toward the deprived, who reputedly are only interested in issues that are 
concrete, material, and life-saving, as if sexuality were not all of these. (Vance, 1984, p. 7)

This is what Hinojosa (2009) calls the false dilemma between the 'seriousness' of poverty and the 'frivolousness' of sexuality in development cooperation. Hinojosa exposed this dichotomy by documenting the links between gender/sexual incoherence and economic deprivation; poverty and sexual violence; compulsory heterosexuality (Rich, 1994) and queerphobia; and hegemonic masculinity and various forms of violence.

Despite the extended silence in development theories, 'developers' (in a loose sense) have always been implicitly concerned with sex/sexuality. I contextualise these debates within long histories of Western fascination with, and intervention into the genders/sexualities of 'native' others. This interest in collecting information on, and controlling sex intensified throughout colonial periods in what Frühstück has called the "colonial ruling apparatus of sex" (2003, p. 187). Across the world, social reforms, colonial governance and missionary work (see Adams \& Pigg, 2005) directed the re-formation of sexual practices to 'develop' and 'modernise' the nation. These goals were articulated through discourses including; vitality, racial purity, fertility, order and economic productivity - which were tied to ideas of national progress and imagined through the metaphor of the 'national body' (Frühstück, 2003). Interventions often targeted lower socio-economic classes and marginalised groups, targets who were understood to be 'ignorant' if they had 'non-scientific' understandings of their sexual and reproductive bodies.

Frühstück (2003) has explored these histories, particularly focusing on Imperial Japan. She argued that knowledges about sexuality have been informed by Western moral judgments about the (under) development of 'other' civilizations. Indeed, the project of altering sexual norms was viewed as vital to the health and future of the Empire, and later to the Nation. Taking Siam ${ }^{20} /$ Thailand as an example, I see a history of processes of social modernisation which led to radical changes in the cultural meanings of sex, sexuality and gender. Jackson (2003) has used the method of Foucault's biopower to connect this 'gender revolution' to the strategic 'self-colonisation' that Siam/Thailand underwent to resist the threat of European imperialism. Rather than defending itself militarily, Jackson argues, Siamese/Thai

\footnotetext{
${ }^{20}$ The country was called Siam until 1939, when the name was changed to Thailand.
} 
elites responded to Western accounts of Siamese 'barbarism' by launching a state enforced campaign to refashion norms of eroticism and gender (see Jackson, 2003, 2009). This ongoing project of 'self-colonisation' reached its zenith under the premierships of Field Marshal Phibun Songkram (first premiership 1938-1944; second 1948-1957) with institutionalized gender surveillance such as the assigning of genders to given names and compelling men and women to don separate garments. This example of late Siam illustrates that there are long histories of sex and sexuality being re-formed for the sake of progress/'development'.

Several theorists (Adams \& Pigg, 2005; Hoad, 1998; Mathuray, 2000) argue that these links between nation, progress, and sexuality persist. They view contemporary international development interventions as one of the most "pervasive, influential, and mundane areas in which sexuality is an issue" (Adams \& Pigg, 2005, p. 11). By connecting this persistent rhetoric of modernization to contemporary development encounters Adams and Pigg (2005, p. 14) see continuities, "In contemporary development efforts, one might read medical rhetoric about...the control of STDs... as implicitly concerned with advancing ideas about what it means to be "modern" in one's sexual habits and choices" (see also Nguyen, 2005).

Sex and sexuality must not only be historically located within Western accounts of native others, but they must also be contextualised within development theories as well. Within core development theories, sexual subjectivity is rendered heterosexual and reproductive by default. This understanding of (hetero)sexuality as natural and alternative gender identities/sexualities as individual preferences is present in liberal economic theory, the backbone of the development paradigm (see Bergeron, 2000). (Hetero)sexuality, unquestioned is also incorporated within 'the family'. Hence the main 'economic unit' (Corrêa \& Jolly, 2008, p. 24) that development theorists work from remains largely unquestioned.

Kleitz (2000) has argued the development industry's understanding of sex is never neutral. Both development theory and discourse have fantasised "functional" sexual identities and directed efforts toward their existence. By discourse, I refer to socio-historical systems of meaning that "intertwine with power [to] create speaking-acting subjects" (Foucault 1972, 47). Thus, the imagining (or lack there-of) of sexuality in collapsing eroticism into 
unquestioned, static and meaningless categories, the development industry ultimately obscures the ways in which power operates through sex/sexuality. What I am referring to here is the failure to account for gender and sex orders. These prescribe "how we should live our everyday lives, what we do to earn a living and hold onto our jobs, what kinds of families we have and how we are treated in public, as well as in our private relationships". (Cornwall et al., 2008, p. 11 )

There has been one particular space in the development industry where sexuality has consistently been incorporated - public health. Pigg has characterised these interventions rather bleakly, "A penis in a vagina or an anus is seen as an opportunity for microbes to move from body to body. Period" (Pigg, 2005, p. 44). In public health discourse sexuality is often scripted through the (heterosexist) proxy of 'reproduction'. Hunt (2008) argues that this is as "absurd... [as] it is dangerous. Make-believe is never a good foundation for sound policy-making" (p. xi). The discursive act of burying sexuality ignores the fact that many sexual expressions are non-reproductive. This was emphasised in the 1980s with the emergence of the HIV/AIDS epidemic. One outcome of HIV/AIDS has been that people participating in all types of sexual behaviour must now be recognised and engaged with to ensure effective treatment and prevention. This has seen resources and visibility channelled toward MSM, at the same time as new regulation of this population (Corrêa \& Jolly, 2008, p. 39).

With the emphasis on rational planning and bio-medical technology, public health frameworks have focussed on technical fixes rather than social change. This is disappointing given the expansion of the concept of poverty in the 1990s which was largely re-framed beyond narrow income and consumption based measures toward more sophisticated, multidimensional approaches. Poverty is increasingly seen as a lack of freedoms opportunities and capabilities (Chambers, 1997; Nussbaum, 2000; Sen, 1999) and this, alongside human/sexual rights approaches might be more fruitful avenues for inquiry. Next, I explore the emergent discourse of Queering Development, placing my re-search both within its central concern and outside the realms it has tended to focus. 


\section{Queering Development}

Queering Development ${ }^{21}$ scholarship has arisen only in the last decade. Initially, it was focussed toward revealing a perceived lack of engagement of the development industry with (particularly queer) sexuality (Jolly, 2000a, 2000b; Samelius \& Wagberg, 2005). In the past few years, Queering Development literature has significantly matured, no longer seeing an absence of engagement or a missing dimension (Runeborg, 2008), but rather seeing (hetero)sexuality as implicit in the imaginings of all development subjects. While growing, it still remains a small field of intellectuals who are positioned in the margins, marrying activism with academia. Queering Development literature is critically oriented, with an emphasis on both reflecting upon and advocating for changes in understandings and resource deployments with regard to diverse sexualities. Despite the growing interest, the connections between sexuality and international development remain significantly understudied, especially through grounded fieldwork.

Writing about the implications of development and sexuality emerged earlier in work focussed upon the social construction of sexuality (see Adams \& Pigg, 2005; Pigg, 2005) than it did in the discipline of development studies itself. In Cornwall, et al.'s (2008) important work Development with a Body I see the emergence of a more complicated examination of the role of development on local 'queer' subjects. Recent contributions to this field focussed on identifying the place of sexuality in development theory, policy and practice with recognition that a failure to address queerness does not signify that sexuality itself is not 'there'.

Queering Development authors have also begun to re-frame sexuality in development. These understandings of the role of sexuality in development take us beyond a solitary focus on sexual abuse and risks toward wider and more positive visions of the potentials of sexuality (see Gemmerli, 2009). Cornwall, et al. (2008) have expanded the scope for discussions on sexuality in development, offering a view of sexuality that:

has as much to do with being able to move freely outside the home and walk the streets without fear of sexual harassment or abuse as it has to do with whom people

\footnotetext{
${ }^{21}$ I use 'Queering Development' to describe the small field of scholars explicitly enquiring into the connections between sexuality and development.
} 
have sex. It is as much concerned with how the body is clothed, from women feeling forced to cover their bodies to avoid unwanted sexual attention to the use of particular colour to mark the gender of infants and begin the process of socialisation of boys and girls as different, as what people do when their clothes are off. And where society and the state collude in policing sex and gender orders, it can be about the very right to exist, let alone enjoy sexual relations. (Cornwall, et al., 2008, pp. 5-6)

The new understandings I see in Development with a Body (Cornwall, et al., 2008) have emerged out of wider discussions on the multidimensionality of poverty. Indeed, Sen's influential work (1999) has been crucial to Queering Development author Petchesky's subsequent interpretation of freedom in the context of sexuality in development. She has used Sen's work to contemplate how sexual fulfilment and autonomy can contribute to human wellbeing. As Sen states, "the social commitment to individual freedoms has to be concerned with both positive and negative freedoms and with their extensive interconnections" (Sen, 1999, p. 50), Petchesky (2000) uses this to argue that people have the right to fully develop and enjoy their bodies, she adds that "erotic and emotional capacities depend on freedom from abuse and violence, grasping affirmative sexual rights also depends upon having the enabling conditions and material resources to do so" (p. 97). The emphasis of Petchesky's argument, and those advanced by Queering Development authors is that the positive freedom for sexual pleasure and fulfilment (Cornwall, et al., 2008; Ikkaracan \& Jolly, 2007) is crucial to the wellbeing of all people.

Petchesky (2000) also contrasts this with the irony in talking about sexuality in development, that one can more easily assert sexual freedom as a negative human right, a right to protection from harm "rather than in an affirmative, emancipatory sense" (p. 88). She raises a crucial question that Queering Development authors have been grappling with: why is it easier to "gain consensus for the right not to be abused, exploited, raped, trafficked, or mutilated in one's body, but not the right to fully enjoy one's body?" (Petchesky, 2000, p. 88). 
Part two of this literature re-view outlines the specific gap in the Queering Development literature that is the focus of my re-search efforts; that current Queering Development research has largely failed to engage with the depth of the MSM development work already undertaken by local practitioners. I have been inspired by the passion of Queering Development scholars who argued that development theoreticians and policymakers have not holistically engaged with queer sexualities in development (see Jolly, 2000a, 2000b). Yet in Bangkok I was stuck with a persistent question. I wondered why Queering Development authors argued so ambitiously for donors to implement sexual rights as a framework for action, yet neglect to focus their attentions on local practitioners who may already implement their existing resources in more creative and holistic ways. It appears to me that by emphasising the necessity for 'queer mainstreaming' (Gemmerli, 2009, p. 8) and engaging in debates on the appropriateness of universal human rights policies, that these writers unwittingly invoked a 'top-down' approach to understanding change in sexuality and development. Do Queering Development theorists assume that what is funded is all that is delivered? Where are the local accounts of positive outcomes rather than horror stories (Gosine, 2006)? What else could be (or is already) achieved with the resources practitioners currently have?

Perhaps Queering Development authors imagined that donors were best positioned to lead this movement toward more holistic development through policy frameworks. Besides this, I considered that they might tactically emphasise the importance of broadening the scope of MSM development in the 'global North', with an implicit understanding that local practitioners in the 'global South' were already making progress in their local communities. Whatever the reason, I consider that the privileging of policy centred approaches (see Gemmerli, 2009) and the local accounts which emphasise the more problematic consequences of MSM development give us only half the picture. Because these authors look at Queering Development from the perspective of the 'global North' they see "factual information, dire data and warnings, and what not to do..." and "little to anchor sexual connections in real situations and real bodies" (Lewis \& Gordon cited in Cornwall \& Jolly, 2006, p. 1). Because their work emerges from studies of policies and development theory 
they fail to see "intimate connections between people, 'love', 'pleasure' and 'desire'" which they assert "do not form a part of the development lexicon" (Cornwall \& Jolly, 2006, p. 2). The question we must ask is whose 'development lexicon' do Cornwall and Jolly refer? My experience with local MSM practitioners in Bangkok was of rich discussions of 'love', and sometimes raucous conversations about 'pleasure' and 'desire' too!

While I believe that human rights approaches are a useful platform for thinking about, and intervening into queer sexualities I am concerned by certain absences in the existing literature. If we examine Cornwall et al.'s (2008) work, we see the missing piece is substantial recognition of rights that are being fought for, and realised by recipients, which are facilitated through existing (sexual health funded) intervention spaces. There were several chapters addressing positive ways forward, such as Esiet's (2008) chapter on sexuality education in Nigeria, yet positive impacts of local practise were diminished throughout the remainder of the text. My concern is to write these daily acts of addressing human rights and other concerns back into Queering Development literature, to recognise that the feeling, desiring, queer bodies that the authors so aptly identify, are also already working for their rights, with or without permission from donors.

For Queering Development authors to appreciate the positive changes that are realised by local practitioners, they must come to a more multi-layered understanding of the complex relationships between donors and MSM development practitioners. In my view any so called "queering" of development must also go beyond arguments for incorporating sexuality within existing frameworks (see Gemmerli, 2009). Queering development, to me, would see a more radical examination of the places of queers in the development imagination, and the background goals that development actors aspire toward. Queering development could offer an opportunity to examine development from its foundations, and I believe local MSM practitioners would be a valuable place to start these conversations.

\section{Identity Work}

In my view, the scholars working from a perspective of the cultural analysis of sexuality have more thoroughly engaged with the impacts of the objectification of sexuality by development industry. Authors in Adams and Pigg's (2005) landmark work Sex in Development have seen 'developing' sexual and gender identities as shaped, in part, by 
internationally funded MSM development interventions. Adams and Pigg (2005) view sexualities as "constituted in and through [development] projects that blur the boundaries between cultures, norms and realities" (2005, p. 7). This perspective of 'sexual subjectivities' in development contrasts with donor discourses and funding arrangements which anticipate project impacts upon sexual practises only, rather than any potential to unsettle local identities.

Cohen (2005) explored the unintended impacts (collateral damage) of development interventions on developing queer identities with his work on the 'kothi wars' in India. He outlines how competing groups with alternative identifying labels vied for the resources available to work with a target which donors refer to as 'MSM' for HIV/AIDS projects (Cohen, 2005). The conflict in India arose over the most culturally appropriate form of identification of "MSM" in the local context, with debates over the authenticity and applicability of 'gay' and 'kothi/panthi' identities. These identity "wars" (Cohen, 2005) took place along axes of class, race and gender in India, and intersect with the need for development funders to identify, mobilise and 'partner' with a local target group. Cohen (2005, p. 299) usefully points out what is at stake in these debates, stating, "without a specific identity one lacks entitlement and thus access to foreign NGO funds - words bring money". He offered examples of MSM tactically switching between 'gay' and 'kothi' identities, and outlined the destructive conflict that ensued between two separate groupings being in competition for resources.

The unexpected transformations set in motion by MSM development interventions is also discussed by Nguyen (2005, p. 246). He grounded his discussion in Abidjan in the Cote d'Ivoire, examining how the "social technologies imported by international NGOs to prevent HIV/AIDS furnished an opportunity for Abidjan's homosocial communities to redefine themselves with the "new facts of life'". Arguing along the lines of Cohen, Nguyen saw the uptake of confessional technologies imported to combat HIV/AIDS, such as 'coming out' or 'being openly HIV positive', as having impacts on the fashioning of the self. As Nguyen (2005, p. 264) argued, these technologies - in facilitating the telling of the self - present local conceptualisations of "sexuality as performance" alongside 'Western' understandings linked to sexual identity. Nguyen (2005, p. 265), in reflecting on his research with an NGO "Positive Nation" and the accounts of two of its members, recalled that they were "already fashioned 
into a familiar 'coming-out' narrative, [with] soteriological themes of dawning awareness, self-discovery, and self-realisation...". Again with this example, the stated intent of the donors was to fund HIV/AIDS related activities. These identity transformations were the byproducts of this focus. Yet, in these discussions of the change in the local context brought about by sexual health development funding, I have not read any accounts of positive impacts that are desired by local communities. This is where my work departs from both Queering Development literature and the cultural analysis of sexuality and development, in my explicit focus on the complexity of development relations, and their potential collateral benefits for local communities.

\section{Conclusion}

In sum, this chapter has outlined the position of sexuality in mainstream development theory and policy generally, before examining the work of Queering Development authors in particular. I argued that Queering Development texts have documented the constraints on local practitioners well, but could do more to speak about their possibilities. In the following chapter I outline my heartful methodological approach to this re-search, followed by an examination of the rigour of my study. 


\title{
Second Interlude: Just Talking
}

\author{
sweetheart, \\ i see
}

margins as meeting places

for dialogue;

a polyvocal

chorus of singers

sit on the curb

singing

sometimes together they

\author{
queer the pitch \\ other times, their \\ voices rise \\ cacophonous \\ shrill \\ in beautiful disagreement \\ a commitment to talking together \\ is what \\ i see
}




\section{Chapter Three: Re-search Design and Methods}

[W]riting is never innocent. Writing creates the worlds we inhabit

(Denzin, 2003, p. xii)

\section{Introduction}

Earlier chapters explored the context in which this project was conceived by introducing me as author and surveying the existing literature that speaks to this topic. This chapter attends to the approach and methods used to complete the project. I begin with the design of my study, examining the philosophies that underpin its methodological approach. Then, I introduce and explore the re-search site and population and discuss the human ethics considerations that materialised during my study. My positionality as re-searcher is then discussed. Following this, the sources of information called on are examined as well as the processes used to analyse the information. The chapter concludes with an assessment of the re-search process.

\section{Study Design}

My methodological approach has been in a constant state of becoming. Rather than fastening this thesis to a mainstream perception of methodological rigour, I allowed it to breathe, honestly guided by what I felt and thought as the process evolved. I designed this study both as an output (which it inevitably is), but also as a learning process. I desired to develop what Weems has described as an imagination-intellect (Weems, 2001). Thus, I attended to my personal needs and spiritual and intellectual development alongside the growth of new perspectives. My explicit focus on a learning spirit enabled me to cultivate my curiosity, take up new intellectual passions before circling back around. This flexibility enabled me to develop a reflexive learning-by-doing methodology. The absence of fixed methodological procedures does not however imply that my thesis exists in a void without 
purpose or responsibility, quite the opposite; throughout I have been guided by a core of principles which form the spiritual centre of my thesis. The act of listening to these core principles has formed the basis of my methodological approach.

At the centre of my study was an honest commitment to heartful and caring scholarship, what Pelias (2004) has termed A Methodology of the Heart. This alternative re-search paradigm begins with the acknowledgment that re-search is "always already moral and political" (Denzin \& Lincoln, 2008, p. xi). It advances "a scholarship that fosters connections, opens spaces for dialogue, heals" (Pelias, 2004, p. 1) by anchoring itself in the warmth of the re-searcher's feeling body. I quote Pelias here at length as he helps me situate the spirit of my own re-search:

Instead of writing a work that hits hard, that is straight to the point, that is based in well-formulated arguments, carefully arranged to leave no room for doubt...instead of being armed, ready for a good fight, ready to enjoy the bounty of conquest, I want to write in another shape. I seek a space that unfolds softly, one that circles around, slides between, swallows whole. I want to live in feelings that are elusive, to live in doubt. I want to offer an open hand that refuses to point but is unwilling to allow injustices to slip through its fingers. (Pelias, 1999, pp. xi-xii)

I had embarked on this project in this spirit long before I had even devoured the words contained in "The Heart's Procedure" (Pelias, 2004, pp. 11-12). This alternative methodological procedure posits five principles at the centre of heartful scholarship these include scholarship that is: evocative; multifaceted; reflexive; empathic; and useful. Pelias describes evocative scholarship as "language doing its hardest work, finding its most telling voice, and revealing its deepest secrets" (Pelias, 2004, p. 12). Poet/scholar Weems' expresses this desire for connecting to a re-search language that goes deeper when she says:

I want words that feel and heal, that peel rubber like tires across my head, follow me to bed til I'm dead ... (Weems, 2001, p. 10) 
Following this is multifaceted scholarship, which is re-search that "twists and turns, stands to all sides, considers...before it acknowledges it can never see it all". Third, is reflexive scholarship, which "points to itself in order to say this is where it stands, at least at this moment, with these qualifiers and with these questions". The fourth is empathic scholarship, which is the creation of knowledge that "connects person to person in the belief in a shared and complex world...it welcomes identification". Finally, Pelias identifies useful scholarship as a crucial part of the Heart's Procedure. This "reaches toward an audience. It cares...It is a cultural labourer" (Pelias, 2004, p. 12). The foundation of my evolving methodology is found in the spirit of these five principles.

If re-search is, as I believe it is, always a moral and political endeavour, then a heartful researcher must be mindful of their commitment to the advancement of projects of social justice. Through listening to these heart beats in my re-search, I sought to disrupt the epistemology of the closet (Sedgwick, 1990) which continues to frame the sexual and material practices of everyday life (Denzin \& Lincoln, 2008), including my life at the university. My commitment to social justice for queers is manifest in the explicitly critical, interpretive and bad ass queer spirit of this re-search and my use of methods of resistance within it. This is what Britzman would call an act of unthinking normalcy (Britzman, 1998, p. 80). In looking to tell queer stories in a queer way I am following the lead of scholars who have seen that their often marginalised positions in the world/academy necessitate a different nature of scholarly re-presentation (see Frank, 1995; hooks, 1997). My turn to the interpretive is also evident in the guiding metaphor of this thesis - graffiti. This metaphor helps me see things other-wise, to bring the colourful language and imagery of campy carnival, parody and transgression into the unfolding of this text. The metaphors used in my thesis are more than gimmicks; in this case, "The Metaphor Is the Message" (Richardson, 2002, pp. 372-376).

A desire to create useful and empathic scholarship informed my approach to the subjects of this study. My concern was to focus analysis on the perceptions of khon-thîi-mii-khwaamlàak-lăai-thaang-phêet ${ }^{22}$ in Bangkok around development interventions that engaged with them as MSM. In itself, this goes some way toward advancing my goal of achieving social justice and equity (Denzin \& Lincoln, 2008), by re-vising and re-centring the subjects of study

\footnotetext{
${ }^{22}$ This is a popular Thai language term which can be translated as people with diverse sexualities.
} 
away from policy makers, donors and theorists, instead privileging the co-constructed (see Taylor, Durant, \& Boje, 2007) perspectives of those with the most at stake. I envisioned this re-presentation of participants' voices as creating a new resistant space, a space that would hopefully go some way to countering the his-torical and current scientific oppression (Halpin, 1989) that queers have encountered in re-presentations within academia. I also strive for social justice by re-positioning the role of the development studies re-searcher. Rather than approaching this thesis uncritically, like a 're-searcher-tourist', I saw it as my ethical duty to explore how the re-search benefitted, as well as promoted the selfdetermination of participants, and to reflect honestly on this in the re-presentation of my re-search.

For me, it is not enough to explain that this was re-search for the 'greater good'. I carefully weighed the benefits of individuals participating in my re-search and when I found these were insufficient I reflexively altered aspects of my re-search design. Specifically, I began to carve not only a learning space where collective consciousnesses could be raised and where new meanings were brought forward, but I also endeavoured to create a healing space (see Denton, 2006), where participants and I made meanings that positively impacted on our lives. In the beginning stages of the re-search I found that encounters with participants often centred on negative aspects of MSM experience: unmet community needs, pain, discrimination and misunderstandings, when my intention was to acknowledge these barriers but also to connect to the positive potentialities of queer sexualities. In response, I began to use arts-informed methods including drawing, to generate knowledge and (hopefully) assist re-search participants to attend to potentially empowering ways of reconnecting thoughts. Many participants reported that they enjoyed the opportunity to share their stories, and consider some aspects that might remain unconsidered in the unfolding of daily life; as one participant Timo remarked "if you weren't here asking the questions, we might not be thinking about this" (2009 pers. comm., July)

To gain access to the material this inquiry needed, I turned to the burgeoning field of Critical Qualitative Research (CQR) (see Denzin \& Lincoln, 2008) to inform my re-search design. I saw CQR as a means of better understanding the dynamic flow of living lives through the exploration of individuals' subjective understandings and representations of their own 'real' worlds. Critical theory also aligned with my understanding of a social science which is 
productive and my desire for this re-search with khon-thîi-mii-khwaam-làak-lăai-thaangphêet [sexually diverse people] to be emancipatory, "creat[ing] space for resistive, counterhegemonic knowledge production that destabilizes the oppressive material and symbolic relations of dominance" (Hesse-Biber \& Leavy, 2006, p. 31).

I understand my approach to be one of many queer methodologies articulating within the contours of the critical theory paradigm. I refuse to adhere 'queer' to a fixed definitional point; instead I position it as an amorphous disorientation (Manning, 2009), one which moves in fluid opposition to re-search processes embedded in hetero-patriarchical hegemony. It is my hope that the approach I have taken unpicks the scientific tenets of objectivity, binary constructs and re-searcher detachment, moving my re-search into a more inclusive space, which breaks down the sex, gender and other orders that perpetuate social, political and spiritual injustice. In fashioning my queer methodology I transgress what Wittig (1992) refers to as the re-searcher's Straight Mind wherein "all of history, culture, social reality, language and all subjective phenomena are interpreted and understood through a heterosexual lens" (Hammers \& Brown, 2004, p. 95). Finally, by refusing to perform a straight text I call into question the assumptions of mainstream research.

\section{Entry Point}

My thesis begins from a position that sees the recipients of MSM development interventions as the people best positioned to comment on their own needs and desires for the future (see Chambers, 1997; Fine, 1994). The logical implication of this argument is to invite recipients of donor funding to share their thoughts and on the development process. Generating accounts which privilege local practitioners contrasts with many development studies texts which focus on the actions and perspectives of donors. Rutherford and Nyamuda read this as characteristic of 'developers' positioned at the centre of analysis with 'developing' subjects' reactions read as "responses to a fixed centre, rather than formed and influenced by all manner of circumstances" (2000, p. 840$)$. In re-reading and re-(w)ri(gh)ting the balance in the re-presentation of these relationships it is my hope that those subjects supposedly 'frozen' in development's gaze would instead be able to share their own perspectives. Yet, I do acknowledge the difficulties (as does Skelton, 2001) in striking the 
balance between not-appropriating or speaking for participants and finding some way of sharing their stories.

Being aware of the tension between representation and appropriation, I chose to interact with members and leaders of two sexual/gender diversity peer serving CBOs in Bangkok. While I chose to site my re-search alonsgide these organisations, it is important to note that the overwhelming proportion of MSM in Bangkok are not (and may not wish to be) connected to them. Therefore, I do not position the perspectives of my twenty-seven participants as re-presentative of all MSM in Bangkok; instead, the perspectives portrayed re-present the co-constructed accounts (see Taylor et al., 2007) of actors situated in particular times, places and positions. I hope to have resisted unrealistically heroic accounts of the participants and organisations involved in this re-search, remaining mindful that these accounts are co-generated with people invested in organisations that are themselves unstable sites of class, ethnic, gender and other struggles.

Another position that I wish to clarify is my treatment of words like 'sexualities' and 'gender'. I do not receive these words uncritically, having learned from constructionist debates that all sexualities should be viewed as local (Pigg \& Adams, 2005, p. 5). Constructionist arguments advocated for the analysis of sexuality with reference to social, economic and political structures, and within the paradigms that they sustain. In placing my re-search within this context it is also my aspiration to meet Adams and Pigg's (2005) challenge to re-historicise sexuality within local contexts. Thus, I am mindful that Siamese/Thai histories of sexuality and gender have been produced in a significantly different context to that which was identified by Foucault as an autonomous, reified realm of human life that was produced under certain economic and social conditions (Jackson, 2003).

I tried to ground this re-search as much as possible within local frames of Thai sexuality/gender. Nevertheless, I came up against problems in writing about 'sexualities' outside the context of the 'global North' (in which this object has been reified) and it was difficult to not speak about 'sexualities' when this is the notion that informs development understandings and interventions in 'developing country' contexts. This is a tension that I held throughout my re-search, striving to remain reflexive on both the local and on my own 
(mis)understandings of meanings contained within the words of my participants. Similarly, I recognise that my use of 'donors' may imply a cohesive and stable group. This is not so. Development donors have many different ways of approaching donor-recipient relationships and effecting social change around sexuality/gender. What I wished to do in my study was to 'zoom out' from donors' perspectives and focus more intently on the representations of local recipients. This focus is reflective of both the limitations of my research - the space and time available to me, but it also serves as a mirror to the blurring of local recipients in most texts within sexuality and development. I am also comforted that existing comprehensive reviews on the shifting of international donor discourses regarding queer subjects exist (see Cornwall, et al., 2008)

\section{Positionality}

Throughout my re-search I understood that I, as author, am intimately entwined with this text. My finger and thumb tips (in concert with other body parts) have tapped, caressed, or thumped every page of this work into existence. I am deeply embedded in the production of this knowledge. This is seen in the way I have chosen to frame the aspirations of the research, its methods and questions, the style of my transcription, my reading and methods of analysis, and the selection and rendering of participants' voices, as well as my own. As my re-search is concerned with conceiving of an embodied understanding of queers in development interventions, I believe that the best way to explore my positionality is to make my embodied self subject to examination. Self-examination is not only my ethical responsibility, it is also an opportunity to begin to transform relationships between "researcher (subject)-researched (object) to be... non-hierarchical, equitable, and respectful" (Hammers \& Brown, 2004, p. 87) - this embodiment is also a new and empowering freedom for me in scholarly re-presentation, allowing myself to move beyond fixed approaches to subjectivity and work my hyphens (Fine, 1994).

To this end, I included a collage ${ }^{23}$ of photographs which I have defaced. This challenges the invisibility of my scholarly voice, by putting my body onto these pages and making possible alternative readings of who I am. I intend to highlight and celebrate my own situated knowledge and proclaim that my embodied ways of knowing the world are as 'valid' as any

\footnotetext{
${ }^{23}$ I credit Bochner and Ellis for the use of collage in this way; I drew inspiration from their edited book "Ethnographically Speaking" (2002).
} 
other form of knowing. It also signifies my belief in the impossibility of ((bracketing)) my preconceptions. As such, this work is both 'contaminated' and brought alive by me as a located, gendered and mindful (Bentz \& Shapiro, 1998) re-searcher/inquirer. This 'contamination' is symbolised by my defacement of these images. 


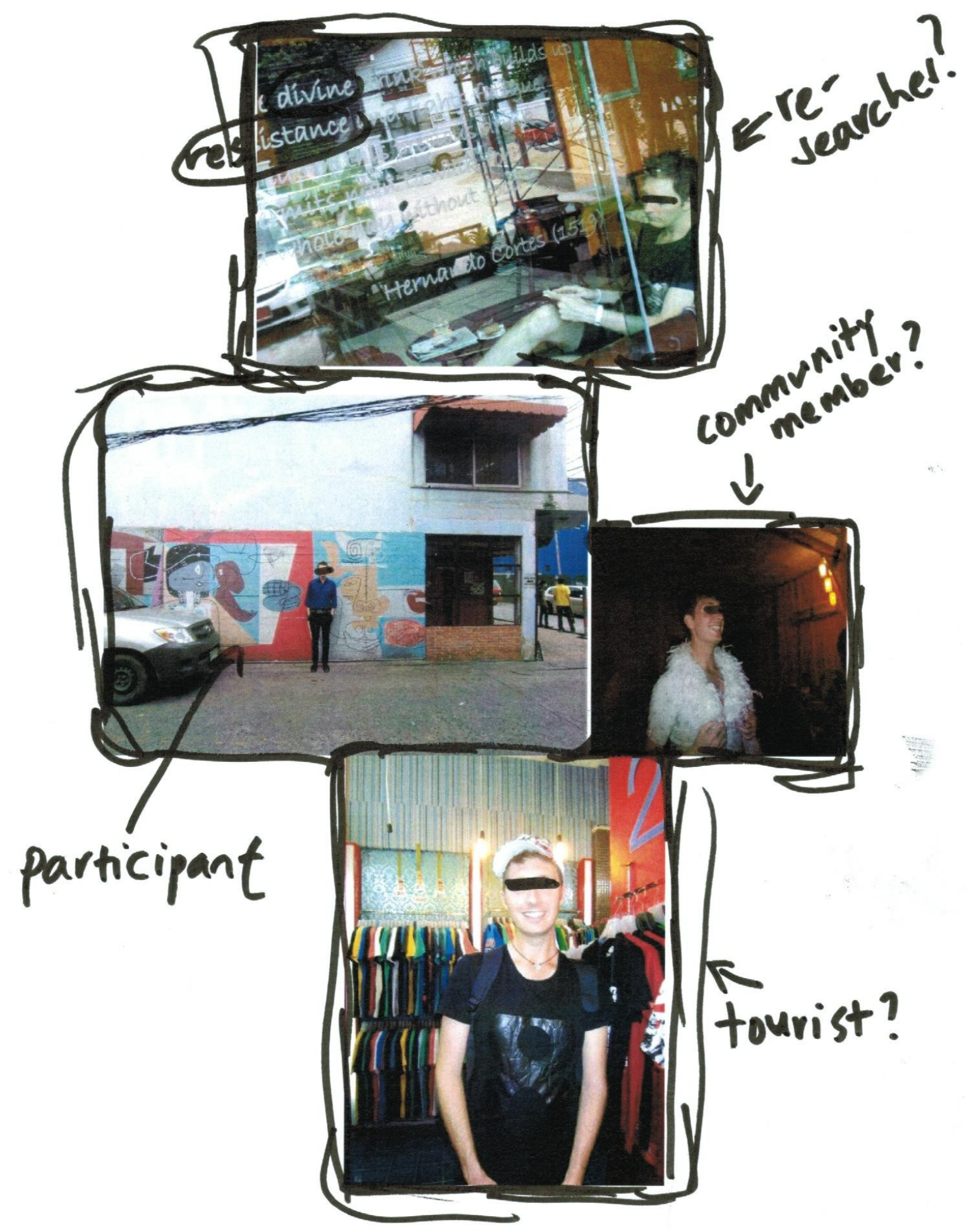




\section{Selection of Field Site and Case Study Organisations}

Several factors influenced my decision to work empirically with sexually diverse communities in Bangkok. The primary reason was my desire to work near to my partner who was then working in Bangkok. Alongside this was the opportunity for my re-search to benefit from the wider network of supportive relationships that this move would enable. I also felt that Bangkok would be an excellent case study location, as it is widely considered the regional centre of MSM development for Southeast Asia. The current HIV/AIDS crisis in Bangkok and the subsequent reaction from donors to increase funding for MSM projects in 2009-2010 also informed this selection.

The process of selecting case study organisations began with a discussion with my partner; he advised that BRO would be one possibility, as he had been previously involved with some of their touristic activities. More re-search revealed several organisations working with MSM in Bangkok, and I contacted them. The first two positive replies came from BRO and RSAT and I undertook exploratory meetings with their representatives. My intention in these meetings was to ascertain whether I felt I could work well with these organisations and whether they were interested in working with me. I also hoped that meetings would mark the beginning of more reciprocal re-search, where I could orient my study toward issues these organisations felt were priorities.

\section{Human Ethics Considerations}

The regulations of the Human Ethics Committee (HEC) of Victoria University of Wellington required that ethical approval be sought and conferred before my re-search was undertaken. Ethical approval was obtained on April 24th 2009 (see Appendix One). Prior to receiving this approval I had initiated contact with the two organisations that I would study alongside and sought their input in the project design. Social relations developed subsequently, and I was invited to public events such as movie screenings before approval was granted. After receiving approval I began to approach potential re-search participants.

Before each interview I read, provided for the participant to read, or had verbally translated a detailed information sheet (Appendices Two and Three) that explained the purpose of the study, and invited participants to ask questions. All participants were asked to read/listen to 
and sign the consent form (Appendices Four and Five) to confirm that informed consent had been obtained. The ethical concerns of the consent form centred on 1. participant confidentiality; 2 custody of tapes/transcriptions; 3. voluntary participation; 4 . withdrawal at any time of the study (see Appendix Four and Appendix Five).

Several other concerns (beyond the "manufactured ethics" (Thrift, 2003, p. 115) present in HEC deliberations were at the centre of my ethical considerations. The potential utility of my project was one of these. While I considered that this topic was ripe for scholarly inquiry, I was concerned with the limited impact that my re-search may have on inequalities, and that it was unlikely to produce any material benefits for my participants. My reading of critical indigenous perspectives (see Denzin, Lincoln, \& Smith, 2008) had informed me that simply noting that participants may be granted an opportunity to be finally heard in an academic realm was not enough. Not only was my re-search not materially benefitting participants, some of the encounters led participants to speak about things that had often remained unspoken, to inquire into areas of darkness. When participants entered these spaces and invited me along, I was aware of the potential impacts it could have upon them. I began to notice that the interactive nature of interviews provided opportunities for healing and soon altered my methods to incorporate aspects of facilitated care. Tang (2006) has identified this focus on the therapeutic possibilities of interviews as an important facet of undertaking ethical queer ${ }^{24}$ re-search.

Participants and I began to collaborate in creating more therapeutic interview spaces. My intention here was to go beyond the interview rhetoric of 'personalization strategies' (see Taylor et al., 2007) toward more meaningful dialogue. Interviews began to take longer; they roamed from the central questions of my re-search to encompass other issues that concerned participants. I began offering participants the opportunity to draw their thoughts or feelings, and to share this with me or keep it for themselves, or to write and re-story how they felt. I also began to include a mapping exercise (see Figures 3.1-3.3 - presented later in

\footnotetext{
${ }^{24}$ I have also remained mindful that despite my own genderqueer identity, I have a different subject position to the female spectrum trans communities I worked alongside throughout this re-search. I have been guided by ethical principles regarding the way I approached my study with these groups. I was inspired by trans theorists like Hale, who have suggested rules for non-trans re-searchers who wish to work with trans re-search subjects, I have included these rules in Appendix Seven for the reader to consider. It is my hope that I have worked with these communities productively and sensitively.
} 
the chapter) which enabled participants to imagine the positive potentialities in the future that is "not yet" (Weems, 2001, p. 3). Participants who it seemed would benefit from a follow up session were given my mobile number or email address if they wished to talk further. I also contacted health professionals as a point of referral for participants who seemed uncomfortable/sensitised by our engagement(s). I believe that this reflexive movement toward re-search that cares was a significant ethical moment. It not only connected to my concern for the individuals participating, it also philosophically grounded my work in the social justice aims that had propelled me into it in the first place. Finally, it gave me as re-searcher a purpose, and presented opportunities for healing myself.

In making the ethical decision to offer the interview space as one for co-healing, I was mindful of hooks (1990, p. 151) parody of the researcher who aspires for emancipatory interactions but ends up colonising and further marginalising her-his research subject:

No need to hear your voice. Only tell me about your pain. I want to know your story. And then I will tell it back to you in a new way...a way that has become mine...I am still the coloniser, the speaking subject, and you are now at the centre of my talk. In attempting to create opportunities for the wounds (Denton, 2006) (of the participants and the re-searcher) to be acknowledged and the knowledge gained from these honoured, I hope I avoided falling into a subject/object, coloniser/colonised trap. Yet, without a more detailed study of the ways that participants experienced these interactions I am unable to state that shared healing spaces were effectively 'held'.

My reading of critical indigenous scholarship also reminded me to ensure that the information generated in this re-search process remained with the local community. This presented a dilemma in trying to write a Master's thesis that could reach sufficient depth within the field of development studies that was still intelligible to largely non-academic English speaking development practitioners. Rather than attempting to combine both of these goals into one work, I viewed my audiences as situated (see Pryke, 2003, pp. 163-4) and intend to fulfil my ethical commitment to return the information in a separate, more accessible piece of work which is centered around the diagram produced from participants dreams (see Figure 8.1.). 


\section{Participant recruitment}

The recruitment processes used in this study were oriented both by convenience and purpose. A convenience/opportunistic recruitment method involves participants who are readily available and who have lived the experience the re-search inquires into. It is also a method that uses time effectively, and enables re-searchers the ability to speak to many participants. I combined this approach with purposive recruitment. I used this in order to include a greater diversity of participants. For instance, although yĭng rák ying and săaopràphêet-sŏong participants were not readily available for interviewing I felt that my work would significantly benefit from their inclusion and went to further effort to gain access to members of these groups. This was combined with a political commitment to ensure that the perspectives of women who love women and transgender women were not invisible in my thesis.

I used a snowball technique to connect to participants. After each interview I asked participants to recommend other people who might be available. I also used my involvement in various activities, and simply hanging out in the organisations' offices to connect with possible participants. I was aware of the potential for gatekeepers within these communities. In an attempt to counter this I built up a large number of relationships and used multiple contact points to recruit participants.

The selection criteria for interviewees were as follows:

1. Present in Bangkok between April-July 2009.

2. Some involvement in development interventions with khon-thî-mii-khwaam-làaklăai-thaang-phêet [sexually diverse people] in Bangkok, whether a member of/visitor/volunteer/employee of a funded MSM organisation or engaged at a national/regional level with MSM development work.

3. Willing and available to undertake an interview.

Explanations of the re-search and invitations to participate were sent to potential participants through email, by telephone or explained in person. The explanation introduced me as the re-searcher, the aims of the study, and indicated the type of material that would 
be covered in the interview, as well as the length of time that it may take (although this was negotiable). If participants agreed to a meeting, I gave them an information sheet (see Appendix Two and Appendix Three). This information sheet explained the purpose of research, and provided an opportunity for them to seek clarification.

\section{Re-search Population}

My re-search involved twenty-seven participants aged between approximately 18-50 years of age. Participants were drawn from diverse backgrounds, and included staff, volunteers, 'clients', activists or Mekong region non-governmental representatives. All participants had connections to one of the organisations at the centre of this thesis. Interviews were conducted with people identifying as gay, gay ${ }^{25}$, săao-pràphêet-sŏong, yĭng rák y̆ing and heterosexual and others who considered their sexual and/or gender identities beyond these descriptions. Most participants gave their interviews in English. Thus, participants who were fluent in English were likely to be privileged. While I did use a translator when this was possible, engagements with participants speaking English could take place on an impromptu basis. It should be noted however, that a significant proportion of the population with whom I interacted in Bangkok did have sufficient levels of English language ability to enable their participation in English.

Participants were of varying ethnicities, including Thai, Chinese-Thai, European, and two other South East Asian ethnic groups. The social statuses of participants were diverse, including university educated professionals, university students, activists and people currently unemployed. Next, I introduce my participants.

\footnotetext{
${ }^{25}$ The use of gay in a Thai as opposed to Western context is expressed in Italics. I use both gay and gay to reinforce the cultural specificity (as well as the global features) of gayness to Thailand. The use of gay has been traced by Jackson to circa. 1960 (see Jackson \& Sullivan, 2000 for further details).
} 


\section{Introducing Participants}

Tana - Regional representative, 20s, gay

Tim - Regional representative, 20s, săao-pràphêet-sŏong

Timo*26 - Master's candidate, voluntary counsellor for RSAT. Also acted as my interpreter, 30s, gay Miao* - Director of RSAT, 30s, -

Toi - Regional representative, 20s, -

Jet - Organisation representative, 30s, -

Mhu - Organisation representative, 20s, chaai-rák-chaai

Dam - Organisation representative, 20s, gay

Noom - Organisation representative, 40s, -

Chaeng - Regional representative, 30s, female, straight

Nok - Activist, 30s, ying rák ying

Au - Activist, 40s, yĭng rák ying

Ae - Key informant, 30s, female, straight

Shine - Key informant, 30s, gay

Tong - Organisation representative, 30s, gay

Mario - Organisation client, 30s, gay

Cho - Organisation client, 20s, gay

Tui - Organisation representative, 20s, gay

Ton - Organisation client, 20s, gay

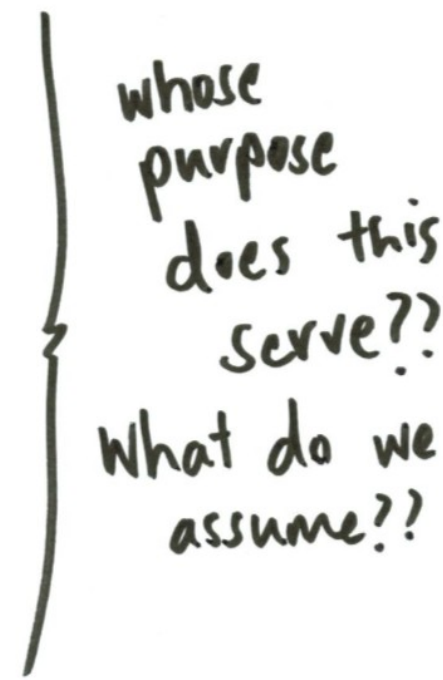

Oud - Activist, 40s, -

Sam - Regional representative, 20s, gay

Jan* - UNESCO regional HIV advisor for Asia and the Pacific \& Chief of the HIV Coordination, Adolescent Reproductive \& School Health Unit, 40s, gay

Lek - Organisation client, 20s, săao-pràphêet-sŏong

Kung - Organisation client, 30s, gay

Tik - Organisation representative, săao-pràphêet-sŏong

Gob - Activist, 30s, gay

Pom - Organisation representative, 20s, gay

${ }^{26} *$ These participants elected not to use pseudonyms. 


\section{Individual Semi-Structured Interviews}

As my re-search was issue oriented and concerned with listening to subjugated voices, I elected to use semi-structured interviews as the core method of my study. I understood these as meaning-making partnerships between myself and participants. The content of the interviews was generally consistent with the aide memoire (see Appendix Six). Nevertheless, my interpretation of this schedule remained dynamic; I was attentive to the particular interests and expertise of participants to enable a more dialogical interview process.

I attempted to make interviews convenient. This meant being flexible with the time interviews occurred, which varied from early morning breakfasts, to late night desserts. The choice of venue for the interviews was flexible, to ensure that the participants felt as comfortable as possible when discussing what could be for some, highly sensitive information. Venues ranged from participants' apartments, quiet cafes and bustling workplaces, to bars and food courts, and one interview was conducted in motion, between subway stops. The context of the interviews were varied, at times only myself and the participant were present, at other times they took place in busy public spaces, with action taking place in the peripheries. Some interviews took place in twelve minutes total; others lasted over three hours. Most interviews lasted over one hour. The interviews were generally open-ended, that is, I set aside a morning or afternoon in case participants wished to continue our discussion. They were flexible in content too, able to move with the interests and expertise of participants, and my own questions that emerged at that point in my re-search. I saw little utility in keeping to a fixed schedule. To do so would be to ignore the praxis of this re-search. The questions I knew yielded shallow answers or were redundant were passed over, and the other questions that rose in importance, and demanded further attention were addressed. I recognised my role as a participant in a reciprocal interaction, and was open to disclosing information if participants asked questions of me, or when it felt like it would create a safer space.

At the beginning of each interview an ethics checklist was undertaken (see Appendix Four and Appendix Five). My reading of whakawhanaungatanga (Bishop, 1996) had sensitised me to the difficulties some participants might face in halting a re-search interaction, so I used a rolling consent process of repeatedly checking in. Participants were asked for 
permission to make a digital recording of the engagement. I explained that this would assist with the reliability of transcription. Where possible, the transcripts were returned to participants soon after the interview to check the accuracy of the transcription.

I supplemented transcripts with my own reflections as I undertook the interview. Some participants did not wish to have any contact after the interview took place and I respected their wishes; others gave incomplete contact information which prevented transcripts reaching them. Digital recordings of interviews have been kept on my locked laptop, and transcriptions have been kept in a locked filing cabinet. The hard copies will be stored in a secure cabinet, and held for two years for possible use in further articles and/or professional or artistic re-presentations. I gave participants access to the re-search findings, and the opportunity for those participants who requested input into the thesis to do so periodically throughout its development ${ }^{27}$.

\section{Group Semi-structured Interviews}

As well as individual semi-structured interviews, when opportunities arose I conducted group interviews (see Hoggart et al., 2002) with re-search participants. Three group interviews were held in total. The first included five members of staff and volunteers from RSAT, and was translated by an experienced interpreter. The second group interview was more of a discussion group; it involved the participation of three members of RSAT staff with the assistance of a beginner interpreter. These staff members spoke not only to the interpreter of the interview and myself, but also engaged with each other throughout the process. The third discussion group involved two volunteers from BRO; again, this was conducted with the assistance of an experienced interpreter and participants engaged with me, the interpreter and each other. The group interviews followed a similar procedure as individual interviews. They began with an explanation of ethics procedures, and a question asking process. This was followed by introductions of the people present, if this was necessary. They followed a similar pattern, whereby I asked several open ended questions and created space for participants to bring their own thoughts and opinions forward. Group

\footnotetext{
${ }^{27}$ Participants who left their contact details with me were emailed copies of my work at least once during the writing process. In the weeks preceding submission all participants whose details I possessed were emailed to ensure any recommendations they made could be addressed and/or incorporated - once again I thank participants for their input in the final stages of my work.
} 
interviews were generally shorter in duration than the individual interviews, as I was conscious not to distract staff or volunteers from their duties, and I did not wish to unduly impose upon my interpreters.

\section{Re-imagining Connections through Mapping}

While conducting the individual semi-structured interviews, my procedure underwent many innovations. I realised that focusing participants solely toward the current problems experienced by sexually diverse people in relation to development interventions would not produce the type of information I sought, and secondly would not orient participants toward a critical re-imagining of future interventions. In order to counter this, I asked willing participants to map out several different concerns. I used a drawing activity to engage participants on the significance of the distribution of funding in development interventions into queer sexualities. I used this method for several reasons. First, I was mindful that I wanted to explore (and invite my participants to explore) ways of MSM development interventions being better, being otherwise. It was also a topic that was difficult to put into words, but appeared easier to draw.

The first activity was to map the relative size and importance of different service providing organisations working with MSM in Bangkok. This was accomplished by participants drawing circles relative to a figure representing MSM. Figure 3.1 is Jet's interpretation of the organisations that currently work with MSM in Bangkok. The largest circle is the Ministry of Public Health (indicating the size of the organisation), and the circle farthest away from the MSM figure is BRO representing Jet's understanding of BROs relevance to the life-context of Bangkok MSM.
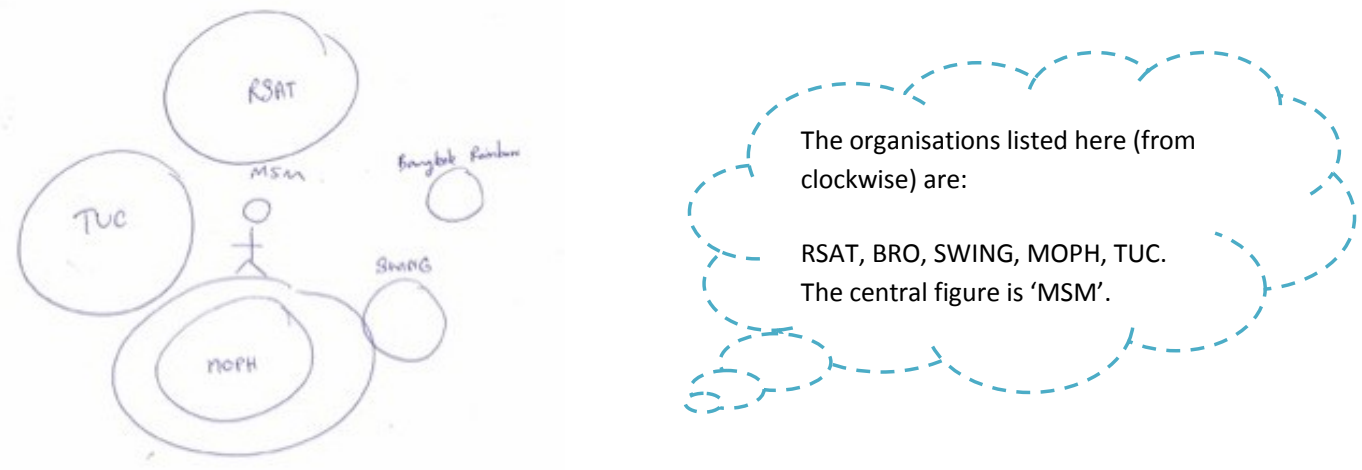

Figure 3.1 Jet's interpretation of the organisations that work with MSM and their relative closeness to MSM 
In the second mapping exercise, I invited participants to draw the relative size and distribution of categories of interventions into MSM in Bangkok (such as HIV or human rights). Participants were free to create their own categories to express their understanding of the realms of intervention. Again, they were asked to orient these areas of intervention in relation to the importance they believed that these interventions had to MSM in Bangkok. Figure 3.2 is Gob's interpretation of the current priorities that were funded, HIV/AIDS is significantly larger than other intervention areas.
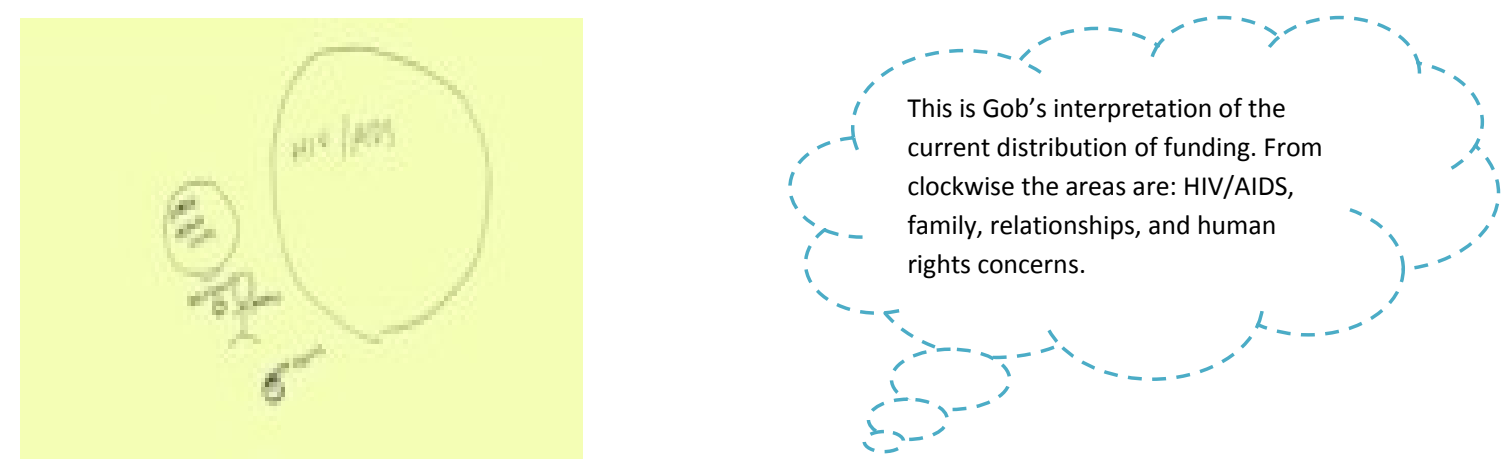

Figure 1.2 Gob's Interpretation of the current distribution of funding

The third mapping exercise enabled participants to envision the future otherwise. This was a utopic opportunity for participants to re-distribute funding to MSM in Bangkok in a manner that they saw fit. Participants mapped this by drawing circles to represent the distribution of funding, overlapping or containing circles within other circles, if they so desired. I hoped that this final mapping exercise would not only enable the generation of rich and complex information that I used in my thesis, but it would also invite participants to express how they would see things constituted otherwise. Mapping emerged as a fun and creative way to succinctly express their views. In another way the mapping exercise was instrumental; focusing our conversation around the maps enabled participants to explore the topic in greater depth. 

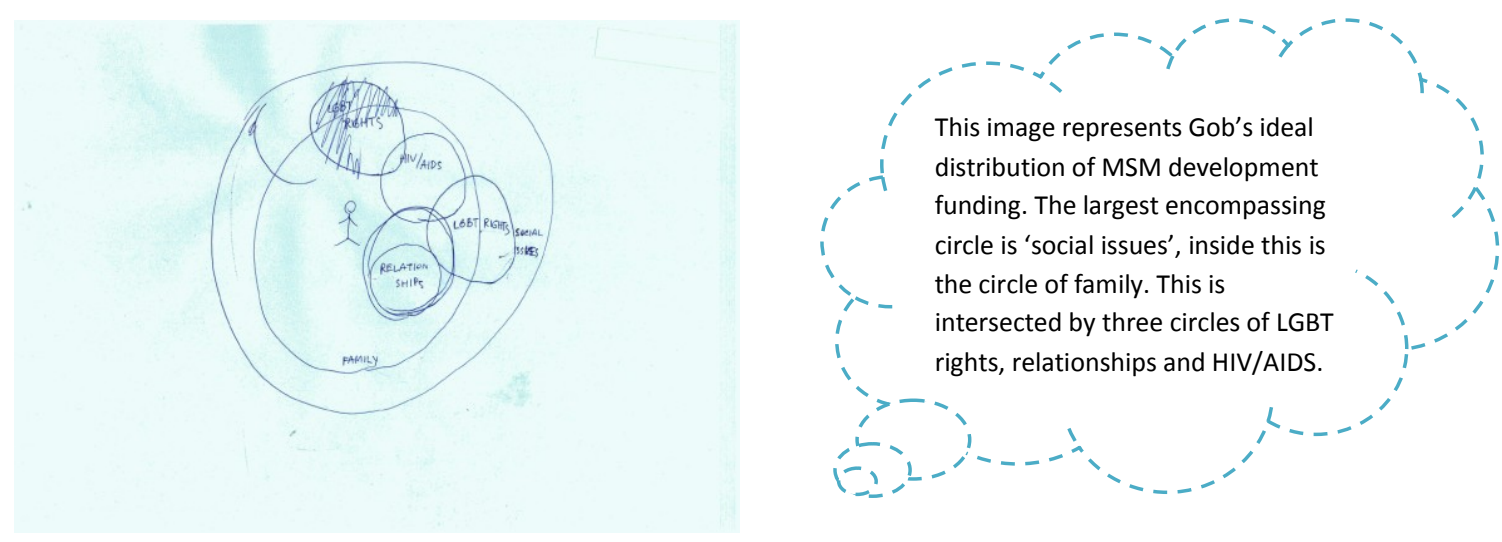

Figure 3.3 Gob's ideal reconfiguration of funded MSM priorities

Several participants declined to participate in this activity. Some were uncomfortable with the idea of drawing. In other cases a lack of time or facilities prevented me from undertaking the activity.

\section{Participant Observation}

Another significant method I used was participant observation. As a part of my re-searcherly role I saw myself as an active contributor to the MSM community in Bangkok hanging out at various community venues. I spent many hours sitting, chatting, eating and surfing the internet at BRO offices, and when I was available, at RSAT. This was my primary way of recruiting participants, but also served another purpose, connecting me to the 'vibe' of the organisations so I could experience the kinds of interactions that development funding facilitates.

I also participated in other activities such as a peer education session at a sex venue, the RSAT 'Camp to Defeat HIV/AIDS' (see p. 105), the BRO affiliated Weekend Away, movie screenings, a Sao Sao Et meeting ${ }^{28}$, and the 2009 Bangkok HIV/AIDS Conference. This community engagement enabled me to establish and strengthen connections, as well my contextualised understanding of my topic.

Throughout the period of my re-search I felt a constant tension between my role as empathetic friend and new community member, and my role as a re-searcher attempting to

\footnotetext{
${ }^{28}$ Sao Sao Et (literally Saturday $21^{\text {st }}$ ) is a khon-thîi-mii-khwaam-làak-lăai-thaang-phêet activist group which established immediately after the disruption of the 2009 Chiang Mai Pride parade. The goal of the grouping is to advance human rights causes for khon-thîi-mii-khwaam-làak-lăai-thaang-phêet in Thailand.
} 
better understand this new context and ultimately generate information from it. This fact caused me some discomfort, as I felt that some of my friends in Bangkok may interpret my goodwill toward them as a means toward an end, rather than the authentic spirit of friendship in which I entered most relationships. Guiltily, I would haul out my tape recorder to ask if we could record again.

\section{Collecting materials}

To learn more about the collateral benefits of MSM development interventions, I collected a number of materials during my stay in Bangkok. Materials collected included:

- Health promotion postcards, posters, brochures

- 'Sexually Diverse' business advertisements

- Newsletters, emails

- Newspaper and magazine clippings

Upon returning to Wellington I decided to focus on materials that were published or distributed by the two organisations I was re-searching. Of these materials, I classified all as sexual health-promotion based. Perhaps this reflects the funding priorities of donors. Yet, in a close reading of several of these texts, and by sharing them with participants, I was able to pay attention to other messages coming through. I selected two postcards from many possible materials for analysis in Chapter Seven; both of these postcards were given to me by Dam in July 2009.

\section{Information analysis}

In keeping with the heartful core of my thesis, my system of analysis was an ongoing and evolving process. It began in the interview itself, with manifest content analysis, note taking and reflection on what I heard in the engagement. I transcribed the interviews verbatim as soon as possible, and then began on a four level system of data analysis. I began using a system of open coding, reading each transcript critically several times and making notes in the margin of the ideas that the transcript prompted. Then, I worked these ideas into initial themes. This was followed by a second level of coding where I created categories across transcripts to illustrate the experiences of the group of participants, as well as individuals. I 
looked for patterns and themes across all of the information I collected. These themes were informed by similarities and differences with reference to my literature re-view and other interviews I had conducted.

When I returned from Thailand I began a more systematic analysis using the NVIVO program. I processed my interview transcripts by assigning passages to nodes. While grateful for the opportunity to use this process to think through some of the layered thematic dimensions of my re-search, I did not find that this process enabled the type of analysis that my re-search demanded. I felt that I was doing violence to the research texts, by pulling them apart and isolating words. So I undertook a different approach, which saw me stay with the paper copies of the transcripts. This fourth level was more contemplative; I looked at the transcripts often, read them out loud, and began making poetry out of the sentences contained in them. Reading the transcripts became a part of my daily routine, and kept me connected to my material, allowing me to ruminate on the questions that remained prescient. This constant revisiting was an extremely important aspect of my analysis. I believe that having these accounts as a part of my life significantly deepened my analysis. I would also argue that we dismiss the process of writing as analysis at our peril. Writing is philosophical, and is where much of the analysis of my re-search has occurred. I also must note that analysis took place in dialogue with others; it was not only a solitary venture conversations were often the sparks, and/or the sounding boards for my analysis.

At times I found the process of analysis intensely difficult. Many of the interviews touched on aspects of discrimination, pain and anger, and I felt a personal resonance with these. It was difficult for me to sit for long periods and listen to these stories without being deeply affected, so I began to develop systems of self-care. I visited a counsellor to receive clinical supervision for some of the difficult issues that had arisen in the re-search process. I believe that this is an important consideration for any queeresearch student who may be in contact with material that they might find upsetting; I also believe that students embarking on such projects should consider incorporating clinical supervision into their re-search plan. 


\section{Arts-Informed Methods}

I used arts-informed methods as both communication and aesthetic elements in my thesis (Cole \& Knowles, 2008). I stumbled into arts-informed re-search when I was in a state of confusion. I felt disenchanted with traditional methods that often ignore the magic of creativity. Arts-informed re-search is part of a larger agenda that hopes to put the "life juices" (Cole \& Knowles, 2008, p. 57) back into re-search. It represents what Neilsen (2008) calls scholartistry. These methods also connected to my desire to attend to queer poetics, an aesthetic that Mary Galvin suggests "comes out of necessity. In a culture structured significantly by heterosexism, the mind that can imagine other sexualities and gender identities must also imagine other ways of speaking, new forms to articulate our vision of difference" (1999, p. xii). At other times arts-informed methods were employed softly, gently teasing out subtle points and connections, creating spaces for contemplative thinking, and forms that moved like liquid between boundaries.

Developing my thesis has also been a profound nurturing of my artist self. Throughout, I engaged with, and represent my work in ways that felt authentic to me, and the re-search. I have been able to honour diverse ways of knowing, as well as awakening a diverse repertoire of forms of expression. It is my hope that I engaged with these forms of representation deeply to honour the diverse ways of knowing that stand outside recognised intellectual frameworks.

\section{Poetry/Lyric Inquiry}

Writing poetry is emotionally preoccupying; it opens up unexpected, shadow places in my self. (Richardson, 1992, p. 131)

Writing poetry has been a constant accompaniment to my other forms of writing in my thesis, continuing a practice that I have kept for many years. Neilsen (2008) describes poetry writing with an academic intent as lyric inquiry. She argues that writing poetry is both a phenomenological process and practice which may become art, or may simply create an aesthetic experience for the writer and reader (Neilsen, 2008). In my thesis lyric inquiry has primarily been a system of analysis, a contemplative practice that has enabled me to draw new points together, and utilise the power of metaphors and imagery to think other-wise. It 
has a secondary function in my thesis as an element of communication, a visceral way of connecting to the feeling-side of this re-search, and the vulnerability of this re-searcher.

\section{Performance}

As well as producing a written account of my thesis I created a spoken word performance that would preserve the integrity of some of the conversations I had shared with participants. I had felt uneasy through the coding process, with the number of stories that ended up on the cutting room floor. I wanted to put the stories to use, to share their messages. I also felt that this could be a meaningful way of honouring participants' experiences. By bringing their accounts to an audience at my university I also saw it as an opportunity to include people who may otherwise not have accessed the stories in my research; to come to know them and the meanings contained within them. I also recognised that this performance would serve as a catalyst for conversations, which might propel action toward solving some of the problems identified in the performance. I read through my transcripts and chose six stories that I would like to share with a university audience. I chose stories that moved me, and were diverse enough to allow audience members an insight into the different sexual cultures of Thailand. I also chose stories that I hoped would challenge audience members, and linger with them after the performance finished. I sent emails to six participants to explain the nature of the performance and to ask for their consent to share the stories. I was humbled by the response I received with four participants consenting to share their story, the other two electing not to have their stories shared in this way.

I wanted to perform the stories in a way that would remain true to the narrative and emotive quality of my re-search encounters (see Rogers, et al., 2002). I immersed myself in a diverse array of literature, looking for examples that would enable me to create a space for the audience to feel similar to that which Carl Leggo describes in poetry:

...letting words seep into

my body like night frost in morning stone...

(Leggo, 2006b, p. 86)

I found technical inspiration in my reading of "Readers' Theatre" (see Donmoyer and Donmoyer, 2008). I read my texts out loud and found rhythms within them. I altered aspects 
of the texts, eliminating my questions and some repetition, but left the stories largely as they were told to me.

Alongside my intention to connect to the audience was a desire to use the performance as a way of deepening my analysis. For me this performance project enabled me to get closer to my data. Being with texts so closely forced me to re-peat-re-peat-re-peat; words lodged in my head, tumbled around, and came out in different configurations. I had the opportunity to play with the words and be inside them. The words emerging from my mouth and tickling the open air embedded them in my memory (see Figure 3.4), to be turned over and mulled upon in different contexts, not only when I was sitting at the university. During the hours I worked on the texts the participants involved "moved into my psychic interior... [they] have not yet moved out" (Richardson, 1992, p. 133).

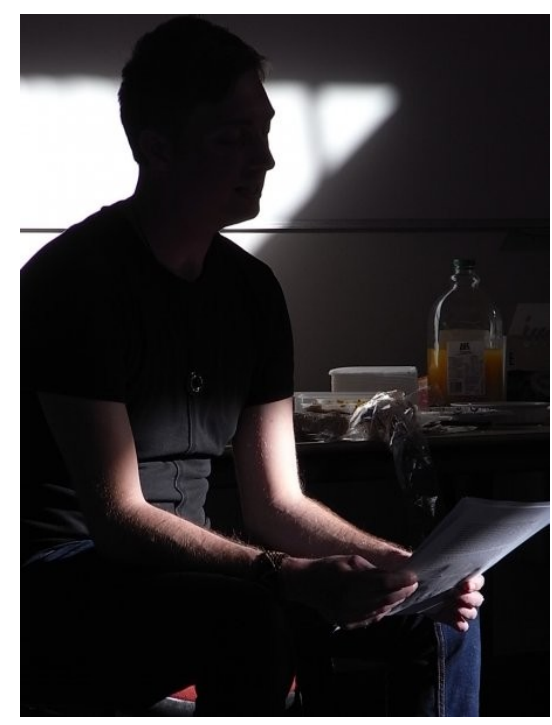

Figure 3.4: Picture taken during my re-search performance

[Photo credits: Adisorn Juntrasook]

\section{An Assessment of my Re-search Process - The rigour of this re-search}

In this section, I seek to open up spaces of uncertainty in my methodology. Rather than reduce this assessment down to a paragraph entitled "limitations" I sought to engage with a reflexive consideration of my re-search process, grounded within the criteria I established to guide it. First among the questions I wish to address is a consideration of the participants of this re-search. While I was able to speak to participants who represented an array of gender/sexual communities in Thailand, most of my participants identified as gay. My work 
therefore should not be considered a survey of khon-thîi-mii-khwaam-làak-lăai-thaangphêet development in Bangkok, as my reasons for speaking to participants was directly related to their involvement in the MSM work of the organisations. There were preferences toward participants who spoke fluent English, which enabled impromptu interviews.

Other considerations include the potential benefits that participants may reap in return for engaging in this process. I was guided by feminist ethics, believing that ethical research must link to empowering changes in the lives of research subjects. But as I observed above, my re-search questions did not specifically challenge material conditions of inequality, nor did it produce any tangible benefits for participants. While for some participants our engagements may have been therapeutic, this may not have been the case for all. There is a risk that some re-search encounters were upsetting for participants and that I did not perceive this during our interviews.

While I attempted a more participatory and less colonizing form of scholarship, I had difficulty in inviting community members inside my re-search process. I met with members of both organisations before the re-search began, in an attempt to clarify the type of research that would be useful for them, and what we could expect from each other. While I attempted to bring community members into my re-search process, and to enable people other than myself to make decisions, participants were reluctant to assert themselves in what they saw as 'your research'. There also seemed to be a lingering notion that I was a research 'expert' and I often felt that participants were loath to interfere. I am also aware that they were cautious of having to assume more responsibilities in their already busy schedules. As such, the control over initiation, methodology, evaluation, and representation of this knowledge was largely vested in me.

I kept participants informed about the distribution of the knowledge that we generated, however I could have spent more time going through the complexities of where the information was going and what use it would be put to, simply reading that it may be used for academic articles does not convey much to a person who does not read these frequently. I also ensured that re-search participants who requested access to re-search findings had first access, and that there has been sufficient time to incorporate their feedback into my final report. 
I acknowledge the power that comes with being the writer of this text. Despite my wariness in revealing "The Truth" about developing MSM in Bangkok, by interpreting the materials in my thesis there is the transmission of indefinite threads of meaning into some kind of (provisional) 'certainty'. But I consider this an acceptable responsibility, and am heartened by the thought that the text I have produced will engender further forms of dialogue with scholars, students, communities and practitioners.

\section{Conclusion}

In this section, I examined the heartful methodological approach I employed in this research. I positioned myself, before exploring some of the ethical considerations of my study. Then, I outlined the methods I used to undertake my study in detail, before reflecting on some of the limitations of my study. In the next section, I establish the context of khon-thiimii-khwaam-làak-lăai-thaang-phêet [sexually diverse] organising in Bangkok and the two organisations that I studied. 


\section{Third Interlude: Re-membering the Re- searcher's Body}

Got fire in my belly,

Plenty,

Enough to light the fireworks,

That go boom boom bust

Fizzle and sizzle all over the park,

And shake the night sky into light.

But now I am learning to listen

Both

To my smouldering cinders

Which light my face red,

And

The cool palm of my back,

That strong, flat centre

That slows my departure,

Bends to listen,

And attend to pain.

Cool, calm, collector of information,

Quiet carrier of responsibility,

It holds its weight,

Balances and re-balances.

I also feel the rhythm of thoughts,

Coursing through,

Brainwaves,

Grooving and galloping,

A pulse,

They flow like liquid, rapidly building ovens,

Putting out fires.

Re-search can teach

Us to listen to the body in concert,

Sometimes silencing the bubble slick bang

To listen to the other sounds. 


\title{
Chapter Four: Rainbow Organisations - Establishing Context
}

\begin{abstract}
International humanitarian and political institutions - articulated through nongovernmental organisations (NGOs), multilateral aid agencies, or activist networks - together create one of the most pervasive, influential, and mundane arenas in which sexuality is at issue. (Pigg \& Adams, 2005, p. 11)
\end{abstract}

\section{Introduction}

In this chapter I contextualise khon-thîi-mii-khwaam-làak-lăai-thaang-phêet [sexually diverse] organising in Bangkok. I explore the key terms and identities used locally, before placing MSM organising in Bangkok within a national context. This is followed by concise introductions of the two organisations I studied alongside. I include this chapter for three principle reasons. First, it assists the reader to grasp the broader context into which this research inquires. Second, it establishes a platform to begin the analytical sections of my research. Third, it provides a helpful resource to other re-searchers who wish to inquire into the histories of khon-thîi-mii-khwaam-làak-lăai-thaang-phêet [sexually diverse] organising in Thailand.

\section{Thai 'MSM' Sexual/Gender Minorities - Key Terms}

The principle 'Thai' ${ }^{29}$ system of constructing sex, sexual identity and gender identity views all of these concepts within one term, phêet - which Jackson (2003) has described as a sexual/gender category. Jackson and Sullivan (2000) identified the three 'traditional' phêet as chaai - man, - y̆ng woman and kàthoei - third gender. 'Men' are defined as anatomically male, expressing normative masculine behaviour with a primary sexual interest in women; 'women' are anatomically female, expressing normative feminine behaviour, with a primary sexual interest in men. Kàthoei was an identity that previously applied to:

\footnotetext{
${ }^{29}$ I use 'Thai' carefully, acknowledging that there are several heterogeneous cultural groups living in Thailand, who name and understand gender/sexuality in alternative ways.
} 
both non-gender-normative females and males, as well as to intersexual individuals, today the term tends to denote only people born with a male body who have more or less feminine behaviour and dress, as well as sexual interest in men (Ojanen, 2009, p. 6).

These so-called traditional terms now exist alongside other forms of identification that have arisen in the previous two centuries. One is the term săao-pràphêet-sŏong (second category of woman) which can be used in lieu of Kàthoei as a less derogatory label. Another is the gay identity. Jackson and Sullivan date the use of the gay identity in Thailand to circa 1965 (2000, p. 3). This was a significant break from earlier understandings of sexuality in that it purported to describe self-identified masculine, male, homosexuals who form partnerships of various sorts with other self-identified masculine, male homosexuals. Contrary to understandings of the word gay in the 'global North', in a Thai context gay is not positioned as the binary opposite to straight. Indeed as Ojanen (2009) notes, the term heterosexual is largely unintelligible outside academia in Thailand, as it is encompassed within the existing categories of man and woman.

Within the gay identity itself are gendered constructions including, gay king and gay queen (or alternatively, fàai rúk - penetrating side and fàai ráp - receiving side). Gay king denotes a more masculine gender identity, and a (primary) insertive role in anal and oral sex; gay queen denotes a more feminine gendered expression and a (primary) receptive role in anal and oral sex (Ojanen, 2009). There is another category known as versatile, both, or gay quing, which expresses a flexibility in insertive/receptive erotic acts. The term bi refers to normatively masculine males who are sexually interested in partners of various genders. Totsaworn (as cited in Ojanen, 2009) argues that in practice the sexual roles of many selfidentifying gay men are neither stable nor enduring.

Within Thai scholarly and NGO communities the word chaai-rák-chaai is used (men who love men) interchangeably with the English MSM (men who have sex with men), the latter having been developed to reach 'men' (often including trans-women) who do not selfidentify as gay, but have sexual encounters with other ' $\mathrm{men}^{\prime 30}$. Recently there have been

\footnotetext{
${ }^{30}$ However, RSAT has identified its goal to use MSM only for health promotion work, and chaai-rák-chaai for other purposes, such as human rights advocacy and community building.
} 
significant developments in composite terms for Thai 'sexually diverse' communities. A composite term, which refers to both male and female homosexuals is rák-rûam-phêet, literally "loving the same sex". This term has significant currency in media representations of people of diverse sexualities. The term is controversial, as it has often been mis-translated as 'loving intercourse'. Instead, the less ambiguous khon-rák-phêet-diao-kan (person who loves the same sex) has gained ascendancy in academic writing (Ojanen, 2009). The most recent innovation is the campaign by CBOs such as RSAT for khon-thîi-mii-khwaam-làak-lăaithaang-phêet [people of diverse sexualities]. This is the term used throughout my thesis to refer to the wider sexually and gender diverse community in Thailand, as it has found the most acceptance in the community groups I engaged with ${ }^{31}$.

\section{Intervention Context: Sexual Health (and Other Concerns)}

Thailand is widely considered a hub of MSM sexual health promotion at the Southeast Asian regional level. Long viewed as an HIV/AIDS success story with its early achievement of Millennium Development Goal (MDG) Six ${ }^{32}$, significant investments have been directed through Bangkok with the hope that Thailand's success will be transferred through the region in a South/South framework (see Ivers, 2010; Singh, 2008). Thailand has attracted significant HIV/AIDS related funding for several reasons, including its comparatively supportive policymakers and its relatively strong healthcare infrastructure. Furthermore, there is an industry perception of donor reluctance to direct funding toward other areas in Southeast Asia without proven records of achievement.

Yet Thailand's early accomplishments in preventing the spread of HIV/AIDS are not reflected in the outcomes of specific 'at/risk ${ }^{33}$ populations', including MSM. While the general figures present a rosier picture, when analysis is confined to MSM in particular there have been rising cases of HIV prevalence. Using cross-sectional HIV prevalence assessments generated by the TUC collaboration between the Thailand Ministry of Public Health (MOPH) and the US

\footnotetext{
${ }^{31}$ It should be noted that this terminology has not reached wide public usage, where words such as gay and kàthoei are more prevalent.

${ }^{32}$ Millennium Development Goal Six - To combat HIV/AIDS, malaria and other diseases.

${ }^{33}$ I use at/risk to question the ways that MSM may be positioned in the international literature, both as at-risk as potential victims of sexually transmitted diseases, and as a population posing a risk to other MSM and the wider public. We see the latter in countries such as New Zealand with the regulations placed around MSM and their possibly 'risky' blood donations.
} 
Centre for Disease Control (CDC), we see trends of a rise in HIV prevalence among MSM over five years, with the most recent statistics in 2007 indicating a 30.8 per cent prevalence rate. In 2003 HSEP began surveillance of HIV prevalence among Bangkok MSM. This was expanded in 2005 and 2007 to encompass male sex workers and female/third sex identifying transgender people, as well as two new geographical areas of Phuket and Chiang Mai. In Bangkok, the prevalence of HIV infection among MSM increased from 17 per cent to 30.8 per cent between $2003-2007$. These high HIV prevalence rates garnered wide donor attention, with policymakers anxious to prevent further inimical increases. It has also led to an influx of funding which expressly targets MSM in Thailand as a 'high risk' group.

Alongside the sexual health concerns of MSM are a myriad of other development challenges, which exist outside of international donors current focus. Ojanen (2009) provides a useful survey of these challenges based upon his reading of Thai and English language re-search. His 2009 publication charts the diverse interpretations of the social contexts for MSM in Thailand, which range from Winter's (2006) view of relatively high acceptance, to Sulaiporn and Pimpawun's (2009) more pessimistic views. Ojanen proceeds to broadly explore the challenges faced by MSM in Thailand. These include,

- Law - through non-acknowledgement, lack of legal protection, no rights to marriage or registered partnerships, inability to access welfare benefits paid to heterosexual couples, denial of the right of adoption, and no rights to inherit wealth created together as a couple. The inability to alter sex and gender transitions on personal documents. There are also reports of police harassment and violence. (Ojanen, 2009, p. 11)

- Employment and Education - difficulties getting jobs in the public and private sectors (especially săao-pràphêet-sŏong), lower wages, and fewer promotions. For săaopràphêet-sŏong, poor working conditions including barring them from wearing women's clothing, using female bathrooms, and/or forcing them to remove breast implants as a condition of continued employment. (Ojanen, 2009, p. 12)

- Families, friends and partners- difficulties in feeling accepted by families and strong pressures to marry. Difficulty finding friends. Ojanen (2009) draws on research by Totsaworn to probe a lack of acceptance by heterosexual men of their gay friends. 
Similarly, Totsaworn notes that MSM may have difficulties maintaining satisfying relationships due to an absence of social acceptance and positive role models to express what such a relationship may look like.

- Religion-săao-pràphêet-sŏong are prohibited from ordaining as monks, which can pose significant problems for families who are reliant on 'sons' to make merit ${ }^{34}$ for their parents.

- Health and healthcare - MSM face several challenges outside HIV/AIDS including continued pathologisation in counselling, psychology and psychiatry (see also Jackson, 1997; Ojanen, 2010).

Ojanen's (2009) comprehensive study reveals the numerous challenges that are faced by 'sexually diverse' communities in Thailand. The findings of his study were consistent with the thoughts expressed by re-search participants during our interactions.

\section{A History of Queer Community Organisations in Thailand}

'Sexually Diverse' community organising is a relatively new phenomenon in Thailand. The first organisation based inside a sexually diverse community was Anjaree, a yĭng rák y̆ing ${ }^{35}$ centred peer serving group founded in 1986. Anjaree began by creating safer spaces for its members to meet and hold social events, eventually seeing its role move toward public organising and active engagement with the media. Anjaree has been active and relatively inactive periodically, yet as participants in my re-search noted, a number of the networks created within it persist, and there remains hope that it or a related organisation will resume activities. Community organising for MSM began with activist Natee Teerarojjanapong. He is credited as being the first gay community organiser in Thailand. In 2001 the 'The Rainbow Way' was founded, which subsequently changed its name to Rainbow Sky Association of Thailand (RSAT). The next major organising milestone in organising in Thailand came with the TUC collaboration between Thailand's Ministry of Public Health (MOPH) and the United States Centre for Disease Control (USCDC) for the first MSM HIV prevalence study. The study revealed the severity of the HIV epidemic facing MSM

\footnotetext{
34 'Making merit' is a process of accumulation of good deeds or thoughts that one can carry throughout one's life or to ones next life.

${ }^{35}$ Ojanen credits the development of the terms 'chaai-rák-chaai' and 'yı̆ng rák yı̆ng' to Anjaree (2010, pers. comm., May).
} 
in Thailand, and saw a flurry of international interest and resources. The number of organisations focussed on MSM related issues mushroomed, growing from zero ${ }^{36}$ in the year 2000 to over twenty ${ }^{37}$ in 2009 . From 2006 these organisations and the majority of the resources that enable their work have been coordinated through the Thailand Sexual Diversity Network. The Thailand Sexual Diversity Network enables member organisations to retain the distinct foci of their operations and targets, whilst attempting to ensure greater coordination, transparency and accountability. In-country monitoring ${ }^{38}$ also aspires to build local capacity. The network is coordinated by RSAT.

The following is a list that re-presents organisations identified by participants in interviews and generated in mapping exercises (see Figures 3.1-3.3).

- Rainbow Sky Association of Thailand (National)

- Bangkok Rainbow Organisation (Bangkok)

- SWING (several regions)

- Sisters (Pattaya)

- MPlus+ (Chiang Mai)

- Rainbow Group

- Violet Home (Chiang Mai)

- The Poz (Bangkok)

Figure. 4.2 List of Organisations which Target MSM in Thailand

Other organisations/occupations were identified by participants, but I chose not to represent these on the list, limiting it to organisations that directly focus on 'development' interventions with MSM. ${ }^{39}$

\footnotetext{
${ }^{36}$ RSAT existed as a more informal 'group' by 1999 , but not as an organisation.

${ }^{37}$ This number includes RSAT regional affiliates.

${ }^{38}$ Here, we must remember that this is the intention. Some participants expressed doubt at RSATs capacity to monitor these funds effectively while others have more positive characterisations.

${ }^{39}$ Nevertheless, recording these other sources of support for MSM individuals and communities in Bangkok is important. Other organisations included: Non-queer focussed CBOs; National and regional (including queer)
} 


\section{Organisation Profiles}

What follows is a brief introduction to the two organisations that were at the centre of my re-search, BRO and RSAT. My objective here is to welcome the reader into what may be unfamiliar territory, as well as to provide a base for comparison between the organisations.

\section{Rainbow Sky Association of Thailand}

RSAT is a national sexual diversity organisation. It began in 1999 as a grass-roots community initiative in response to a perceived increase of HIV infections and the problematic portrayals of MSM in the Thai media. The organisation was founded in 2000 under the name of The Rainbow Way. This name changed in 2001 to Rainbow Sky Group to reflect a shift in emphasis toward engaging with a wider community - a rainbow coloured sky is something that covers us all, representing a society which has fundamentally changed its perspective on sexual and gender diversity. RSAT began by undertaking outreach work in Lumphini Park ${ }^{40}$ first on a voluntary basis, later receiving funding for basic health promotion materials. The significant rise of RSAT came after its cooperation in the TUC prevalence study in 2003, which revealed high rates of HIV prevalence among MSM in Bangkok. After this evidence was established, RSAT received funding to found its permanent office in Bangkok. In 2003 RSAT was officially registered with the Ministry of Culture in Thailand.

RSAT's stated goal is to work with all 'sexual diversity' groups, including MSM, WSW and TG. It has minimum quotas for WSW representation on its executive board ${ }^{41}$. While RSAT aspires to work with all 'sexually diverse' groups the vast majority of its funding must be accounted for by sexual health promotion with MSM alone. RSAT estimates that it has around 1000 volunteers ${ }^{42}$. The organisation is currently establishing their presence in thirtysix provinces, with at least two paid staff in each province. Although RSAT began as an HIV/AIDS prevention oriented organisation, it now positions itself as a community

media publications; Queer, Transgender and Women's Rights Activists; Sex and entertainment venues; cafes, restaurants and other queer businesses; Shopping malls; Academics and researchers

${ }^{40}$ Lumphini park is a well known within the chaai-rák-chaai community in Bangkok as a 'cruising' space.

${ }^{41}$ While this is the stated intent of the organisation some participants expressed doubt over whether these minimum quotas are actually reached.

42 The records of the actual number of volunteers have not been kept. Likewise, this estimation does not differentiate between active and in-active volunteers. 
organisation with a mission that its director Miao (2009, pers. comm., June) explained "promotes life quality and wellbeing" for sexually diverse people.

\section{Bangkok Rainbow Organisation}

BRO is a Bangkok based organisation. It was founded in 2002, with a differentiated purpose from existing sexual diversity organisations. Its target group are MSM who identify as gay or chaai-rák-chaai. As one of its four co-founders explained, BRO has focussed on improving the support for MSM during the day:

pub, disco, gay bar, only night activities...so we see gay film, gay(s)...go to the orphan house, help the children, help the temple... and seminar(s), last 3 or 2 years, we have many seminars about gay, and we have the team go to the school, go to the university, for small seminar for the gay people. (Noom, 2009 pers comm. June)

It particularly focuses on working with the media, to counter negative portrayals of sexually diverse people, and promotes media that constructively address sexual diversity issues. BRO has an estimated membership of over 1000 MSM, with a much smaller core of regular volunteers. It has one fulltime administrator, and seven paid outreach staff that work on a part-time basis. For the first five years of its existence the organisation did not receive sustainable outside funding, and services and maintenance were provided by its members voluntarily. While the 'lifestyle during daytime' is the stated focus of the organisation, their staff are funded to work for the safety of MSM who partake of the 'lifestyle at night'. BRO is principally funded to provide peer outreach and education to various venues in Bangkok, and receives no funding for the work it desires to do ('lifestyle during the daytime') in social marketing and media monitoring.

Members of the organisation are recruited by interacting with the website and/or networking by existing members. Peer Education Camps are another significant way of attracting new members. These involve staying one or more nights out of Bangkok and undertaking intensive HIV/AIDS education/health promotion activities. BRO's primary 
funder is the MOPH; it also received funding in 2005 to establish its website ${ }^{43}$, and received support from the Global Fund ${ }^{44}$ in 2010.

\section{Conclusion}

In this chapter I introduced the context of my study, grounding my analysis in histories of khon-thîi-mii-khwaam-làak-lăai-thaang-phêet [sexually diverse] organising in Thailand. I summarised some of the key identified challenges that confront MSM in Thailand and sketched an outline of the two organisations I studied alongside. In the following chapter I explore the constraints facing local practitioners. This is achieved by exploring participants perspectives of the field of power relations between international and local donors and practitioners working in Bangkok.

\footnotetext{
${ }^{43}$ This funding was provided by UNESCO Bangkok (Noom, 2010, pers. comm. May).

${ }^{44}$ The Global Fund is the largest public/private partnership designed to fight AIDS, tuberculosis and malaria. It is a financial instrument only, aiming to attract and disburse resources to combat these diseases in partnership with local organisations and agencies.
} 


\section{Fourth Interlude: Queeresearching...}

I connect the dots

and choose to leave my t's uncrossed

$|1| 1|1| 1 \mid$

I draw the lines,

charting paths through the...

finding meaning in the ....

$|1| 1|1| 1 \mid$

I see the signs,

shapes that shift like puzzle pieces

made of water

$|1| 1|1| 1 \mid$

I heard the words, the silences

I heard the shutting of eyes, and

the drawing of breath, the crossing of legs,

$|1| 1|1| 1 \mid$

I am here. 


\section{Part Two: Introducing the Analysis}

I have distilled the key messages from the following four sections into this simple map. I hope this will make the layers of analysis more accessible, as well as preparing readers for some of the complex (and contradictory) layers to my analysis.

In Chapter Five I argue that donor-recipient relations are sites of constraint and agency for local MSM development practitioners in Bangkok. Rather than power structures between donors and recipients being inflexible as I often read in Queering Development writing, I argue they are dynamic. I also argue that local practitioners view donor-recipient relations as partnerships, where they can negotiate outcomes that advance their self-identified goals.

In Chapter Six I return to the power analyses offered by Queering Development. Despite the complexities of donor-recipient relationships, I argue that local practitioners still work in a constrained field of power, where donors exercise power over deciding which areas will receive funding. I contend that donor discourses of 'evidence' and 'research' militate against other ways of knowing sexually diverse development concerns. I also argue that the unequal landscape of power between donors and recipients may influence local practitioners to undermine some of their key safer sex messages.

In Chapter Seven I add another layer to Chapter Six. Despite the donor-recipient relationships being complex and unequal, I argue that local practitioners leverage existing (sexual health) resources to create collateral benefits for their communities. In Bangkok these collateral benefits included human rights work, identity work, advocacy and a number of other development concerns. These are the hidden spaces of utility that local practitioners create out of existing resources.

In Chapter Eight I add a final layer to my analysis. I step back from the current workings of the MSM development industry in Bangkok, to ask participants to dream how they would constitute the situation otherwise. This chapter can be seen as a final layer of analysis, one which dialogues with each of the previous chapters. 


\title{
Chapter Five: "It's More Complex than that!" - MSM CBO-Donor Relationships in Bangkok
}

\begin{abstract}
Development is not a machine that secures fixed and determined outcomes but rather is a site of contestation, its boundaries carved out through the situated practices that constitute livelihoods... (Moore, 1999, p. 656)
\end{abstract}

\section{Introduction}

In Chapter Four I examined the context of MSM development organising in Bangkok, placing my work firmly inside local histories. In this chapter, I inquire into donor-recipient relationships as they were experienced by my participants in Bangkok. My inquiry revealed that participants understood these relations as complex, messy and dynamic. This moves beyond less complex portrayals of 'powerful' donors and 'vulnerable' recipients offered in Queering Development theorising. This chapter re-presents accounts of donor-recipient relations, viewing local MSM development practitioners as being never fully selfdetermining, and likewise never fully determined. By beginning with an examination of the complexities of donor-recipient relations, the reader is better able to engage with forthcoming chapters which re-conceptualise accounts of local agency within the wider context of unequal power ${ }^{45}$ structures.

\section{Existing Accounts of Donor-Recipient Relations}

I entered 'the field' having read Queering Development work extensively. The influence of these readings is present in early reflections in my re-search journal where I note my frustrations with the expressed intentions of donors to privilege HIV/AIDS, and other sexual health concerns:

\footnotetext{
${ }^{45}$ In this study I draw on Foucault (1978) to re-conceptualise power beyond binary configurations of powerful/powerless. I view power as exercised and rather than possessed as well as productive as well as potentially repressive. I also take up Foucault's argument that power circulates through discourse between individuals and groups. I also draw on Rowland's (1997) modalities for conceptualising power: power-over (domination, control, and hierarchy), power-to (individual power to attain an end) and power-with (resistance, a way to challenge or subvert domination).
} 
I acknowledge the importance of the HIV/AIDS prevention, treatment and care work in Bangkok, but [also] recognise that there must be something more...that by only intervening in HIV/AIDS development agencies are missing some of the major concerns of those they aspire to assist. (Personal Journal, March 2009)

I had many pressing questions early in my study: why did khon-thîi-mii-khwaam-làak-lăaithaang-phêet [sexually diverse] groups accept funding when so many of their real concerns were silenced in these funding arrangements? Where were human (sexual) rights? Stigma and discrimination campaigns? Pride? In effect, my re-search journey has been about better understanding the 'realities' that preempt these questions, it has been about recognising the complexity of donor-recipient relations, and exploring the margin spaces of development funding.

Authors such as Adams and Pigg (2005), as well as Cornwall et al. (2008) have made extremely valuable contributions to understanding the intersection of development projects with gender/sexual minorities. Within these Queering Development accounts however, I have observed a tendency for authors to read the relations between donors and recipients as powerful/vulnerable or subject/object. Donor agendas are often rendered sinisterly within Queering Development critiques. For example, Pigg and Adams expose how the 'mundane' façades of development programs frequently "function as the instruments through which neo-colonial, nationalist, and identity politics are articulated" (Adams \& Pigg, 2005, p. 2). Donor discourses are characterised by Queering Development authors as 'medicalising' and 'pathologising' sexuality "in ways that speak perfunctionarily to local values while advancing donor and state concerns about population growth and disease control" (Adams \& Pigg, 2005, p. 14). The missing question in Queering Development theorising seems to be: if donor-recipient relations are so unequal, and the impacts of funding are so problematic, why do local community elites actively engage them?

In offering alternative views to those presented in Queering Development I have remained mindful that these authors produce knowledge with obvious political investments in the expansion of the understanding of sexuality within the development industry. I have considered that they may emphasise donors' power (at the expense of local practitioners) strategically, in order to advance these political concerns for the broadening of 
development assistance and for more context informed projects. Yet, Queering Development accounts of the donor/recipient relationships leave an incomplete picture. These limitations were revealed to me in the earliest interactions of my re-search. When I shared literature-derived accounts with local practitioners, they responded that they were unintelligible given the context of Bangkok. My participants resisted relatively powerless subject positions, constituted within the discourse of Queering Development, their accounts of the complexity of these power relations are shared below.

\section{Participants' Perspectives on Donor-Recipient Relationships}

After interacting with local MSM development practitioners I better understood both the utility and limitations of my early assumptions about the power relations between donors and recipients. While donors clearly do fund demarcated arenas for intervention, the actual relationships they enter into with recipients (and the outcomes of funded interventions) are more contested than I had initially envisioned. To come to this realisation it was necessary to look beyond donor discourses, seeing them only as organising ideas that are malleable and ultimately co-produced (see Pigg, 1992). Thus, my analyses of donor-recipient relations are grounded in the local histories of MSM (and khon-thîi-mii-khwaam-làak-lăai-thaangphêet more generally) in Bangkok.

My participants emphasised the co-construction of donor-recipient relationships. They described these relationships using words such as 'collaborative', 'partner' and 'reciprocal'. Rather than viewing these relations as a static power imbalance, participants offered alternative accounts, such as Timo's characterisation of the donor-recipient relationship as a "game" with agendas from both sides meeting in negotiation and compromise (2009, pers.

comm., April). In positioning donor-recipient relations as a "game" Timo did not suggest that they operate without power differentials, instead he emphasised that they are a mix of interests. Timo's characterisation of recipient agency was shared by Gob. Gob positioned local practitioners as creating "considerable room to tailor the funding to suit local needs" rather than being "dictated absolutely by the donors" (2009, pers. comm., May).

Gob and Timo's understandings of the reciprocity in donor-recipient relations was underscored by Tim. She argued that donors also rely on recipient organisations: 
because if there is no one to work for the donor, they won't get the budget themselves. It's kind of like an exchange to each other. You work for me, I work for you. You have my money, and I have the salary because I give money to you... (2009, pers comm. May).

From these excerpts it is evident that these local practitioners see donor-recipient relations as complex and dynamic rather than perpetually unequal.

One interesting reason for participant's accounts of the reciprocity of donor-recipient relations was offered by Nok. She discussed Thailand's 'non-colonial ${ }^{46}$ past in her characterisation of donor-recipient relations. Nok noted that this absent history made Thai organisations more trusting of knowledge and funding from the 'global North', and less likely to read power relations along (post)colonial axes of power. In response to my question about discourses of 'gender' 'sexuality' and 'human rights', Nok stated her belief that these concepts are ultimately adapted by local implementers to address Thai needs:

No it [human rights] is not Thai, but we accept anything from Westerners, no? TV or escalators, this is it...but you have to adapt it [human rights] so that it fits our society somehow (2009, pers. comm., June).

Nok's interesting take on the globalisation debate resonates with Appadurai's account of cultural globalisation as a layered phenomenon that "does not necessarily... imply homogenisation" (Appadurai, 1996, p. 17). Her reading of these terms also echoes Jackson's (2009) portrayal of Asian queer cultures, which sees a "complex picture of processes that are producing the apparent paradox of simultaneous sex cultural differentiation and convergence" (Jackson, 2009, p. 17). Rather than reading linguistic convergences as necessarily problematic, Nok's excerpt prompts me to again re-visit the limitations of Queering Development accounts. These Queering Development accounts would benefit from grounded analyses, to enable them to account for the 'realities' of implementation. In Thailand, as Jackson argues, the vocabularies of queer cultures "reveal a high degree of local

\footnotetext{
${ }^{46}$ This is a contested term. See Jackson (2010) for a fuller discussion of the debates surrounding 'postcolonialism'/ non-colonialism in Thailand.
} 
linguistic autonomy rather than a copying of Anglophone Western models" (Jackson, 2009, p. 18).

I wish to pause to consider the transmission of "Western" understandings of sex, sexuality, and gender through local development networks. While scholars are correct to reflect cautiously on the impacts of hegemonic 'Western' systems of knowing in developing contexts, they should not assume that these new 'facts of life' will be simply mirrored in their new context. As Adams and Pigg (2005, p. 67) explain:

Scientific efforts create a self-conscious, autonomous subject who identifies his or her subjectivity in and through a medicalised sexuality - a sexuality that is seen as divorced from other domains of social life. At the same time....the "sexual" refuses the isolating tendencies that its scientific rhetoric's would give it.

This sentiment was certainly reflected in interactions with participants in Bangkok who explained that English loan words such as, "gender" and "sexuality" were incorporated into a Thai linguistic and symbolic world. This was reflected by Timo:

They might use those words but I would say it is quite Thai. We might use some Western terms, but they might be used creatively, you might hear the word 'gender', but it might be translated as phêet, which is not what Westerner's would understand as gender usually, I mean, gay, tom, dee, kàthoei, these would be phêet, so you wouldn't hear these being referred to as genders in the West. (2009, pers. comm., May)

Tim explained her beginnings with "Western" languages about sexuality and gender in the Thai context:

It's very new in Thailand James, because when I first worked with [MSM CBO] I didn't know about gender, sexuality, concepts or whatever. I didn't know, but when I continued working on these issues for 2 or 3 years... when we are talking about HIV/AIDS we have to know, we have to adopt the sex, gender and sexuality concepts to get them on the intervention or the programs, and working with the target groups. So it's very popular in the last few years. (2009, pers. comm., May) 
She continued by explaining how these words are then incorporated into a Thai symbolic and linguistic world:

we cannot divide these concepts from Western, but the way we use, we try to develop these concepts, ah, and develop them, to fit and to suit the Thai context na. I think many organisations they make their own curriculum on sex, gender, sexuality, that fit to their target group, and the Thai society... you have to indicate the sex, gender and sexuality on your own knowledge and develop it, to fit your context, your life context. So I think in the past few years we worked a lot. We don't just adopt the Western concepts and use it like it is...we try to develop our own concept.

Other examples of this are the terms transgender, transsexual and sexual orientation which might be described as "sexual tastes" in Thai. Tim also found power in the new knowledges' that she had access to, as they enabled her to identify herself in new ways. She also revealed that this questioning led her to ask whether she, as a transwoman had to fulfil the role of the receiving partner in anal sex, or whether anal sex was even necessary for her sexual relationships. Furthermore she explained that the way she publically identified herself had changed:

I don't identify myself, actually when we work on this gender and sexuality things, I learned a lot, and I don't know at that time if anyone asked me how I identify myself I say: I identify myself as myself... but actually in some situations when I went to the meeting that have lots of transgender, I might identify myself as transgender. (2009, pers. comm., May)

Another re-search participant Mhu revealed the important knowledge he took from engagements with an organisation funded to fight HIV/AIDS with MSM in Bangkok:

When I was a student the only word I knew was tút ${ }^{47}$, because that is the first word that people know, but when I came here I came to understand more. What does gay mean? What does tom mean? What does kàthoei mean? How do they dress? Where are they? In the past I could know [heterosexual] men and women well. (2009, pers. comm., June)

\footnotetext{
${ }^{47}$ A word similar in tone to the English "faggot".
} 
From participants' accounts we see an emerging picture of active recipients who use language and labelling to its greatest possible political effect. A prime example of the subjectivity of recipients is revealed in the difficult situations where funding may be withheld if the 'incorrect' label is adopted. For example, Miao (2009, pers. comm., June) noted the organisation he works for adopted the English term 'MSM' to ensure all groups, including gay, bi, transgenders' and sex workers could be covered by the interventions of the organisation he represents. He explained that this was a strategic manoeuvre, which reinforced the community-building aspirations of this organisation. From this example we see the complexity of power relations between donors and recipients, where donors exercise power over setting agendas and recipients exercise power to work the margin spaces of these relations to leverage benefits.

Several participants touched on a related example, which is the recipient's ability to leverage translations for cultural relevance. The Thai translation of Men Who Have Sex with Men is chai-thi-mi-phetsamphan-kap-chai. Often however, the term chaai-rák-chaai is used. The Thai word rak means 'love', rather than 'sex'. This language was described by Gob as a purposeful disregard for donor discourses which emphasise the frank discussion of sex itself. He explained that this met recipients' desires to limit terms that hyper-sexualise MSM. I asked him to explain why sex was left out of the Thai translation, and he responded:

because it [MSM] is from the medical circle, it has to be clinical; and it views sex as something that is clinical.... But that is not the fact of life, and people outside the medical community or the relief community have a hard time accepting these terms I think, because yeah, sex is a very culturally loaded term.

Gob's excerpt reveals an awareness of the importance of using language that connects to the realities of the life-worlds of community members. Furthermore, members of the recipient organisations I interacted with reported that their use of English terms such as 'MSM', 'sex' and 'sexuality' was strategically limited to conversations requiring medical/epidemiological terminology. Tong, a member of BRO shared that 'MSM' was reserved for interactions with donors only, and was infrequently used in interactions with community members (2009, pers. comm., April). 
The accounts offered above pose two important questions. First, they pose questions for Queering Development accounts of donor-recipient relations, by observing the relationship as a productive and fertile space where re-negotiation can occur. Second, the accounts enable questions to be asked of the concept of 'global gayness' by re-positioning queer agency away from the West only.

\section{Participants' Perspectives on Donors' Priorities - Well Intentioned 'Condom Mania'?}

It's hard to measure and evaluate non-health interventions. Donors care about figures, how many condoms have been distributed.... (Tana, 2009 pers. comm., June)

James: [pointing to piece of paper for mapping] so, how big is (funding for) HIV/AIDS?

Gob: This paper is not big enough; everything seems to be about HIV/AIDS that is the thing though... (2009, pers. comm., June)

A significant finding of my re-search was the local practitioner perception that donors focussed the vast majority of their resources on education/prevention for HIV/AIDS and other sexual health concerns in Bangkok. This perception corresponds to global trends for funding interventions with gender/sexual minority males ${ }^{48}$. The awareness that HIV/AIDS was attracting the lion's share of funding was widespread among participants, Jet notes:

Donors always focus on HIV/AIDS and sexual health; they don't care about another object, like how you feel within the society. If you are going out and you say 'hey I am gay', what are they doing to you? They don't care! They care only how you got infected, how you can prevent yourself...and how you can tell the other people about the information about HIV/AIDS (2009, pers. comm., June)

Jet's reflections were shared by Oud, who saw donors' priorities as similarly onedimensional and phallocentric:

\footnotetext{
${ }^{48}$ Here I use 'males' to question the privileging of biological understandings of masculinity rather than the socially constructed gender 'men'.
} 
For donors the focus is on physical health issues, they don't focus on the mind. They still think health issues are about (points to crotch) just that. They think a person is 'gay' and 'sex'. They don't think 'gay' and their life, their stage in development, the interactions with people around them. They just think: don't let them get sick, and that is that. (2009, pers. comm., June)

In this section I do not suggest that organisations in Bangkok are not interested in preventing the spread of HIV/AIDS. There is much evidence to the contrary. The participants in my re-search revealed that they wish to complement their work on HIV/AIDS with projects on other issues of importance for khon-thîi-mii-khwaam-làak-lăai-thaang-phêet.

Participants' accounts of donors' development focus on sexual health centred their mutual participation in the global development industry. Participants noted that this was not unique to Bangkok. It was apparent to Tim that the foregrounding of HIV/AIDS is a "global concern" (2009 pers. comm., May) and Nok observed:

I think in the past ten years, or twenty years, the world has more interest in HIV/AIDS, especially in Third World countries, so the money came here to work on this issue a lot. (2009, pers. comm., June)

Participants also shared their belief that this foregrounding was an issue faced not only by MSM. Tim stated that "many kinds of groups, who receive the funding all around the world" encountered problems in expanding the scope of their interventions (2009 pers. comm., May). When asked for their reflections on why donors funded HIV/AIDS projects, participants offered a number of understandings. Toi believed that "Donors fund HIV because there is a need, and it is obvious" (2009, pers. comm., June). Other participants offered responses suggesting that the measurability of the HIV/AIDS concern made it more attractive to fund. For example, Nok noted "(f)or HIV you can measure how many per cent HIV infected people there are, and how much lower it goes". Ae shared her belief that "it's so easy to fund because it's easy to measure, and you can't argue about it" (2009, pers. comm., June). This perception that donors were comfortable to fund a cause like HIV/AIDS prevention was prevalent throughout my interactions with participants. 
While many participants observed the role of HIV/AIDS in the foreground of MSM development in Bangkok, they also noted the limits to a narrow focus on HIV/AIDS only. Tim argued that the seemingly singular emphasis on sexual health decontextualised development challenges from the life-worlds of recipient MSM:

within one person you cannot think about HIV/AIDS all the time, or 'HAVING SEX YOU HAVE TO USE A CONDOM!!' (laughs)...When you have sex there are many barriers that makes you not use a condom, or make you unable to negotiate with your partner. So I think we should look at that, rather than try to tell people to use condom and Protex ${ }^{49}$ and you will be free from HIV/AIDS. It's not like that (2009, pers. comm., May).

This simplification was outlined by Oud. He argued that donors' de-contextualised and measurable interventions were missing the point:

Once you have no self-respect, you just do any kind of risky behaviour. But donors don't look at this, they look at flyers, they look at 5000 leaflets, but they don't consider it after that. They don't measure quality. They just do the easy job. (2009, pers. comm., June).

Jan shared Oud's view and elaborated:

[donor understandings of interventions are] based on a very simplified idea of behaviour change, so it's the health belief model... If you believe that all you need to change risk behaviours is better health seeking behaviour and better knowledge and attitudes in individuals, this is the way to go of course. You try to reach as many people as you can, pump knowledge into their heads, and then everything will improve. Well, we are now from 17 per cent infection in 2003, to a 31 per cent infection rate in 2007 in Bangkok despite all our interventions, so it is obvious something is not working the way we planned it... (2009, pers. comm., June).

Other participants suggested that the donor focus on bodies and sex, rather than on alternative concerns, was an example of how the challenges faced by 'sexually diverse'

\footnotetext{
${ }^{49}$ Protex is a personal lubricant used in sexual health promotion.
} 
people are largely ignored by international donors. Timo went on to characterise the international focus on HIV/AIDS:

even if they are gay, the fact that they are dying might be a little bit uncomfortable for people like the WHO or something. And even if you couldn't give a shit about gays dying, a lot of them are bi's, and so if you don't do anything about them...it gets into the general community, so I think that stuff has impacts. It's easier to argue for those needs. (2009, pers. comm., May).

His response exemplifies a perception amongst participants of dehumanisation and underlying heterosexism in the approach of international policymakers. Timo's other perception was also routinely felt by participants in my re-search who characterised interventions with MSM as a means to an ends; a method of preventing HIV/AIDS spreading among 'innocent victims' such as women and children rather than 'unnatural' and therefore 'guilty victims' such as MSM.

\section{Conclusion}

In this chapter I have offered complicated and contradictory accounts of donor-recipient relationships in Bangkok. I have done this by "closely look[ing] at the situated dynamics of these relationships in a way that goes beyond the notion of a 'confrontation' between modern and indigenous values" (Adams \& Pigg, 2005, p. 2). This present chapter emphasised the muddiness of power, proliferating examples of contested intents and outcomes that cannot be rendered dichotomously. Through offering a vision of these relationships as messy and complex I am able to more vividly demonstrate the agency of recipients than has been registered to date in Queering Development work. 


\section{Fifth Interlude: Borders Bleed}

Interlude

Re-search is a teacher, Upon its body words are Written,

Thoughts are thunk.

Here is one:

Borders bleed, As much as they Contain.

Leaking lines are Sites of promise \& of Pain.

Seek to draw lines thick, Paint black marks,

And fullness, fluid, seeps out Stains.

"Truth" is a piss stained mattress

It is a stink you can't cover up. 


\section{Chapter Six: Fields of Power/Knowledge - Structural Limitations to Practitioner Agency}

Donors have too much power! (Tana, 2009, pers. comm., June)

Gay men don't get money, HIV gets money, let's stop kidding ourselves. I hate those arguments. (Sam, 2009, pers. comm., June)

\section{Introduction}

In previous chapters I located my study in Bangkok and explored the messy and dynamic donor-recipient relations that my participants described. In this chapter I focus on the constraining factors as that were perceived by participants within these relationships. I argue that despite global rhetoric of 'partnership' (Overton \& Story, 2004) in donor discourses, in interventions with MSM in Bangkok the hegemonic discourses of 'health', 'science' and 'research' militate against alternative community concerns. This chapter should be read as one layer of analysis, to be complemented with Chapter Seven which focuses on local practitioner agency.

\section{Structural Constraints - Limitations on Practitioner Agency}

Re-search participants emphasised that donors established the boundaries of the MSM development agenda in Bangkok. A majority of participants stated that they believed donors approached development practitioners in Bangkok with pre-defined agendas. This was reflected by Toi, "of course the donor comes with their own agenda, they have a pot of money but they say it can only be used for technical support". Toi continued, asserting that donors not only exercise power to demarcate funded areas, but this was inevitable given the resources were theirs to distribute (2009, pers. comm., June). Another participant, Gob, responded that "I think the way it works is that they [MSM CBOs] try to tailor projects to suit the donors specifications. That's the only way it works" (2009, pers. comm., June). I read in Gob's excerpt a view of recipients using their agency to manoeuvre their work to 
meet the requirements of donors. Yet, it is donors who are positioned as exercising power over directing the (explicitly intended) outcomes of MSM development in Bangkok.

Gob's perspective is echoed by Tana, who succinctly explains that often recipients "don't have strong enough voice[s] to argue with foreign donors" (2009, pers. comm., June). This point was expanded on by Chaeng, who neatly outlined the frame of the power relations between international donors and recipients in Bangkok. She noted the systemic pressures placed on donors to deliver measurable results, observing that this 'compelled' donors to exert their power over MSM development agendas. It is worth quoting her at length here:

oftentimes the donors, especially the international donors, will come in with their set of agendas and [their] mandate for the results of the funding they provide, and usually it is for a certain period. So they need some results out of it. So, they have quite an agenda for specific results, and the funding is limited to some level, so that becomes the frame of the work for the implementers. Although the donors know well that working with targeting the MSM population there are a lot of issues that the people working with MSM need to work on, not just sexual health. But because of the timeframe, because of the funding levels and the results that the donors need to show, they have to focus on things they can measure and that becomes the frame, and they can't include long-term visions (2009, pers. comm., June)

Chaeng's excerpt reveals the systemic constraints on donors. She reveals that donors too must manage their resources and achieve results and this serves to limit the conversations donors and practitioners can have regarding MSM development. Jan expanded on Chaeng's discussion of the 'evidence based' nature of donor investment. He observed that donors set the agenda of what is fundable by using the hegemonic discourse of 'scientific research':

it's like a traffic accident prevention, you can either focus strongly on road safety when people are already driving around, but there might be a lot of other factors, like trying to influence peoples' drinking behaviour...you have to establish a clear link that these prevent accidents - that more social empowerment interventions for MSM have an effect on HIV incidence. I think these have not been conclusively proven in this region. (2009, pers. comm., June) 
From Jan's excerpt I read a commentary on the present structure of donor/recipient relations which sees donors as capable of exercising power over defining what knowledge about MSM development needs is, and consequently what is, or is not, fundable. The content of Jan's passage was put into relief by Chaeng, who commented on the challenges Bangkok sexual/gender diversity organisations come up against in advocating for alternative MSM development agendas:

I see that they [MSM organisations] receive most funding from HIV programmes. It is because there has been research, national level surveys on HIV prevalence beginning in 2003 in Bangkok... and among MSM the prevalence has risen, and it is quite a jump between 2005 and 2007. So it was an alarm, it became an alarm among donors and implementers working with MSM populations. So, funding with donors has been put in HIV because of this concern.... so in the last four to five years most of the organisations have been receiving funds for HIV prevention. However in working with them I noticed that the main passion of these organisations, and of the staff working in these organisations, is on their human rights as a person, no matter what gender, what sexuality they are... they have more passion working on these issues. (2009, pers. comm., June)

Chaeng's account offers an insight into the structure of donor-recipient relations. As Chaeng pointed out, despite local practitioners desire to work on human rights issues, donors are only prepared to fund arenas that have been quantitatively researched. Chaeng's account of limited donor investment in areas identified by local organisations as crucial to MSM development needs connected to accounts offered by participants within these organisations. For example Pom states, "our [RSAT] funding, mostly it's HIV prevention, so human rights is very limited, very, very little, so we just have to work by ourselves, we don't have much funding for that" (2009, pers. comm., June).

Another indication of the power donors wield is seen in their right to define what is, and what is not appropriate in local contexts in Bangkok. Recipients spoke of the importance of monitoring and evaluation procedures undertaken by donors. Specifically, they explained the 'accountability' that they must show to ensure continued funding for sexual health oriented peer education camps. One area that participants reported donors were wary of 
was sexual activity between participants at peer education camps. At an overnight camp that I participated in, condoms and other safe sex technologies were withheld from participants (presumably to 'prevent' sexual activity) and the camps activities continued until late at night, and resumed with early morning aerobics. Several participants explained that this was intended to prevent sexual activity occurring, and word getting back to donors that their funding was used to host a 'sex camp'. There was a "no sex" rule that was brainstormed on the first day ${ }^{50}$, and photographs were taken to document this on the whiteboard, presumably to prove they had acted 'responsibly' if complaints were taken to donors. One participant, Noom, explained that MSM development organisations must prove that these sessions are not being used for excessive sànùk [fun] (2009, pers. comm., May). The final pieces of accountability are the pre- and post-camp tests; these are to ensure that the health promotion messages specified by donors have reached the target groups ${ }^{51}$. This is an example of how donors use technologies of control to exercise their power.

What concerns me from the accounts explored above is that practitioners' interpretations of donors' funding imperatives may be leading them to undermine their own 'safe sex promotion' messages, by withholding the very materials that could create safer sexual encounters at their own sexual health promotion camps! This leads me to question whether donors' sex-negative agendas (or practitioners' expectations of their agendas) are being adopted by local practitioners to ensure continued MSM development funding, which could undermine their message of making real-life sexual encounters safer, which is their core aim.

The accounts presented above certainly point to local perceptions of an unequal power relationship between donors and recipients in MSM development in Bangkok. What then, may be the impacts of these unequal positions on targeted communities? In discussions with Jackson at the outset of my re-search, he questioned whether recipients needed to reframe local identities to fit the mould specified by their donors. Following my participants' accounts I can answer in the affirmative. Donor expectations can lead to organisations

\footnotetext{
${ }^{50}$ In reviews of my thesis some participants have expressed doubt about the authenticity of this 'brainstorm' with some participants suggesting that this rule is intended to appear on the board from the beginning.

${ }^{51}$ Here it is also important to emphasise that the Royal Thai Government is one of the primary donors in this context, through the HSRI under the MOPH and The Thai Health Foundation, which is channelled through the Women's Health Advocacy Foundation.
} 
invoking certain identities to match donors specified target groups. This was explained by Tana, “...we can't use 'kàthoei' in our reports to donors!" and, "it seems when kàthoei come to Bangkok they have to choose, either gay or trans" (2009, pers. comm., June). Tana's concern about the power donor discourses have, to set agendas and mould identities was expanded on by Timo, who stated:

... I think maybe the fact that it [MSM] includes transgender people has something to do with funding, if you have funding for MSM and you attach transgender to it you can claim [extra] funding for that. (2009, pers. comm., May)

My reading of Timo's account sees both the agency of practitioners to shape the languages they use for the greatest political impact, but it also reveals a perception that donors set the agenda for which groups will receive funding, rather than this decision being made by, or in conversation with, local practitioners.

Another question that arises for me is to what extent donor funding may take the sting out of MSM activism in Bangkok? For example Timo characterised the 'Rainbow Sky way' as attempting to conform to donor expectations, and not 'rock the boat'. He also believed that their hesitancy to demonstrate leadership in the face of donor pressure was limiting:

when you kind of try and mainstream yourself, you put some you know, brackets around yourself, so Rainbow Sky has kind of defined itself in a non-militant way and also in a very non-specific way. I think the official documentation which explains what Rainbow Sky is, I don't think the word gay is there... it is defined in a very broad kind of way. That's part of the Rainbow Sky strategy.... to be presentable to mainstream society. (2009 pers. comm., May)

Timo went on to provide a specific example of how the sanitising of sexuality worked in Bangkok:

This year [2009] we were to have Pride, but it didn't work, so we don't. Part of the plan was to involve straight people as much as possible, to be inclusive, you know create activities that straight people could join in and feel happy! $(2009$, pers. comm., May) 
Reading Timo's accounts here through a critical lens, I am able to position donors and recipients within an uneven terrain of power. It is clear throughout these accounts that donors (who distribute the resources) are perceived by participants to exercise greater power over determining how these same resources are prioritised. Reading the accounts through a queer politics lens, leads me to ask another related question; to what extent do donor agendas, which bring together MSM leaders to focus on HIV/AIDS, distract, or even prevent these same leaders from working on alternative, more subversive agendas? Despite the accounts offered by my participants, this question still requires further inquiry.

\section{Case Study: BRO and the Media}

BRO provides a useful case study for examining the importance of donor priorities in setting MSM development agendas. BRO is an organisation that focuses on promoting human rights for gay men ${ }^{52}$ in Bangkok, as well as connecting with national media to actively fight against negative messages directed at khon-thîi-mii-khwaam-làak-lăai-thaang-phêet [sexually diverse people] in Thailand. Their expressed objective when working with the media is to generate social capital but their funded work aligns with the explicit focus of funders and addresses HIV/AIDS. BRO is involved in undertaking peer outreach in sex, entertainment and education spaces in Bangkok, as well as training peer outreach workers. Noom expressed some frustration at the lack of resources available for the central priorities of the organisationz:
We want to focus on the media, because it is very important... media have the influence... have more impact... When the media presents a good image for the gay, the people know, the people understand... But all funding is with HIV, you know? Not funding for gay movement, gay human rights, gay activities with media, no. (2009, pers. comm., May)

From Noom's excerpt I read that even when local organisations have organised around a problem that they identify as a core issue facing their community, donors are still in a position to privilege certain areas for funding at the expense of others.

\footnotetext{
52 This was the term used by the organisations director.
} 


\section{Conclusion}

In this chapter I offered participants' accounts of the landscape of power between donors and recipients of MSM development funding. In analysing these accounts I argued that donors exercise considerable power over recipients to determine the priorities of, and conditions attached to, funding for MSM development in Bangkok. I also questioned the impacts these unequal power relations may have on the ability of local practitioners to use culturally specific languages to describe their target communities. These unequal power relations may leave practitioners less able to 'walk the talk' of safe sex, and sex positivity, or address alternative concerns that are not funded by their donors. These questions emerge at a similar junction to the one which saw me depart from traditional re-search writing and re-presentation. This departure was motivated in part, to prevent my queer work being coopted by mainstream re-search and my strong desire work with/in the margins.

In the next chapter I provide another layer to the account of donor-recipient relations, arguing that despite constraints local practitioners are able to create collateral benefits from existing donor funding to attend to challenges that they identify as central to their purpose. By reading these two chapters together, readers can learn from (and knit together) both the structural constraints and enablement's within the social forces of funding MSM in Bangkok. It also allows readers to better understand the human agency of practitioner subjects to make these relations work for them, and their communities. 


\section{Sixth: An Erotic Interlude}

Oooh development baby

I love it when you talk like that, Yeah, blur that line

MSMmmmmmmmm

Come-on, that's it, go deeper

deeper

deeper

$\mathrm{mmmm}$, get that spot

Don't close your eyes

Like your thinking about someone else

You're always reaching for the condom packet

Fuck, you are $\mathrm{SUCH}$ a selfish lover

safe-sex, safe-sex, safe-sex

You've got safe-sex on the brain.

Mum told me "bout guys like you

I'm just safe-sex to you

Is that it?

Another piece of meat,

You stop from going bad?

Another notch in your belt?

Well, I have my own passions

Hahaha

I fantasise

I desire

I want

More

Your fetish for prophylactics doesn't

assist me

consummate my dreams to

walk safely down my street

with my hips swinging

yeah, all kinds of safe.

Wanna taste my lovers lips on my wedding day

have my Mum'n'Dad there too

and my boss

want a gayking and gayqueen on the throne,

I want fireworks baby,

but all you give me is rubbers. 


\title{
Chapter Seven: Re-searching Hidden Spaces - Collateral Benefits of MSM Interventions in Bangkok
}

\author{
AIDS is just one issue in our community, and so are rights. Funders often force us to \\ do the things that are important to them, but we say if we can't do community \\ stuff, we won't do it [work on an intervention] (Miao, 2009 pers. comm., June) \\ In some points HIV money can lead to a better life, that is not only talking about \\ HIV/AIDS, or people who are most 'at risk'. (Tim, 2009 pers. comm., May)
}

\section{Introduction}

In the previous chapter I explored the uneven power terrain within donor-recipient relations which constrains local practitioner agency. In this chapter I offer another layer to this account. Here, I depart from existing Queering Development authors and discuss the agency that local practitioners exercise. I explain the hidden spaces of development funding, the extra 'work' that practitioners undertake as a result of, or facilitated through, the resources provided for sexual health promotion, treatment and care for MSM in Bangkok. These 'bonuses' might also be usefully understood as strategic planning, prudent management of resources, and efficient resource delivery. I have chosen to label them the collateral benefits that practitioners leverage out of existing donor funding. This better recognises that local practitioners use them in this context to attend to their self-identified priorities and passions. In this chapter I summarise the collateral benefits that participants observed, these include:

- The 'creation' and maintenance of MSM community groups

- Physical presence, social networks which enable 'extra' work

- Human rights work

- Identity work 
First this chapter begins with the existing accounts of MSM agency in Queering Development literature.

\section{Accounts of local MSM development practitioners}

The meta-accounts of Queering Development authors tend to understate the agency of local MSM practitioners. These stress the limiting agendas and negative impacts that donors inflict on local MSM development practitioners. Cornwall et al. (2008) and Adams and Pigg (2005) works underline the assumed negative impacts of "Westernisation" and "global gayness" (see Altman, 1997) in development funding arrangements. Clearly, these are reasonable questions to be asking of development policymakers and theorists, yet I am concerned that these accounts lack balance, and effectively diminish the agency of local MSM practitioners. In this chapter I seek to re-write/right this balance by accounting for the collateral benefits of existing donor funding.

In contrast to the views expressed by Queering Development authors, many re-search participants offered positive views of donor-recipient histories. Rather than focusing on the 'unsettling of local identities', or the 'modernisation of sex', local MSM participants emphasised the positive consequences of donors' sexual health based funding. The crucial point here is that the outcomes identified as positive by participants actually went much further than sexual health as shown by Figure 7.1.

Below I have created a simple diagram (Figure 7.1) which presents the collateral benefits practitioners create out of existing funding. Donor's funding is directed toward 'sexual health', yet through this funding, extra benefits are created by local practitioners who leverage these resources to attend to their own (often alternative) development priorities.

Figure 7.1 Diagram of Collateral Benefits of MSM Development practice in Bangkok

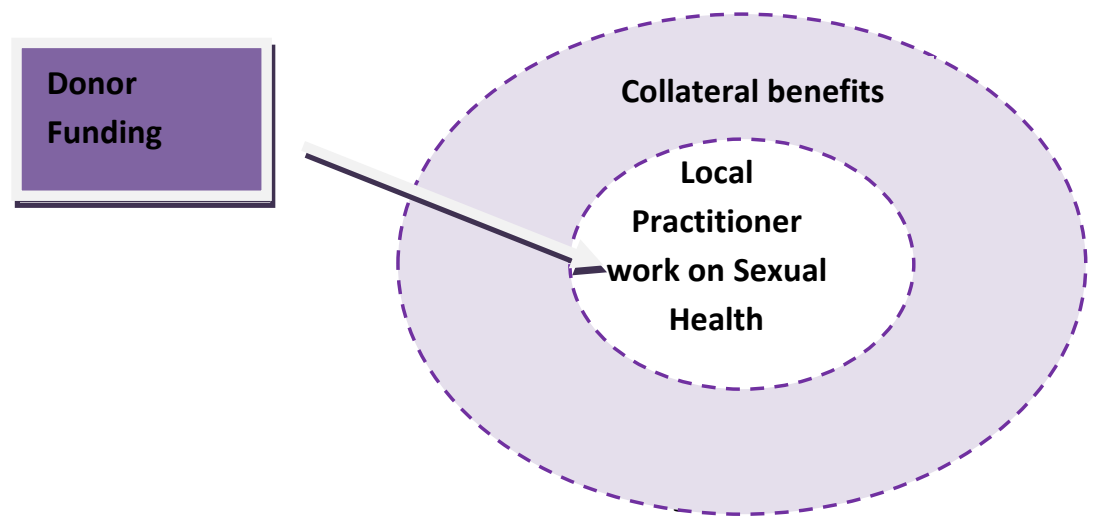


In Chapter Five I used an excerpt of my re-search journal to share my early thoughts on donor-recipient relations in Bangkok. This excerpt identified an almost singular focus of donors on MSM sexual health. I then asked the question: Why do khon-thii-mii-khwaamlàak-lăai-thaang-phêet [sexually diverse people] accept funding from donors when many of the goals they have identified as priorities for their organisations are not included in this funding? In part, the answer to the question is that sexual health is of crucial importance to these communities and must be addressed. But there is another reason why these khon-thîimii-khwaam-làak-lăai-thaang-phêet [sexually diverse people] seek and receive funding, and these are the collateral benefits of local MSM development practice.

These collateral benefits were emphasised by re-search participants. But it was not until I better understood the complexity of the donor-recipient relationship that I could identify them in interview transcripts. Oud, for instance noted that donor-funded interventions had brought together previously disparate sexually diverse communities in Bangkok. He emphasised that funded interventions mobilised 'sexually diverse' groups behind a common goal; in this case HIV/AIDS prevention. Oud observed that, "if you didn't have HIV you wouldn't deal with gay issues at all [in Bangkok]. In a way it has been good for the gay community, we have something to fight against" (2009, pers. comm., June). Oud's point was expanded on by Jan he connected the birth of MSM organising in Bangkok directly to donors mandate to have community involvement in sexual health research and interventions (2009, pers. comm., June).

The points Oud and Jan raise are worth pausing on for a moment. They enable us an insight into what Adams and Pigg (2005) describe rather sombrely as "unintended outcomes" and what I prefer to label as collateral benefits. I re-examining these phenomena I wished to focus on the agency of local practitioners. Thus, I have chosen to label these impacts as collateral benefits to better account for the positive outcomes that may well be intended by local practitioners, but may not be anticipated by donors. From Oud and Jan's accounts it is evident that even if donors funding is only explicitly directed toward HIV/AIDS, the impacts stretched far beyond this. In Bangkok, participants contend donor resources have helped establish, and continued to maintain, community-based sexual diversity organisations. The 
existence of these organisations means more than sexual health promotion. They represent a significant collateral benefit of development intervention into MSM sexuality in Bangkok.

Next, I wish to explain how it is that MSM development organisations have a greater effect than they are funded to have. The first extra benefits that I have selected to explain are the physical premises and social capital that donor funding enabled. Several participants indicated that the offices of RSAT and BRO are where a significant amount of extra community based work - including human rights and advocacy - is undertaken. This 'work' is facilitated by having premises in which to meet, telephones, internet access and so on. Collateral benefits also accrue through the bringing together of a large group of MSM community members. Existing sexual health campaigns bring together many khon-thii-miikhwaam-làak-lăai-thaang-phêet [sexually diverse people] oriented toward working in their communities. Moreover, working on these health interventions develops the capacities of 'sexually diverse' leaders. There are scores of opportunities through conferences, workshops and professional development facilitated by donor funded work, to be exposed to alternative ways of thinking about sexuality/gender, and best practice methods of advocating for khon-thîi-mii-khwaam-làak-lăai-thaang-phêet [sexually diverse people]. These significant collateral benefits - premises, social networks and leadership development - enable recipient communities to effectively work on other issues of importance to them. This 'hidden space' was neatly summarised by Timo (2009 pers. comm., May):

Rainbow Sky has been successful in pressing out of their staff and volunteers a little bit more energy to do other stuff as well. So that's been rights issues, working with the National Human Rights Commission for example, and kind of addressing issues as they come, whether it was the military issue, or the personal title issue for the transgender group.... If you look at it from the donors point of view, you could say they are getting what they paid for, and a little on the purchase. ${ }^{53}$

In reading Timo's excerpt through a PAR lens, I am able to listen to the agency of local practitioners to effect change with limited (donor facilitated) resources. From the

\footnotetext{
${ }^{53}$ I also believe that we could re-view this statement through a more critical lens. It is possible that paid staff may be expected to work beyond their paid roles. It is also possible that staff might feel pressure to do this unpaid work, given operating discourses of 'commitment' to the cause and 'love' for the organisation. As such, this statement should be read with some caution.
} 
perspectives of my participants, this 'extra' benefit was both obvious, and a necessary part of the bargain. This was emphasised by Miao. He observed that RSAT had recently been funded by a domestic donor to promote healthy lifestyles (including diet, exercise, and antismoking) within their target groups. Miao observed that, "this new funding doesn't come from nowhere, it comes from struggles [to prove] that there is more than AIDS in our lives" (2009 pers. comm., June).

What is important to remember in Miao's account is that these are struggles that have been waged with some security of existing international donor funding, and the capacities of paid staff and volunteers built over years working on MSM health promotion ${ }^{54}$.

The wider transferability of donor funded resources is not only limited to the organisers of CBOs. Communities, described as 'target populations' in health promotion discourse, may also use a service established to intervene in sexual health for other purposes, whether this is intended by the MSM practitioner organisations, or not. For example, RSAT is funded to provide telephone counselling lines and an MSN based hotline through donors sexual health funding. Callers to these services can ask any questions about issues that concern them. The conversations that occur on the telephone lines and online media include, but also go beyond sexual health (see Ojanen, 2009). Participants also reported callers asking legal questions, asking for advice about hormones or where they could be more involved in a community. This evidence signifies a collateral benefit. But as I presented in the previous chapter, and as Jet discusses below these are mediated by local practitioners constrained field of power:

we cannot count the information [of telephone counselling queries addressed] in our data and give [it] to the donors... we only focus on the information that we got from the clients about HIV/AIDS. But of course other questions come up, we have got the data so we can talk to them another time, and if we got the donor, the

\footnotetext{
${ }^{54}$ The struggles that Miao refers to (convincing donors that there is 'more than HIV/AIDS') also coincide with new streams of funding that have opened because of changes in donors agendas, such as the specific budget within Global Fund Round Eight for human rights work with HIV/AIDS 'target' groups, such as MSM, IVDUs, female sex workers, and migrant workers.
} 
donor money about that topic or about that subject we also already have the information to work on. (2009, pers. comm., June)

This excerpt reveals donor funded services are currently being used by both MSM 'targets' and local practitioners to meet the needs in their community. These needs are being attended to whether or not donors explicitly fund services to address these needs. Clearly, this is a benefit of donor funding to MSM concerns in Bangkok, and a visible example of the agency of local practitioners and communities to leverage resources made available through existing donor-recipient relationships.

In the next section, I include two case studies to further explore how these collateral benefits work in Bangkok. I selected two texts and my participation in an event that funded through resources allocated to sexual health promotion. Both cases are extremely common to the local MSM development context (the postcards coming in a series, and the camps being held multiple times per year, across $\mathrm{CBO}$ organisations) to direct my analysis toward the every-day functioning of these collateral benefits. 


\section{Case Studies}

Social change can be generated through social practice as it grows out of the everyday activities of individuals. (Dyck \& Kearns, 2006, p. 88)

\section{Case Study One - MSM Sexual Health Outreach Postcards}

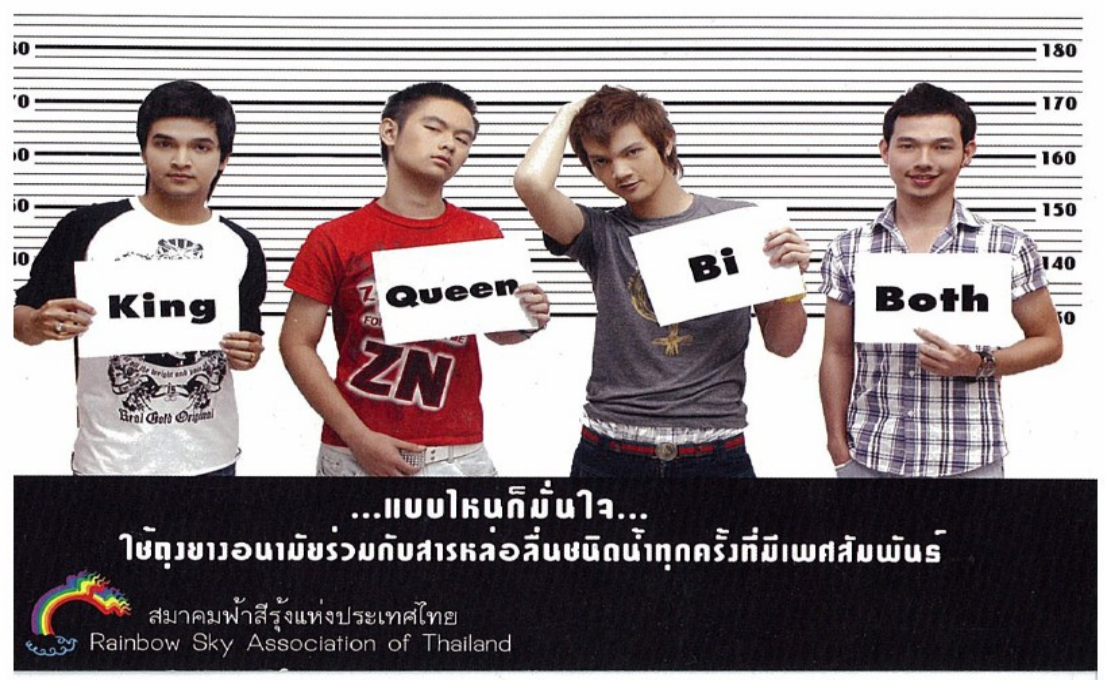

Figure 7.2 - A 2007 postcard used for outreach activities [Source: Rainbow Sky Association of Thailand

From an initial viewing Figure 7.2 could be interpreted as material designed to promote MSM sexual health awareness. The text reads, "Any preference can be confident... Always use condoms with water-based lubricant when having sex" - commonly repeated information in Bangkok MSM health promotion circles. Furthermore, RSAT, the CBO that created the postcard, is primarily funded to promote the sexual health of MSM, with a particular emphasis on the prevention of HIV/AIDS. While the text at the bottom of the postcard does express a clear sexual health promotion agenda, my reading of the accompanying image, and the readings of several of my re-search participants, reveals a plethora of alternative messages that have been received. These both include, and extend beyond the borders of the explicit goals funded by the donor.

All of the participants whom I asked to read this postcard noted its health promotion message. The text itself is a standard one that complies with donor expectations. The image however is complex to interpret. Several participants who read the postcard, interpreted 
the image as a warning that all phêet [genders/sexualities] could possibly contract sexually transmitted diseases; a reading that emphasises that consistent condom use during anal sex is safer no matter what sexual position a partner takes. Other participants re-read the image in quite a different light.

Timo (2009 pers. comm., May) and Dam (2009, pers. comm., June) perceived a different narrative. The second layer of meaning that they distinguished was much deeper, questioning the limits of identification in the gay community in Thailand. The common terms King, Queen, Bi and Both, which purport to index the gendered behaviour of the individual and to signify their expected sexual behaviour, were read as 'mixed up' in this postcard when read against the gendered presentation and body language of the men pictured. For instance, the man pictured holding the "Bi" label adopts a pose that Timo described as "queen-like", with his "inviting" raised arm (2009 pers. comm., July). Likewise, Gob noted that the young man labelled as "queen" is pictured with more "masculine" body language. Cho noted that the background itself may be read through the Thai experience of having ones National Identity card photo taken; thus the imagery could be read as the 'capturing' of identity.

This second layer of interpretation presented by Gob, Timo and Dam is not unproblematic. Not all participants observed, or agreed with these alternative readings. Some participants understood the postcard more humorously, connecting it to sub-cultural jokes about MSM identification, where for instance, a man may identify as Both while his sexual practice is primarily Gay Queen ${ }^{55}$. Tui (2010 pers. comm., February) however questioned whether this play on identity would be received by recipients suggesting that it may instead be interpreted as a line up of criminals, reinforcing the notion of 'deviant' subjectivity. Tui also questioned whether the postcard unintentionally displayed multiple messages, and noted that much advertising material is open to multiple interpretations.

As is evident from the varied responses of my participants, this 'sexual health promotion' resource is far from straightforward. I interpret the image and the accompanying labels of as

\footnotetext{
${ }^{55}$ As Timo notes, this is often used to portray a more 'masculine' identity. An example of this could be someone whose sexual practice is usually receptive describing himself as "top but can be bottom" (2010 pers. comm., October).
} 
a form of social and community education. This view was supported by participants Gob and Cho. Similarly, a discussion with Dam revealed that raising awareness about what being gay is, how it is gendered, and how eroticism is socially constructed in Bangkok were pressing issues for RSAT. This prompts me to ask: does this postcard attend to the goals that RSAT expresses as important to their purpose alongside the goals that donors fund them to work upon? If the answer to this question is in the affirmative, then this is a clear example of the agency of local practitioners to effect change despite the structural constraints of donorrecipient funding relationships. Whatever the answer to the question posed above, this postcard can still be understood as a collateral benefit of existing donor-recipient relations, as participants revealed that they find power in the alternative interpretations that they have come to.

\section{Case Study Two - Peer Education Camps}

Like the postcards above, my participation in an RSAT peer education camp enables the reader to better understand the collateral benefits of MSM development practise. While I attended only one camp, titled the "Camp to Defeat HIV/AIDS" in June 2009, I had discussions with participants about their experiences at identical camps, and these discussions revealed that the style, content and activities used were similar for both BRO and RSAT. The camps were designed as intensive peer education programmes to equip participants with skills to engage in sexual activities safely and to spread this message within khon-thîi-mii-khwaam-làak-lăai-thaang-phêet [sexually diverse] communities. Taking place outside Bangkok, these camps usually involved one or two nights' sleepover. The number of participants generally ranged from 20 to 60 . The camps were facilitated by volunteers, who had previously been trained through the same camp system. These volunteers are referred to as 'seniors' [phi] , and the trainees are referred to as 'juniors' ${ }^{56}$ [nong], which differs somewhat from the generally accepted peer education model where the differences in status between trainee and trainer are minimised (Murray, 1996). Instead, these differences

\footnotetext{
${ }^{56}$ The terms phi and nong are commonly used forms of address (see also Murray (1996) for cross-cultural limitations of 'peer-peer' health promotion in Southeast Asia).
} 
were emphasised in an effort to create role-models of the seniors from whom the juniors are expected to learn ${ }^{57}$.

Local MSM peer education camps are a complex mixture of donor and recipient imperatives. Merging both donor syllabi and local interpretations and additions, they are an excellent example of how existing MSM development interventions contain hidden spaces of recipient agency, and collateral benefits for local MSM communities. Ostensibly these camps are designed to promote sexual health awareness and develop the skills of leaders who can undertake peer sexuality education programmes with local MSM. The majority of activities in the camp I participated in did address these HIV/AIDS related goals, however, alongside this were additional impacts.

For example, the camp provided an opportunity to build community, with activities such as "The Mirror". This particular activity asked participants to journal their experiences at the camp, as well as providing other participants space to write affirming feedback, and things that they learned about that camp member. As Noom noted,

welcome friend come, write for you...it's like the mirror, when you see, when the people comment you, you don't know about yourself, many friends, comment, comment, comment, about you. OK now you know (2009, pers. comm., May)

This was an activity designed to build self-esteem and group cohesion, which has collateral benefits far beyond HIV/AIDS prevention! Indeed, Lek touched on this in our interview. She explained that attending the camp had enabled her, as a săao-pràphêet-sŏong [trans woman], to better understand the commonalities between her and gay members of the camp. Lek commented that she had begun to feel comfortable interacting with other phêet [genders] and had built friendships with gay participants at the camp (2009, pers. comm., June). Timo, a long-time camp attendee reflected that Lek's experience was not uncommon, "generally it [peer education camps] does bring these groups together, and foster some understanding that: "hey they are facing the same stuff as we are'"' (2009 pers. comm., May). Activities such as 'The Mirror' while funded through donor priorities of 'sexual health

\footnotetext{
${ }^{57}$ Ojanen has also connected these practices to university orientation camps. (2010, pers. comm., October)
} 
promotion' extend beyond these goals with collateral benefits for MSM practitioners and communities.

Local practitioners expressed that another benefit of these camps was the ability to attract members and volunteers to the organisations. Members of RSAT explained that the camps were an active attempt to ensure the sustainability of their organisations. Dam reflected on this, understanding the camps both as an HIV/AIDS prevention activity and an exercise in medium-term organisational sustainability. Dam explained that this was a strategic move, given the spectre of unstable resource flows; "the volunteers will keep the organisation alive, even without the funding we can still make progress...the volunteers are everything" (2009, pers. comm., June). From re-viewing these statements, I read accounts of the RSAT peer education camps as local practitioners working the margin spaces of development funding to attend to their priorities. If however, we simply view them in donor terms then we are liable to miss all that happens alongside (or even despite) the stated intentions of these activities.

The preceding two sections introduced two case studies which illustrated the extent that local practitioners and communities leverage existing resources to create collateral benefits. Next, I explore the findings of my re-search relating to the particular collateral benefit of labelling and identity work in Bangkok.

\section{Labelling and Identity 'Work'}

...we try to promote the diversity of sexualities, because some people are not sure how to define themselves, so we give them information, there is more than just one particular definition about their sexuality or gender (Pom, 2009, pers. comm., June)

In my own work, a number of participants expressed concern around the seeming absence of local identities such as kàthoei in development and CBO discourses. One participant, Tana stated that "when kàthoei come to Bangkok they have to choose, either gay or trans". This led him to question whether the targeting of kàthoei identifying people as MSM, săaopràphêet-sŏong or gay/chaai-rák-chaai was culturally appropriate: "we had to adopt the 'MSM' community, and thinking, and we are erasing our own identity' (Tana, 2009, pers. comm., June). Nevertheless, Tana's concern for the maintenance of the kàthoei identity set 
him apart from most of my re-search participants. Many participants identified the reframing of language away from potentially stigmatising words - such as kàthoei - towards language created for and by communities as a significant collateral benefit of donor funding. Employees of funded organisations in Bangkok such as RSAT have been instrumental in leading campaigns within NGO networks and with the media to cease the use of stigmatising labels. For example RSAT has battled against the media use of the term chaai-rák-ruamphet, which can connote both 'loving the same sex' and 'loving to have sex'. RSAT objected to its use as it could reinforce stereotypical hyper-sexualised images of MSM in Thailand, ignoring the affective and emotional attachments of same-sex loving men. Newer language was developed (by funded organisations) with the intention of moving away from both stigmatising and pathologising labels. Khon-thîi-mii-khwaam-làak-lăai-thaang-phêet ${ }^{58}$, which may also be paraphrased as "people of diverse sexualities" was created by the Sexual Diversity Network to replace existing umbrella terms such as bukhon-thii-mii-khwaambieng-been-thaang-pheet, meaning "sexually deviant" or khon-rák-phêet-diao-kan, which could be understood to conflate same-sex desire with transsexuality. Timo described khonthîi-mii-khwaam-làak-lăai-thaang-phêet [sexually diverse people] as "a very Thai conception, it's been created by NGO people, trying to find an umbrella term, it's used all the time" (2009, pers. comm., May). Dam reflected that khon-thîi-mii-khwaam-làak-lăaithaang-phêet "replaces the categorised box and Western conceptualised terminologies of MSM, GLBTQI... [these] actually don't fit the Thai context since we believe that our sexuality is more diverse than existing LGBTIQ" (2010, pers. comm., May).

The points Timo and Dam illuminate are significant ones. This 'identity work' is undertaken by organisations funded to address MSM sexual health promotion. Identity work is important work, but it does not have an immediate bearing on HIV/AIDS prevention and treatment goals, or any other funded objective of donors. Hence I read the accounts presented above as evidence of the hidden spaces of development funding, impacts that do not make their way into donor reports or development theorising. As the participants quoted above note, some of these impacts may be seen by some local practitioners as

\footnotetext{
${ }^{58}$ Ojanen (2010 pers. comm. May) understood the development of khon-thîi-mii-khwaam-làak-lăai-thaangphêet to have been created to meet the need for a non-pathologising composite term.
} 
potentially problematic, while others of them may be understood as collateral benefits for MSM in Bangkok.

I close this section on the extra benefit of identity work by sharing a reflection I made in my re-search journal on the active re/construction of identities in Bangkok by MSM development practitioners. This journal entry was made after my viewing of an RSAT 'sexual health' performance at the National HIV/AIDS conference:

The national HIV/AIDS conference was a little out of town; I had a last minute invitation from one of my participants who suggested we could split the taxi fare. This was a relief as I was running low on funds. The convention centre where the conference was held was stall after stall of HIV/AIDS information, projects, international organisations and small local groups. The stalls contained everything from policy documents to merchandise, model vaginas that displayed female condoms to noisy educational puppet shows. I set out to find the RSAT stall and found some people I recognised. Realising there was to be a performance shortly I bought some coconut juice and hung around. The music started playing and some of the guys took up their positions. There were four in total, each with a slightly different stylised sequin outfit. I asked my friend Jet from RSAT to translate. He explained that there were four of the different MSM phêet [genders] represented by each of the dancers; gay queen, gay king, both, and bi. Each dancer led in turn and was introduced through his phêet [gender] to an audience of uniform wearing students. Later, I asked Jet to explain the performance; he told me it had been designed to educate the public and other MSM about the existence of the different MSM phêet [genders] as well as providing an entertaining safe sex message to bring to MSM sex venues. Reflecting on the dance later I could see its mixed outcomes. It appeared to not only be a novel way to offer the safer sex message but in performing the dance to groups of students RSAT was able to communicate much more about the existence and specificity of MSM sexual cultures in Thailand. Despite the existence of these alternative impacts, the funding of the work could be attributed solely to MSM sexual health promotion. (Personal Journal, June) 
Reading through my reflection I am struck by the agency and creativity that local MSM practitioners displayed. Not only did they attend to their donors' expectations of safe sex education, they also attended to their own self-identified goal of educating the public about local MSM sub-cultures. I read this journal entry, together with those explored above, as a sophisticated understanding of the multiple impacts donor funding can have locally. Rather than understand the alternative positive impacts of MSM development practice as "unintended outcomes" (Adams \& Pigg, 2005) I chose to re-read these spaces as often anticipated and desired collateral benefits that local MSM practitioners work to achieve. Next, I wish to explore another hidden space of existing donor funding - community building.

\section{Community Building 'Work'}

The significance of community building has been discussed in the international literature on HIV/AIDS prevention (see Parker and Aggleton 2003). Widely recognised and funded as a delivery mechanism for HIV/AIDS interventions, community building is funded due to its potential to reach large numbers of targeted people quickly. By having a 'social focus', these interventions may reach people who do not find a focus on HIV/AIDS prevention itself a stimulating enough reason to participate in a project. But as Ojanen's (2009) work has shown, while HIV/AIDS may be one significant challenge faced by MSM in Bangkok there are many others such as discrimination, low-self esteem and isolation.

In my re-search participants identified community building work is both an instrument to address sexual health goals, as well as a collateral benefit - a goal in its own right. The development of RSAT itself is in part, a collateral benefit of donor investments into queer sexualities. This was identified by Jan, who observed RSAT's "whole reason for being, is linked to the need for donors to have community representation in their [HIV prevalence] research" (2009, pers. comm., June). Miao reflected that this had positive impacts:

Before RSAT these groups [phêet] didn't understand themselves as well. It is bridging more understanding. This kind of funding is creating communities...yes, we are definitely creating communities (2009, pers. comm., June). 
He went on to explain that the creation of "community leaders" working across regions, generations and HIV infection statuses in Thailand could be attributed to interventions funded by donors. Miao identified the development of a network of complementary organisations in different regions, or focusing on differentiated target groups, "RSAT has been an organisation which has trained leaders of the other organisations, which creates national MSM communities" (2009, pers. comm., June). Toi agreed the funding of one organisation could enable collateral benefits to others:

Community mobilisation is a positive, if you want to do a project you have to find people, there are a lot of community organisations led by MSM, run by MSM. It leads them together, now they have a stronger voice. (2009, pers. comm., June)

From the excerpts of Toi and Miao, I see evidence of 'sexually diverse' community building that has impacts beyond HIV/AIDS and other sexual health concerns only. This act of bringing together diverse phêet [genders] prompts participants to challenge the stereotypes and prejudices they may hold toward other socially marginalised groups. This was exemplified in a moving excerpt shared by Tim, who identified as săao-pràphêet-sŏong:

I will give the example about myself, before I first came to work with RSAT na, I might not [have] really like[d] the person who works in the sex business, right, but when I worked with them, I start[ed] learning from them, I start[ed] learning what they do, who they are, how the society or the culture, force[s] or push[es] or influence[s] them, influence[s] them, so I start[ed] to understand people...it is like on-the-job training for your life, so you learn more about sexuality, and you learn how to respect people who are different from you, who have a sexuality that is different, and not like you only. (2009 pers. comm., May)

From Tim's excerpt I read a sense of community-building that impacts far beyond sexual health promotion, toward the broader goals of togetherness held by the leaders of these funded MSM organisations. Tim's experience enables us to question how health promotion projects may influence community attitudes and understandings of the sexual and social self. 
Similarly, recipients' agency in undertaking community building work is evidenced in the principles supporting khon-thîi-mii-khwaam-làak-lăai-thaang-phêet [sexually diverse people]. RSAT makes significant attempts to involve all phêet [genders] within their organisation despite the fact that funding must be primarily accounted for by MSM projects. RSAT has attempted to ensure that WSW are effectively represented with quotas for female board members. This shared sense of community was reflected on by Tim, who explained the tactical phêet-wide community building undertaken at the network level,

when we come to working on human rights in our country...we say that we work as a sexual diversity network, this included bi, lesbians, intersex, to work together, and even if lesbians don't have their own organisation, they have their groups that work for their community" (2009 pers. comm., May)

I believe the accounts above present evidence that the values of community building exist as ends in themselves, rather than simply as nodes to address sexual health concerns.

While these responses reveal community building as important for local organisations, participants also found it personally profound. Mhu is involved in $\mathrm{BRO}$, an organisation primarily funded to carry out HIV/AIDS prevention related work. He is a peer-educator working in public spaces where MSM meet to provide information about safer sex, and collect data for sexual health monitoring purposes. Mhu's excerpt below enables us a closer look at the impacts 'sexual health' community building may have,

My family don't know that I am gay, so coming here has allowed me to get to know about all these places where there are lots of gay people, it's as if to gain a new family where I can express myself, and express myself about gay things in a way that is unconditional... I have gained a new family. (2009 pers comm. June)

It is crucial to note that these collateral benefits do not simply coincide with donor funded interventions, or exist solely as instruments to address sexual health concerns. Instead, they are actively desired by queer community leaders. The examples above illuminate how these organisations in Bangkok expand donor funded spaces and consciously stretch their reach. This was clarified by Miao who stated that for him, "community is both a tool and a driving force; we are doing things not just because they need to be done, but because they mean 
something to us" (2009, pers. comm., June). The excerpts above demonstrate the complex meanings and local interpretations of these interventions, complexities that are understated in the international Queering Development literature.

\section{Human (and Sexual) Rights Concerns}

As I indicated in Chapter Two, human and sexual rights concerns take centre stage in Queering Development writing (see Cornwall et al., 2008). Queering Development authors convincingly argue for donors to approach MSM development within human rights frames. I contend that in Bangkok, local practitioners are already undertaking a substantial amount of human rights 'work' as a matter of course. First, sexual health promotion for MSM was understood by many participants as a human rights issue itself, to individuals' control of their bodies, as well as equal access to healthcare and education. Second, participants identified that other human rights issues were encompassed within sexual health related interventions. Dam shared his perspective on this, stating:

[human rights concerns are] naturally incorporated into the program, the donors make it clear it is HIV, but eventually when it comes to the community we integrate it together, people's lives cannot be categorised, they must go altogether (2009, pers. comm., June)

Dam's position is supported by Jet, who stated,

we work with HIV/AIDS most, but we also transfer to MSM rights because however they are linked together, we have got the violence against us, and we have the stigma about being gay, so we are asking about our rights (2009, pers. comm., June)

This perspective was also evidenced in an interview with Miao. Miao noted the social construction of sexuality and gender, and stated that deconstructing these was a goal for his organisation (2009 pers. comm., June). While social transformation is not an explicit focus of these MSM sexual health promotion interventions, Miao identified it as a by-product experienced through the ways that workshops and resources were designed and implemented. 
Alongside human rights issues being addressed within sexual health interventions, participants reported the collateral benefits created by these interventions (such as telephone counselling lines, premises, experienced staff and volunteers) could be mobilised to work on human rights issues. Timo observed that human rights concerns were being addressed in the personal time of employees and volunteers. This was confirmed by Dam who stated that staff and volunteers "have been working much more than their job descriptions are, but they spend their free time to work on human rights" (2009, pers. comm., June). He continued by characterising donor feelings on these openings, "Several donors have agreed that we should work on human rights. They don't pay, but [they] don't obstruct". Dam illustrated the agency of recipients who attend to their obligations, while doing other community focussed activities, "when we write reports it corresponds to the needs. We know what to report, but we also know what we should do in the community". (2009, pers. comm., June)

Clearly donor funded MSM sexual health interventions do much more. They can also result in important 'work' on justice and freedom from discrimination as was poignantly explained by Tik:

back when I was living in the countryside when something happened, when I was victimised in terms of crime or something, if I went to file a complaint at the police department, they wouldn't take my complaint, or things like this. If I was looked badly on in society I wouldn't have known who to turn to, but here we have people who can help you with legal issues and stuff like this.

As Tik's excerpt reveals, donor funding, and local implementation, of MSM sexual health work can result in additional outcomes, or collateral benefits. These collateral benefits may be, in some cases, a motivating factor for staff, volunteers or 'targets' to participate in a sexual health promotion project. For participants in my re-search the human rights work they undertake in the margins of their paid work may in fact be one of their central priorities. 


\section{A Balancing Act}

The accounts offered above reveal donor-recipient relations to be a balancing act, where both parties negotiate for their own interests. While donors may exercise power to determine the structure of these relations, recipients can make it work on the margins. While donors have historically put in place policies with which some local organisations do not agree ${ }^{59}$, organisations have been able to manoeuvre their interests into meeting those of donors.

Tim stated that:

some organisations like (name of organisation) they receive money from USAID.

They also work with sex workers, because most trans in (name of city) engage in sex work. So, at that time when I am talking about sex workers, we don't say transgender sex worker, we just say 'transgender'. (2009, pers. comm., May)

Queering Development literature privileges accounts of development recipients who seemed 'cornered into' interventions that were prioritised by donors. Discussions with local practitioners revealed more balance to these arguments, they declared that they did exercise agency to decide upon their own foci for intervention. For example, Tim noted that recipients have the:

freedom to create their own activity, to specify their own target group. There are many different target groups. Some organisations might work with male sex workers, some might work with MSM, some in saunas and some organisations might be working with MSM in the rural area, some organisation[s] might be working with MSM with a positive status. (2009 pers. comm., May)

While Queering Development authors may understand all these groups under the rubric of 'MSM', in Bangkok, local practitioners saw opportunities to demarcate priority groups as symbolic of their agency to make decisions and effect change locally. Alongside accounts of greater complexity and freedom to delineate interests within 'MSM', re-search participants

\footnotetext{
${ }^{59}$ Such as USAID's history of policies prohibiting explicit work with sex workers and confrontational human rights approaches.
} 
contrasted an interpretation of what Cornwall and her colleagues (2008) might call a LGBTTQQ ${ }^{60}$-type "alphabet soup". While Queering Development authors may see this as an unfortunate outcome of donor agendas to universalise sexuality and identities; in Bangkok, recipient organisations emphasised the positive benefits of this cooperative action. Many participants understood cooperation as a logical step, which prevented the division of communities, and enabled them to work together on issues where their interests were aligned. Again, local practitioners accounts of their agency in donor-recipient relations differ from those presented in Queering Development literature.

Local practitioners carefully weigh this balance, and when the gains or potential collateral benefits are insufficient, recipients will decline funding from donors. This was explained by Noom, he said his organisation had declined, and would continue to decline offers of funding that did not match the aspirations of their communities:

I said we don't mind, we can get or not get funding we don't mind. I said if you think like this, I am against you. We fighting, funder or not funder (2009, pers. comm., May)

This perspective was also shared by Ae, who stated that the organisation that she led consistently rejected funding offers from donors because donors' expectations did not align with the priorities and principles of her organisation. She stated that she was more content to make do, or seek alternative funding sources, rather than undertake onerous or irrelevant directives from donors (2009, pers. comm., June).

In the same way recipients must balance their desire to remain independent, with their desire for funding from donors. This was revealed to me in discussions with Noom, when he explained why BRO chooses not to register with Thai government agencies as an association or organisation. Noom explained that to register would make it more likely to receive donor funding, but it may place the organisation in a more difficult position to comment on political or media issues. He argued that registered organisations are not as comfortably positioned to be critics of government policy "because when you fight something, because

${ }^{60}$ Lesbian, gay, bisexual, transgender, transsexual, queer, questioning, intersex 
you have this from the government, the ministry of culture will call you [and say] 'I will close you na', they have many problems, but we can fight". (2009, pers. comm., May)

\section{Conclusion}

In this chapter I explored the hidden spaces of donor-recipient relations, particularly focusing on the collateral benefits of existing funding. In re-searching these margin spaces I offer a complex perspective on the agency displayed by local practitioners of MSM development. I offer a view of local practitioners as active agents who attend to joint donorrecipient foci as well working for wider social change using the resources available to them. In moving toward this view of Queering Development that encompasses both structure and agency I address the imbalance in the international literature by proliferating examples of much greater agency than has been accounted for to date. As the previous chapters revealed donors and recipients are positioned in an unequal field of power, where donors are able to establish and insist on particular agendas. Yet, within this unequal landscape are the margin-spaces of agency that local practitioners occupy, creating collateral benefits for their communities. In the following chapter I depart from participants accounts of the situation as it seems to be, toward dreaming of the future for MSM development interventions. 


\title{
Seventh Interlude: i connect the dots
}

\author{
queer community member \\ tourist
}

friend

qualitative re-searcher

alternative dissertation writer

boyfriend

political party member

activist

supervisee

Thai language student

HIV negative

sibling

lyric inquirer

coffee drinker

participant

patient

community development practitioner 


\section{Chapter Eight: Expanding Intervention Spaces - Dreams from Bangkok}

\section{Introduction}

In this chapter, I wish to move beyond present donor-recipient relationships and the challenges facing local practitioners to foreground participants alternative visions for the future. I have elected not to interpret these dreams exhaustively, to enable the visions of participants to be heard as they were told to me and to accord more space to participants' voices at the end of my work ${ }^{61}$. Rather than undertaking an examination of each participants dreams, I have chosen to collaborate on a visual re-presentation of participants dreams (Figure 8.1). This picture was drawn by trans comic artist Sam Orchard ${ }^{62}$ and is my attempt to create a useful and inspirational resource for local practitioner communities, out of the visions people shared in this study.

\section{Miao's Dreams - MSM Interventions in a Circle of Life}

Miao dreamed of a renovated space for interventions with MSM in Bangkok. He began his dream by noting the need for a new re-search that "asked the community ${ }^{63}$ what it actually wants" (2009 pers. comm., June). This vision sits in contrast to the existing situation in Bangkok where donor funded research is undertaken in discrete realms of MSM lives, such as sexual health, rather than any broader exploration of MSM wellbeing ${ }^{64}$. Miao then offered his own revised conception of donors approach to funding MSM interventions. He described a framework whereby all interventions would exist within a "circle of life"; within this circle were three interrelated causes, "deconstructing gender power structures", "health issues, proactive and receptive" and "rights, law, pride and public image". Miao

\footnotetext{
${ }^{61}$ Limits of space prevented me from including each participants' dreams in this chapter. Where possible I ensured that dreams that were left out were addressed in included excerpts. I am heartened to remember that these stories may become the basis of further re-search and publications.

${ }^{62}$ Sam Orchard is a trans-guy comic artist and youth worker who currently lives in Dunedin. He publishes comics on his website http://roostertails.wordpress.com/

${ }^{63}$ The community Miao is referring to here is the khon-thîi-mii-khwaam-làak-lăai-thaang-phêet community.

${ }^{64}$ It is important to note that research work undertaken by graduate students and academics falls outside of the context I am referring to here.
} 
continued advocating for a focus on funding for the "wellbeing of sexually diverse people" as the primary goal of MSM development interventions. He argued that a focus on holistic wellbeing would not necessarily be at the expense of HIV/AIDS work, instead HIV/AIDS prevention, treatment, and care would be re-conceived as instrumental to wellbeing, rather than the final product of interventions.

\section{Tana's Dreams - Ending Stigma and Discrimination}

Tana's dreams resonated with those of Miao. He also dreamed of a re-designed intervention environment; one which placed more emphasis on transforming the "real li[ves]" of MSM (2009, pers. comm. June). Tana dreamed of increasing the resourcing of a specific area that he felt was currently underfunded by donors - work against stigma and discrimination. He described his dream like this: "If I had my own money I would fund more projects that fund [work against] stigma and discrimination, I would put a huge amount on this, I would put slightly less money on health information".

Tana also felt that interventions might benefit from including more people than MSM only. He continued, "I used to come up with the idea of how to integrate the MSM community within other genders, when we categorise people with sex and gender, it is a sort of discrimination". To explain his point, Tana related a story about a young man with whom he had been working. He dreamed that instead of this man keeping his queer and straight networks separate in intervention spaces; that interventions could work with his existing friendship and support networks, bringing them into the intervention spaces as well.

\section{Jan's Dreams - A Contextualised Approach}

Jan also re-visioned the environment for MSM development interventions. He expressed his frustration at the current scope of interventions and imagined a space for more contextualised and grounded interventions that came out of the lived experiences of local MSM themselves:

I think that we need to much better fine tune what we try to do, understand these things with the real life-world of men who have sex with men. We don't do this by spreading knowledge of risk and transmission only. If you don't link it to issues of self 
worth and self view people think they are basically bad, and they have to go through this phase of suffering, then HIV is perfect for that, you might as well just die a horrible death. We need to understand the background things that are already in the brain whenever we try to instil these facts about HIV, because they often coexist, and are so ineffective in terms of changing behaviour, if you don't engage the beliefs that people already have about risk, about friendship, a lot of wider issues related to sexuality, I think the interventions will continue to fail. (2009, pers. comm., June)

Jan drew on his experience working in the MSM development field, and recent research he had undertaken to outline how this more contextualised intervention may appear:

I think there is a slowly growing realisation that it is naïve to only look at risk behaviours and HIV, if you want to improve the sexual health, or general health or wellbeing of MSM. There are now a number of studies that have been done, not in Asia I think, that show how there are problems of drug abuse, stigma, discrimination, of feelings of inadequacy, of depression, which are also linked to so called risk taking, also blaming the victim in a way, in that they take risks and are stupid basically. Now, it is not looking at risk situations, or situations where transmission of HIV occurs, or whatever, you can put it in different ways, it is still I think, the whole effort in preventing HIV among MSM is steeped and draped in the health belief model, which has a very strong focus on individual responsibilities and individual actions, and in trying to increase knowledge and attitudes like in the expectation that people are able to rationally make the decision that they want to change their behaviour, and kind of bereft of the wider context in which these processes will take place, the whole idea of peer education, outreach: 'there is ignorant MSM out there, we are going to reach them, we educate them and then they change their behaviour' and there is very little investment in other kinds of interventions that might look more at the structure in which MSM operate, or try to integrate other aspects related to their wellbeing in their life sphere. (2009, pers. comm., June)

Jan's excerpt revealed that a personal interest in protecting oneself against HIV/AIDS is only one of a myriad of determinants which affect individuals' sexual behaviour. Jan's dream of a renewed focus on holistic wellbeing (as opposed to the current compartmentalising 
approach which focuses on physical, or specifically sexual health), and contextualised approaches to achieving this (as opposed to largely pre-determined approaches) were consistent with the sentiments expressed by a number of the other participants in my research.

Timo's Dreams - Funding for Psychological Wellbeing and Changing Legal Structures

Timo dreamed of an intervention environment that placed more emphasis on professional counselling and psychological support for MSM, "if you really feel that you are not accepted anywhere in your family or in your workplace or anything, that can drive you to suicide, so you can say other issues [than HIV/AIDS] may be life threatening" (2009, pers. comm., May). Timo was concerned that non-MSM specific health professionals may pathologise queer identities alongside any mental illnesses with which a client may present. He dreamed of professional psychological support being provided at spaces like RSAT, and on their counselling telephone lines, and online support services. Timo hoped that this support could be provided not only for gays but also for yĭng rák yĭng and transgender community members. He also hoped that existing services could be guaranteed funding on a longer term basis than is currently the case, to create an environment where organisations would feel secure to invest in their services and the capacity of their staff.

Timo dreamed of interventions working to improve Thai legal structures, to support MSM wellbeing. He identified that, while this was currently not a priority for donors, this legal environment enabled discrimination and intolerance to continue "so legal stuff, of course it would be time to get all of that legal protection, discrimination laws and marriage laws, those kinds of things". He maintained that it was short-sighted to work with one primary objective without looking at how the legal system underlying this continued to hamper identified development goals such as HIV/AIDS education programs, for example by making public sex venues technically illegal.

Gob's Dreams- Finding a Space for Families and Recognising Love and Intimacy 
Gob dreamed of MSM interventions that invested in "self acceptance, psychological counselling, relationships and family", recognising their core importance to MSM wellbeing. He felt that donors current sterile focus did not effectively comprehend MSMs position within the important frame of family relationships:

Western organisations are not interested in family acceptance. I think it is because they can claim scientific rationale for their intervention, but when it comes to family, relationships area, it is fraught with cultural differences, donors tend to avoid the landmines. They don't want to impose or be seen to be imposing whatever they think is right, and if they are perceived as such it might jeopardise their other works, it might be based on a Western perspective on human conditions, with more emphasis on individuality rather than... as a part of a larger unit like a family or the society. And it has more solid scientific backing which the West can claim supremacy in. (2009, pers. comm., June)

Gob felt that a focus on MSMs relationships with existing support networks were worth funding both as objectives themselves, but also as an effective instrument to address HIV/AIDS prevention, treatment and care:

It is easy to target HIV/AIDS as a disease, it is harder but probably more efficient to look at it as a phenomenon that happens within the context of the MSMs life, and within the contexts of relationships also...talking about MSMs as a large anonymous group, faceless group without taking into concern their sexuality or other facets of their lives, um, probably is too reductionist approach to a problem or to an issue that is so wide-ranging and deep penetrating as HIV/AIDS. Because it doesn't stop only when you don't or do have sex. (2009, pers. comm., June)

He went on to identify HIV/AIDS challenges as both medical and social, and offered his own perspective on which groups might be included in advancing this issue:

when we are talking about trying to find solutions for HIV/AIDS, not just in the health context but in the social context, everyone should be included...I think it would be 
better if donors saw lesbians as a part of an integrated part to HIV/AIDS solutions (2009, pers. comm., June)

Gob also challenged the limitations on sex and intimacy that are invoked by donors' funding discourses, dreaming instead of donors conceiving of eroticism in a holistic and personcentred way:

like we talked earlier, how 'sex' is all about penetration, sometimes I think I am born in the wrong century, I write, and when I am really into someone, I write poetry...Maybe 'sex' can also include stimulating intellectual conversation, or like sharing some intimate moments that doesn't have to see the appearance of penises...I think that they short-change sex by seeing sex as clinical - penetration, or wearing or not wearing condoms, and ignoring the implications of sex in terms [of] human relationships. (2009, pers. comm., June)

Gob also dreamed of broader funding arrangements that centred on MSM as family and community members. This, he argued would prevent the singular focus on sexual health, which he believed:

distracts you from other things because I don't think you can deal with the HIV/AIDS issue on its own, while ignoring all other social, family and psychological factors that you know surround that, make up a person.... know it is a thorny issue for even Western governments, because they don't want to be seen as promoting homosexuality in these Third World countries where there are religious or legal prohibitions against, you know, alternative sexual orientations, sexualities. (2009, pers. comm., June)

Tim's Dreams - Working in Networks and Political Representation

Like many of the dreamers in this section Tim expressed a desire for a contextualised approach to funding MSM interventions:

HIV/AIDS is quite far from their [MSM targets] thoughts in some points, yeah people have sex, sex is a kind of daily life activity right? But in some points I think HIV/AIDS 
is far from their thoughts, they just want to have a better life, they want to have a space in the society, they can pride themselves what they can be themselves in the society [sic], I think this is the main point when you start looking to work with gay men and transgenders. (2009, pers. comm., May)

In dreaming of context informed interventions, Tim was careful to reiterate that this should not see the end of successful HIV/AIDS work, rather additional resources should be found for alternative intervention categories, "I don't think it's too much [funding for HIV/AIDS], but I do think we should have some funding that works on another issue, parallel with HIV/AIDS". (2009, pers. comm., May)

Not only did Tim see contextualised approaches as being central to the future of developing MSM, she also hoped for a collaborative approach to working with donors:

So I think, that the one possible way in the future might be to form the coalition on GLBT network or something, I mean a kind of formal network that can negotiate to the donor, or can work on the funding or the fundraising to work for the whole community, the whole gender diversity effort. This is one possible way. (2009, pers comm. May)

Finally, Tim dreamed of the political representation of Thai queers by queers themselves:

...I can't say that Thailand is a heaven for the gay men or transgender; if it's a heaven we might have a president or the prime minister who is a gay man! Here in Thailand if you are transgender they have less opportunity to find a good job, even if you have a good education...or they can find a job, but very stereotypical, cabaret show, makeup artist, and if you are very good in dressing and makeup you can find a job cosmetics, or cosmetic company, or hair salon, which is so, everyone perceives that transgender do these kinds of jobs very well, but no one thinks that they can work in other jobs as well. (2009, pers. comm., May)

\section{Nok's Dreams - Human Rights and Other Fronts}

Nok dreamed of donors funding other fronts outside sexual health in Thailand: 
like other human rights issue or gay marriage, or when we are fired from work, we need to have a discrimination law to protect us against this discrimination, push for social acceptance, not only among our own family, among our friends, but to help society understand that we are human beings. I think it is good to have community, it is good to have friends, and it's good to have people we can share our problems with, it shouldn't stop there, because otherwise the next generation will face the same problems that we have been through if we don't change the whole system. (2009, pers. comm., June)

Nok also felt that new physical spaces needed to open for WSW to meet:

Right now the younger generation, they meet their friends on the Internet, right? And they have their community on the Internet. And they can go to, I don't know, like you play games on the internet, they have this room, like lesbian room, tom-dee room, that she can go there and play with other tom and dees, so it is like, is this community, or not? For me it is not real, in one way it is not really in their own lives, like they have to escape, they meet and they can be who they are, they can have friends, but then when we come back to the world what is happening? (2009, pers. comm., June)

\section{Pom's Dreams - Thinking Beyond Sexual Health}

Suppose we were very rich we wouldn't need to do AIDS work. I don't know if it's just in Thailand, but why do gays always have to do AIDS work? Maybe we could do something about what being gay or tom or dee actually means, is it just here? Or I don't know. Suppose one day there is a cure for AIDS, then what are we going to do!? (2009, pers. comm., June)

Pom dreamed of expanding the conception of health, to encompass broader concerns such as fuller information about hormone treatments for trans people, smoking, mental illness and alcohol and drug abuse within the wider queer community. He also advocated for funding for training with health care professionals to educate them about appropriate ways to address sexually diverse patients. 
Pom also identified interventions with families as one of the key challenges for the future. He echoed Gob's concern that families should not be ignored in interventions with MSM, with resources being targeted toward the sexual behaviour of the individual only. Pom felt that this minimised the often important role that MSM play in the family, "I would like to see more outreach.... with families, with the family institution, for example showing more successful toms and dees, to gain more acceptance within families". Finally, Pom dreamed of funding to address human rights concerns, "so we work without the resources, but if we have more funding, or the public space to exchange ideas and knowledge that would be great...rights are important basically, because transgender people have feminine bodies, but they still have the Mr. on their ID cards". (2009, pers. comm., June) 


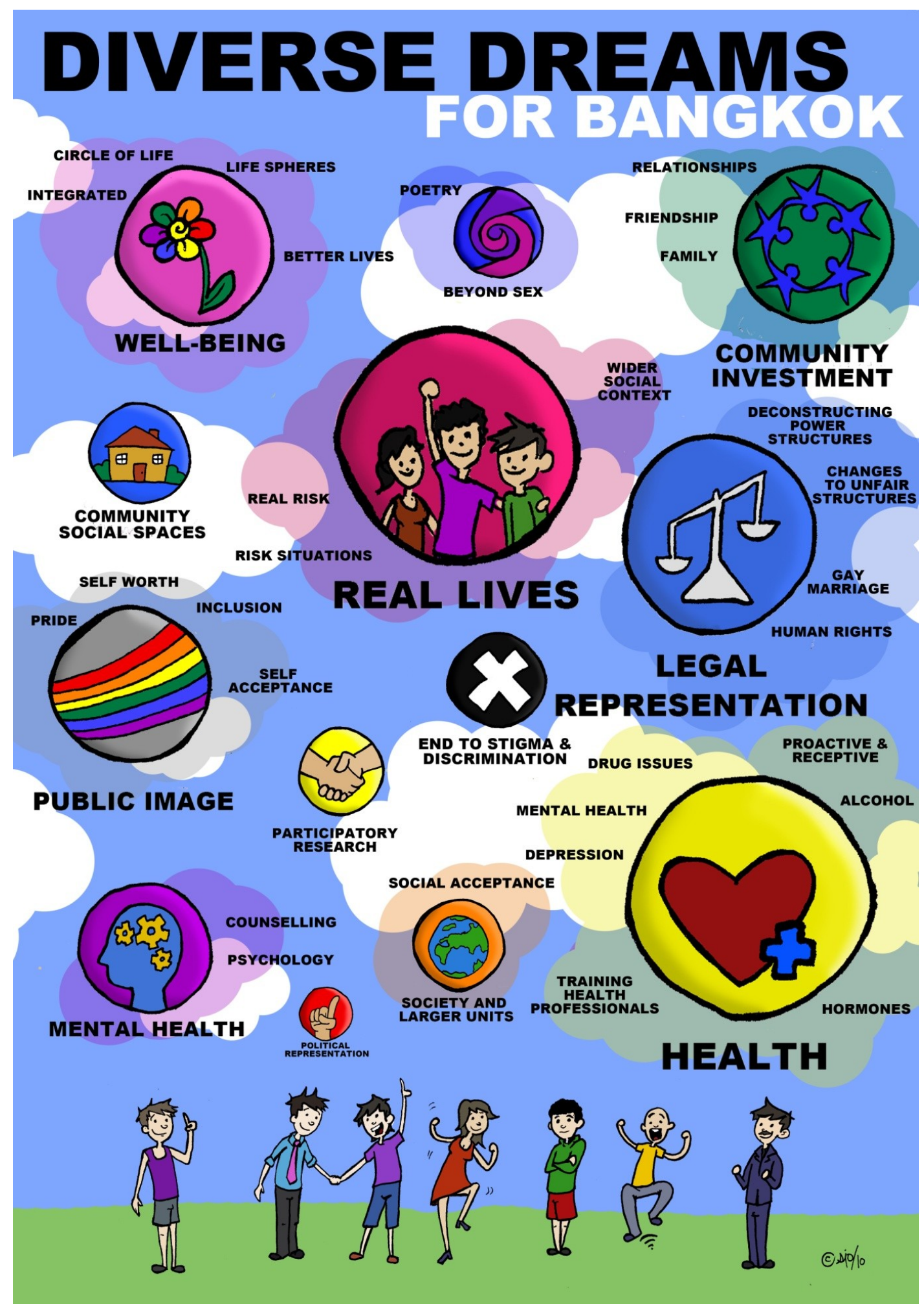

${ }^{65}$ This diagram was created out of a discussion that I had with Sam Orchard. Sam produced the diagram. 
Here, I offer a vision of MSM development practitioners as architects of alternative visions. In the referential interpretation above (Figure 8.1) I have distilled the key themes that emerged from participants' dreaming. Rendering these dreams into an accessible image invites examination of the dreams as a whole. It also creates a useful resource for the MSM development practitioner community in Bangkok. It will be used as the cover page for the resource which I intend to send back to the communities I was working with.

My friend and fellow queer activist Sam Orchard has drawn each of the seven "characters" whose dreams were shared above. He used my interpretation, and made clouds from the terms participants 'dreamed up'. To interpret the dreams, I analysed interview transcripts associated with participants dreaming to identify the most frequent words/themes. The individual dreams are scaled, so that ideas mentioned twice will appear double the size of those mentioned once, and so on. Once I processed the information I sent it to Sam who (in consultation with me) created the images that appear on the diagram.

The diagram is necessarily arbitrary. The words chosen were the words that I interpreted as dreams and connected together, and Sam has created pictures from these dreams, and his artistic re-presentation is obviously socially and culturally situated. Mindful of these facts, I believe the diagram is best understood as a particular interpretation of the possibilities for future MSM development in Bangkok. Looking at the diagram as a text that was coproduced at a particular time, I am able to see it as a starting point, rather than a map for the future.

Looking at the diagram, my first impression is to notice the sheer amount of dreams. The multitude of aspirations that local MSM practitioners have for the future sits in direct contrast to the monolithic attention paid to HIV/AIDS in donor discourse. My second impression is to note the vibrant colours. I see understand these as Sam's way of connecting to a desire among local MSM development practitioners to move beyond what they perceive to be monochrome interventions or identities understood in simplistic black and white terms.

The dreams that my participants shared still include a significant commitment to health. However, they expressed a desire to see MSM development interventions move beyond 
funding only condoms, lubricant and information. They dreamed of health in its fullest sense, focusing on mental, physical and emotional wellbeing. I believe that their understandings offer a useful starting point for donors who may wish to investigate ways of engaging with MSM health more holistically.

From the real lives, well-being, beyond sex, community social spaces and community investment clouds I read a desire for more contextualised interventions that work with MSM as real people, with many facets to their lives. I interpret these clouds as connected to a dream of strong communities. Dreams of community solidarity and support contrast with donor emphases on MSM as the individual. I read into these dreams a desire for transformation of group consciousness within the 'sexually diverse community' in Bangkok. Donors and local practitioners might also be inspired by Gob's dream of looking beyond sex for the khon-thîi-mii-khwaam-làak-lăai-thaang-phêet community-engaging poetry or other creative endeavours that may bring people together. From the political representation, public image, anti-stigma and discrimination, legal change, and wider social units clouds I read a desire for more politically aware MSM development interventions that address power relations between groups and work toward their transformation. These clouds may also offer clues to how local practitioners would see sexual rights implemented. In keeping with the principles of "khon-thîi-mii-khwaam-làak-lăai-thaang-phêet" and the dreams outlined by participants I would interpret a desire for sexual rights to be claimed beyond identification and the categorised identities of certain people.

I am hopeful that this picture will act as a source of inspiration, a place that local practitioners can refer to to explain the complexity of the challenges and possibilities for intervening in MSM wellbeing in Bangkok.

\section{Conclusion}

This chapter shared the rich dreams offered by re-search participants during our many engagements. It has also presented these dreams in the form of an inspirational poster/picture that I hope will be of use to the organisations with which I worked for this research. The following chapter revisits my re-search aims before providing a fuller discussion of the key findings of my study. This takes shape as a detailed exploration of my central arguments, including reflections on the complexity of donor-recipient relations, the 
collateral benefits of practising MSM development and my learning's about the postgraduate queeresearch process. This is followed by a discussion of the significance of my re-search, and the identification of areas ripe for future study. 


\title{
Eighth Interlude: Dreams
}

\author{
I do not seal up my \\ body \\ from producing dreams \\ they appear at night in full colour, and $i$ wake up with their taste in my \\ mouth \\ they ooze out of me, sweat from my pores, or gush like a wound in my \\ neck \\ they re-infect scratches, wounds: they are the puss and phlegm and snot expelled, \\ they are the stones i spit up from my \\ throat
}

$\&$

$$
\begin{gathered}
\text { i read them in the bruises on my } \\
\text { thigh }
\end{gathered}
$$

Sticks and Stones May Break My Bones etc. etc.

fucking lies

these are the subversive dreams of catharsis

dreams that find form as the warm balm of relief

like an

orgasm

seductive possibility

putty of if that I mould between my

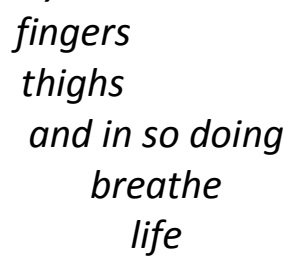

here i can't even say where my dreams begin and my book-words stop gentle reader

$i$ tried to whisper them into every page to rub words together and make the fire of dreams

to produce a colony of dreams that squawk like nesting birds, with whispering wings... 


\section{Chapter Nine: Conclusion - Complex Relationships and the Collateral Benefits of Practising MSM Development in Bangkok}

There exists in many places a wide and porous zone where multiple meanings and cross-cutting social processes construct sexuality. In contrast to this porosity, public health interest in sexuality presents itself as a hard cusp where a particular kind of modern, reified, and biologised concept of sex pushes against other sexualities. In practice, however, what international health interventions produce are frayed and flexible edges where knowledge and practice is transformed. (Pigg, 2005, p. 53)

\section{Introduction}

The excerpt I have taken from Pigg is at the centre of my inquiry into the consequences of MSM development practice. Pigg's notion of "flexible edges" seems to resonate with my own inquiry focussing on margin spaces, the collateral benefits of donor-recipient relations. In this chapter I re-view my thesis, beginning with an examination of its seven key findings. Then, I explore the contents of my thesis chapter-by-chapter. Throughout, I attend to the four questions which guided my study, connecting my chapter findings to these questions. Following this, I discuss the implications of my work on both Queering Development and queer postgraduate re-search. I conclude the chapter by offering spaces for future study in Queering Development and for queer postgraduate re-search more generally.

\section{Key Findings}

- The mainstream development industry has limited engagements with queer sexualities, particularly in policymaking and development theorising. Sexuality itself is often rendered heterosexuality by default.

- Queering Development is a recent challenge to these limited accounts. Queering Development authors have argued for the mainstreaming of diverse 
sexualities/genders within development theorising, policymaking and practice. Yet, in their accounts Queering Development authors tend to offer only theoretical positive possibilities and negative impacts of current work. This leaves the positive work (including multifaceted human rights work) that is already undertaken by local practitioners largely unaccounted for.

- Local practitioners in Bangkok viewed donor-recipient relations as complex and messy sites of constraint and possibility. They positioned donors as having more power over defining the boundaries of these relations.

- Yet, local practitioners also positioned themselves as having significant agency to work toward their own passions and priorities by creating collateral benefits through harnessing the wide potential of existing resources. The collateral benefits already being addressed by local practitioners included: identity work, human rights work, community building, informal advocacy, addressing stigma and discrimination, and so forth.

- Thus, practicing MSM development in Bangkok emerged as a messy field of power, with layers of constraint and enablement, and power to effect change residing with both donors and local practitioners.

- Participants dream of MSM development being otherwise. They see space for interventions in a number of different realms of MSM wellbeing including, health, contextualised interventions, and wider social transformation.

- Postgraduate queeresearchers can carve out alternative spaces within re-search texts to 'work their hyphens' and produce work that feels more authentic to their own voice and politics.

\section{Chapter Summaries}

In Chapter One, I examined the context from which this work emerged. In my (I)rationale I explained the historical and academic moments (Denzin, 1997) that prompted my inquiry. Next, I established the dual focus of my work; to re-position accounts of MSM in development studies and to re-present the potential of queer students who undertake 
postgraduate re-search. I connected these foci by introducing the metaphor of 'the margins'. Then, I described the multiple and layered epistemological frames taken in my research, which included; critical theories (including queer theory), poststructuralism, structuration theory and PAR. I also emphasised the impossibility of fully articulating the ways-of-knowing/being that informed the development of my work, before outlining the plot-line of my thesis.

In my first interlude I began to answer Key Question Four -

4. What authentic and healing alternatives exist for approaching thesis re-search, writing and re-presentation?

I started by offering an explanation of why an alternative approach to re-search and representation was necessary. I explained the radical (Schostak and Schostak, 2008) departures from mainstream re-search that inspired me, and placed my own work within traditions of alternative, authentic, and arts-informed research. Next, I made the case for creating a desecr(e)ative space for re-presenting my work. I contended that this form of representation is a political act that aligns with the epistemological frames that guided me. Finally, I charted the development of my journey to and through this project, reflecting on the many 'wounds' that prompted my inquiry and allowing the reader an insight into my will to know Thai queer cultures.

These themes were also examined in the other interludes throughout the thesis, which enabled the two foci of my work to be in dialogue throughout.

In my literature re-view (Chapter Two) I set out to answer Key Question One -

1. How is the domain of 'MSM/queer' sexuality understood in development theories and discourses?

In this chapter I illustrated the limited attention paid to queer sexualities in mainstream development policy and theorizing. I began by examining the gaps in current Development Studies policy/theory. I revealed the poverty of mainstream development approaches to queer sexualities, arguing that sexuality was present in these accounts, yet it was rendered heterosexuality by default. Where the development industry has seen queer sexualities, it has been through negative frames of vision, targeting populations whose behaviour needs 
to be rationally controlled, rather than viewing their sexualities as sources of affirmation, pleasure or love. Next, I examined Queering Development literature itself. I celebrated the contributions Queering Development authors made to the understanding of sexuality in the development industry - particularly appreciating their work on bringing human rights approaches to MSM development work. Then, I examined the gaps within Queering Development. I noted authors limited engagements with the positive outcomes of local development practitioners work, and positioned my study to inquire into this gap. I concluded my literature re-view by underscoring the significance of my work, seeking to centre on the agency of local practitioners to attend to their self-identified goals related to MSM and khon-thîi-mii-khwaam-làak-lăai-thaang-phêet [sexually diverse people] wellbeing.

In Chapter Three "Re-search Design and Methods" I circled back on Key Question Four -

4. What authentic and healing alternatives exist for approaching thesis re-search, writing and re-presentation?

I attended to key question four by explaining how Pelias' (2004) Methodology of the Heart influenced the spirit of my inquiry. I explored how this heartfulness may be seen in the care I took in the interactions with participants, and the hopefully sensitive re-presentations of their accounts. Heartfulness is also evident in my embodied and evocative writing. To conclude the chapter I re-viewed the rigour of my study, sharing the difficulties I faced in rebalancing re-searcher/participant power relations and attending to the ethical heartful core of my thesis.

In Chapter Four "Rainbow Organisations - Establishing Context" I returned to Key Question One,

1. How is the domain of 'MSM/queer' sexuality understood in development theories and discourses?

I addressed this question by situating these discourses within the local context of MSM development organisations in Bangkok. I introduced key Thai language concepts before providing a summary of multiple concerns that khon-thîi-mii-khwaam-làak-lăai-thaangphêet [sexually diverse people] have. This was followed by a history of queer community organising in Thailand followed by detailed introductions of the two organisations I studied 
with; Bangkok Rainbow and Rainbow Sky.

In Chapter Five "Fields of Power/Knowledge" I addressed Key Question Two,

2. How are development relationships experienced and understood by local MSM development practitioners in Bangkok?

To begin to answer this question I acknowledged that as agents, recipients in Bangkok are implicitly involved in sustaining/creating the development system, and actively negotiate to achieve the best outcomes they can. I shared participants' accounts of their donors' priorities, which suggested that donors' privileged sexual health related interventions in Bangkok at the expense of alternative agendas. Next, I examined the structural constraints of donor-recipient relations. I outlined participants understandings of these, and contended that donors do exercise significant power over establishing the boundaries of intervention spaces. Local practitioners, in order to receive resources, must ultimately align their explicit work priorities with the expected outcomes of their current and potential donors. Despite the ascendance of the global rhetoric of 'partnership' (Overton \& Story, 2004) in donor discourses, in interventions with MSM in Bangkok the hegemonic discourses of 'health', 'science' and 'research' seemed to militate against the wider and embodied conceptualisations of development needs that local 'partners' wished to advance.

In Chapter Six, "Re-searching Hidden Spaces" I returned to Key Question Two, and added another layer to the examination above. I argued that while participants may experience donors as having more explicit power in defining the boundaries of funding, local practitioners can work the margins of intervention spaces and create collateral benefits. These collateral benefits are the 'bonuses' of current resources which enable practitioners to address the needs they have identified as priorities for their communities. Next, I explored two case studies which exemplify the prevalence of these collateral benefits. First, I introduced two postcards created by RSAT which could be read in multiple ways, but were funded through instrumental sexual health resources. Second, I explored a RSAT peer education camp. I maintained that, despite its funded intent of sexual health promotion, many other issues were 'worked on' during the camp. Next, I explored some specific collateral benefits of donor resourcing identified by participants. These included identity 
'work' that took the debate beyond the notion of 'globalising gay', community building, visibility and sexual and human rights concerns. By advancing a more substantial view of the agency of local practitioners I departed from existing Queering Development accounts which emphasise donors power.

In Chapter Seven "It's More Complex than that!" I attended to Key Question Three,

3. What can the perspectives of MSM development practitioners in Bangkok offer to the development field's understandings of, and interventions into queer sexualities more broadly?

I did this by registering some of the messy, dynamic and debatable donor-recipient spaces which reveal many layers of enablement and constraint. I argued that the analysis of these relations is best situated to a particular context. I offered an alternative view of practicing MSM development, illustrating spaces where donor-recipient relations were mediated by both structure and agency.

In Chapter Eight I also attended to Key Question Three. This chapter was titled "Diverse Dreams of Bangkok". This was an opportunity to depart from what is to register local perspectives of what could be. I shared the varied dreams of seven participants in my research. Their dreams presented several ways forward for MSM development funding and practice in Bangkok, going beyond sexual health, approaching MSM development as contextualised within "a circle of life" (Miao, 2009 pers. comm., June). Dreams included ending stigma and discrimination; psychological wellbeing; changing legal structures; reconising the importance of love and intimacy; new networks for action; khon-thîi-miikhwaam-làak-lăai-thaang-phêet [sexually diverse people] political representation; and work on human rights, amongst others.

\section{Implications for Queering Development}

The observations above raise important questions for how local practitioners experiences are framed in Queering Development writing. If local MSM development practitioners continue to be portrayed as passive victims of an unkind development industry, it will continue to be difficult for knowledge about the agency and collateral benefits of existing 
MSM development to be shared. Sharing these impacts is important because they could act as catalysts for growing more contextualised interventions in the future. Furthermore the existing capacities of organisations to undertake, for example, human rights 'work' should be better understood, and consequently invested in. However, in making knowledge of hidden spaces known, Queering Development authors must be mindful not to out the contextualised work of local practitioners to unwilling donors. While the participants in this particular work noted their donors did not obstruct the 'extra' work they do in, for example, legal change, this does remain a real possibility.

My work has shown that studying both the structural inequalities in donor-recipient power relations and their unseen (and possibly agentic) implications provides for a more nuanced understanding of Queering Development. In simplifying the donor-recipient relationship and overemphasising the failures of development Queering Development fails to account for the spaces of agency that these interventions create. The spaces where opportunities are realised, and communities are born. It is this understanding, of practitioners as both active agents and constrained subjects, which will hopefully encourage Queering Development authors to emphasise not only what actors in the 'global North' are not doing, but also the positive work that local practitioners are achieving. It seems pertinent to point out here that understanding the local articulations of the development industry, that is, studying them from temporally and spatially located positions, offers rich accounts that are grounded in the life-worlds of real development practitioners. As a result these accounts can provide practical solutions for future action. Grounding work in the local context also allows for the proliferation of voices on development's engagement with queer sexualities.

It is of vital importance that I re-affirm that I do not claim to have uncovered the 'Truth' about practising MSM development in Thailand. Rather, I hope to have illuminated the similarities and contradictions of particular practitioners' experiences and understandings of MSM development practise in Bangkok. This study is a small-scale qualitative account that is located in a particular time and place. It should not be understood as a survey of MSM development practise in Thailand, as many participants underlined the great differences in practice between rural and urban regions, and Bangkok (as comparatively well-resourced mega-city) and other cities in Thailand. While Bangkok is the focus of this re-search, I hope 
that the complexities I have raised will be more generally relevant to discussions on the international relationship between the development field and queer sexualities.

\section{Implications for future postgraduate Queeresearch}

The observations above also connect to the implications for postgraduate queeresearch. If queer students are unable to register authentic queer perspectives in writing theses, it seems unlikely that they will be able to undertake queeresearch in a way that aligns with a queer epistemological frame. My experience suggests that to undertake re-search which approaches participants as embodied agents with valuable insights, re-searchers must also appreciate their own ways-of-knowing and doing re-search. For queeresearchers this may mean celebrating their queeresearcher subjectivity. My work has also shown that queeresearch can act as an invaluable personal healing process. Through engaging with the stories of queer participants re-searchers may be able to view their hiz-stories in a new light, as margin-spaces of strength and power.

Importantly, claiming space to write about local MSM development practitioners and my own experience of postgraduate queeresearch is a political act. It has not only been personally productive, but has deepened the analysis of my work. In keeping with the alternative approach to re-presentation I have favoured throughout this re-search I have chosen to finish this section with a poem. 
Being a queeresearcher

Is some kind of power

It is not being mute

Now, I taste words

Spit some out

Savour my own sweet lingo

I do have a voice

I sing from the wound that is my mouth ${ }^{66}$

I have re-searched

Stories I couldn't read

In white page gutters

I'm learning

When healing stops

And pain begins

Watering my beans

Laughing with my whānau

I am taking care

In nurturing my-selves

I am better able to connect, to share

And from where I stand

That is the point

As far as I can see...

${ }^{66}$ Weems (2001) 


\section{Key areas for future re-search:}

- Exploring on a broader scale the different ways that local MSM development practitioners negotiate donor-recipient relations; and how such negotiations are viewed by their donors, and their local communities.

- Investigating how widespread collateral benefits are to MSM development practice.

- Examining how positive human rights to safe and pleasurable sexualities can be (or are being) implemented by local practitioners, with or without funding from donors.

- Re-searching the particular development needs expressed by khon-thîi-mii-khwaamlàak-lăai-thaang-phêet [sexually diverse people] through ethnographic inquiry.

- Asking whether scientific knowledge is 'simplified' or even 'misleading' in MSM development interventions to achieve desired behavioural changes.

- Questioning to what extent sexuality has become a test of 'modernity' in developing countries? Asking whether discourses such as 'GLBT' have become an indicator of a so-called developed society.

- Looking into the experiences of groups who are left out of developing MSM sexuality projects in Bangkok. Including children and young people who still have rights to safe sexuality education. ${ }^{67}$

- Inquiring into the tension between donor (and recipient) desires to see organisations professionalise, and comply with Western concepts of management and accountability, and organisations perceived need to retain their authenticity with their members and communities? Do the management discourses, which are required by donors, alter or interfere with local ways of managing local queer communities?

- Discovering how queeresearch interactions can be used as healing spaces, for both participants and re-searchers.

- Inquiring into the use of 'dreaming' as a critical tool for emancipatory queer research.

\footnotetext{
${ }^{67}$ Here, I am referring to the rights of children and young people sexual health information and technologies. Often donors are reluctant to fund projects that work with young people, despite their vulnerability in certain contexts, for example young people in detention homes or boarding schools.
} 
- Producing autoethnographic accounts of postgraduate queeresearch journeys to inform institutions and supervisors in particular, about support systems for queer students.

\section{Final Re-flections}

As Mani Mitchell said: (2009, pers. comm., May)

the journey

the ripples continue...

The accounts, materials and analyses offered in this work will, I hope, inform how local MSM development practitioners are conceived in future Queering Development literature; and advance the continued study of queer postgraduate re-search more generally. As I outlined in my first Interlude the 'success' of my re-search sits not in the 'Truth' of what was offered, but in whether or not the reader was moved by the words and images it contains. Throughout this re-search I have felt angry, perplexed, proud, sad, joyous, inspired. I hope that I have been able to evoke these emotional responses with the reader as they experience this text. Finally, if this work has helped you think about development in a new way, or if it has touched you, made you feel for the participants and the author, then I have succeeded in what I set out to accomplish. 


\section{Epilogue - Practising Queer Development}

I am sitting in my office at the Otago University Students Association Student Support Centre. I glance out the window and see the vibrant mural outside created by students featuring the queer support motif. I am surrounded by queer objects. The vase full of flowers that I cadge from the gardens at university. My home made pot pourri. Colourful posters loudly proclaiming the necessity of public queer desire grace the walls. My friends Ros and Heidi appear on one of the posters and stand defiant, declaring their love. These are the things questioning/queer students notice as they enter this space. I welcome them into my office and leave to make us a pot of tea, allowing them to be alone with the posters, to read and re-read the images, to begin to feel safe to talk about things held close.

Working as OUSA Queer Support Coordinator has enabled me to experience some of the themes that I have explored in this thesis. Here, I do not wish to minimise the significant differences in context (the legal, socio-cultural, economic environment) between my practice and that of my participants. Instead, I wish to reflect on some of the similarities between my work in Otago and their work in Bangkok. Like my participants my part-time position has extremely limited funding, and (officially) has a narrower scope than I desire, with a stated emphasis on referring students to alternative support. Yet, through the existence of the position, the hours I am paid to support queer students I have also been able to leverage collateral benefits that were not anticipated by my managers. I have been able to initiate a network of queer friendly staff, a weekly student support group, a participatory community art project, run awareness raising events as well as meeting high school age students, youth workers and providing support (both online and in person) to non-student members who still form a part of our wider Dunedin queer/questioning community. We have been able to start conversations about the desirability and limitations of given identities, and build a community of active and engaged queer students.

Like my participants, I do more than I am paid to do. However I could not work on these alternative priorities without the resources that the position enables; the cell phone full of numbers, the inbox full of addresses, the friends and volunteers who make ideas possible, 
the resources in our community library, the boardroom that functions as an afterhours meeting place for our local trans group as well as the occasional queer youth movie night. All of these resources have impacts far beyond the utility that it was ever imagined they would have, and it is through practicing queer community development that these opportunities are realized. I reflect on this fact and smile, knowing that the creativity of practitioners of queer development is a defence against attempts to contain our efforts at wider social change. With small gaps we can carve out wide spaces.

I am reminded of Rainbow Sky, and the origin of their name. After this period of rain, it sees a change so fundamental to society, that the rainbow no longer has its place in the corner of the landscape. Instead, the whole sky has been altered, creating room for the celebration of all kinds of diversity. I am hopeful that the small gaps that currently exist in Bangkok will open into wide spaces, so that this dream is realized. 


\section{List of references}

Adams, S., \& Pigg, V. (2005). Introduction: The moral object of sex. In S. Adams \& V. Pigg (Eds.), Sex in development: Science, sexuality, and morality in global perspective (pp. 138). Durham: Duke University Press.

Adams, S. (2005). Globalizing the facts of life. In S. Adams \& V. Pigg (Eds.), Sex in development: Science, sexuality, and morality in global perspective (pp.39-66). Durham: Duke University Press.

Alsop, R., Fitzsimons, A., \& Lennon, K. (2002). Theorizing Gender. Cambridge: Polity Press. Altman, D. (1995). The new world of 'gay' Asia. In S. Perera (Ed.), Asian and Pacific inscriptions (pp.121-138). Melbourne: Meridien Books.

Altman, D. (1997). Global gaze/global gays. GLQ: A Journal of Lesbian and Gay Studies, 3(4), 417-436.

Appadurai, A. (1996). Modernity at large: Cultural dimensions of globalisation. Minneapolis, MN: University of Minnesota Press.

Armas, H. (2007). Whose sexuality counts? Poverty, participation and sexual rights. IDS Research Summary of IDS Working Paper, from http://www.ids.ac.uk/index.cfm?objectid=A9718059-C51A-7599-390F3AEF8EF0A017

Bedford, K., \& Jakobsen, J. R. (2009). Toward a vision of sexual and economic justice, from http://www.barnard.edu/bcrw/newfeministsolutions/reports/NFS4$\underline{\text { Sexual Economic Justice.pdf }}$

Behar, R. (1996). The vulnerable observer: Anthropology that breaks your heart. Boston: Beacon Press.

Bentz, V., \& Shapiro, J. (1998). Mindful inquiry in social research. London: Sage Publications. Bergeron, S. (2000). Moving off the straight path in economic development policy. Toward a vision of sexual and economic justice, from www.barnard.edu/crow/justice/papers/bergeron.pdf

Berry, W. (1987). The collected poems of Wendell Berry, 1957-1982. Berkley, CA: North Point Press. 
Bingham, N. (2003). Writing reflexively. In M. Pryke, G. Rose \& S. Whatmore (Eds.), Using social theory (pp. 145-162). London: Sage Publications.

Binnie, J. (1997). Coming out of geography: Towards a queer epistemology? Environment and Planning D: Society and Space, 15(2), 223-227.

Bishop, R. (1996). Whakawhanaungatanga: Collaborative research stories. Palmerston North: Dunmore Press.

Bochner, A., \& Ellis, C. (Eds.). (2002). Ethnographically speaking: Autoethnography, literature and aesthetics. Walnut Creek, CA: AltaMira Press.

Bridgman, K. (2000). Rhythms of awakening: Re-membering the her-story and mythology of women in medicine. Unpublished doctoral thesis, University of Western Sydney, Hawkesbury.

Britzman, D. (1998). Lost subjects, contested objects: Toward a psychoanalytic inquiry of learning. Albany, NY: State University of New York Press.

Bulldagger, R. (2006). The end of genderqueer? In M. B. Sycamore (Ed.), Nobody passes: Rejecting the rules of gender and conformity (pp.137-148). Emeryville: Seal Press.

Burford, J., Clark, S., Hammonds, J., \& Morton, K. (2008). Steps to success: Exploring educational support for Somali secondary school students in Wellington. Wellington: Victoria University of Wellington.

Chalmers, S. (2002). My queer career: Coming out as a 'researcher' in Japan. Intersection: Gender, History and Culture in the Asian Context, 7, from http://intersections.anu.edu.au/issue7/chalmers.html

Chambers, R. (1997). Whose reality counts? Putting the last first. London: Intermediate Technology Publications.

Cohen, L. (2005). The Kothi wars: AIDS, cosmopolitanism and the morality of classification. In S. Adams \& V. Pigg (Eds.), Sex in development: Science, sexuality, and morality in global perspective (pp. 269-303). Durham: Duke University Press.

Cole, A. L., \& Knowles, J. G. (2008). Arts-informed research. In J. G. Knowles \& A. L. Cole (Eds.) Handbook of the arts in qualitative research: Perspectives, methodologies, examples, and issues (pp. 55-70). Thousand Oaks, CA: Sage. 
Conquergood, S. (1991). Rethinking ethnography: Towards a critical cultural politics. Communication Monographs, 58(2), 179-194.

Cornwall, A., Corrêa, S., \& Jolly, S. (Eds.). (2008). Development with a body: Sexuality, human rights and development. London: Zed Books.

Cornwall, A., Corrêa, S., \& Jolly, S. (2008). Development with a body: Making the connections between sexuality, human rights, and development. In A. Cornwall, S. Corrêa \& S. Jolly (Eds.), Development with a body: Sexuality, human rights and development (pp. 1-21). London: Zed Books.

Cornwall, A., \& Jolly, S. (2006). Introduction: Sexuality matters. IDS Bulletin, 37(5), 1-11.

Cornwall, A., \& Jolly, S. (2007). Realising sexual rights. Brighton: IDS.

Cornwall, A., \& Jolly, S. (2009). Sexuality and the development industry. Development, 52(1), 5-12.

Corrêa, S., \& Jolly, S. (2006). Sexuality, development, and human rights. Paper commissioned for the Swedish Ministry of Foreign Affairs Expert Group on Development Issues workshop "Sexual Rights, Development and Human Rights: Making the Linkages".

Corrêa, S., \& Jolly, S. (2008). Development's encounter with sexuality: Essentialism and beyond. In A. Cornwall, S. Corrêa \& S. Jolly (Eds.), Development with a body: Sexuality, human rights and development (pp. 22-44). London: Zed Books.

Corrêa, S., \& Parker, R. (2004). Sexuality, human rights and demographic thinking: Connections and disjunctions in a changing world. Sexuality, Research and Social Policy, 1(1), 15-38.

Crossley, N. (1996). Intersubjectivity: The fabric of social becoming. London: Sage Publications.

Culler, J., \& Lamb, K. (2003). Introduction: Dressing up, dressing down. In J. Culler \& K. Lamb (Eds.), Just being difficult? Academic writing in the public arena (pp. 1-14). Stanford: Stanford University Press.

Cupples, J. (2002). The field as a landscape of desire: Sex and sexuality in geographical fieldwork. Area, 34(4), 382-390.

Deitch, J., Sirmans, F., \& Vassell, N. (2007). Jean-Mitchel Basquiat 1981: The studio of the street. Milano: Edizioni Charta. 
Denton, D. (2006). Re-imagining the wound: Of innocence, sacrifice \& gift. In W. Ashton \& D. Denton (Eds.), Spirituality, ethnography and teaching: Stories from within (pp. 131139). New York: Peter Lang.

Denzin, N. (1997). Interpretive ethnography: Ethnographic practices for the 21st century. Thousand Oaks, CA: Sage Publications.

Denzin, N. (2003). The practices and politics of interpretation. In N. Denzin \& Y. Lincoln (Eds.), Collecting and interpreting qualitative materials (pp. 458-498). Thousand Oaks, CA: Sage Publications.

Denzin, N., \& Lincoln, Y. (2000). The discipline and practice of qualitative research. In N. Denzin \& Y. Lincoln (Eds.), Handbook of qualitative research (2nd ed., pp. 1-32). Thousand Oaks, CA: Sage Publications.

Denzin, N., \& Lincoln, Y. (2008). Preface. In N. Denzin, Y. Lincoln \& L. T. Smith (Eds.), Handbook of critical and indigenous methodologies (pp. ix-xv). Los Angeles: Sage Publications.

Denzin, N., \& Lincoln, Y. (2008). Introduction: Critical methodologies and indigenous inquiry. In N. Denzin, Y. Lincoln \& L. T. Smith (Eds.), Handbook of critical and indigenous methodologies (pp. 1-20). Los Angeles: Sage Publications.

Denzin, N., Lincoln, Y., \& Smith, L. T. (Eds.). (2008). Handbook of critical and indigenous methodologies. Los Angeles: Sage Publications.

DeSalvo, L. (2000). Writing as a way of healing: How telling stories transform our lives. Boston: Beacon Press.

Doezema, J. (2000). Ouch! Feminists' 'wounded attachment' to the 'third world sex prostitute'. Feminist Review, 67(Spring), 16-38.

Donmoyer, R., \& Donmoyer, J. (2008). Readers' theatre as a data display strategy. In J. G. Knowles \& A. L. Cole (Eds.), Handbook of the arts in qualitative research: Perspectives, methodologies, examples, and issues (pp. 209-224). Thousand Oaks, CA: Sage Publications.

Duggan, L. (1995). Queering the state. Social Text, 39(Summer), 1-14.

Duggan, L. (1995). Making it perfectly queer. In L. Duggan \& N. Hunter (Eds.), Sex wars (pp. 155-172). New York: Routledge.

Duggan, L. (1995). Scholars and sense. In L. Duggan \& N. Hunter (Eds.), Sex wars (pp. 173179). New York: Routledge. 
Dyck, I., \& Kearns, R. A. (2006). Structuration theory: Agency, structure and everyday life. In S. Aitken \& G. Valentine (Eds.), Approaches to human geography (pp. 86-96). London: Sage Publications.

Ellis, C., \& Bochner, A. (1992). Telling and performing personal stories: The constraints of choice in abortion. In C. Ellis \& M. Flaherty (Eds.), Investigating subjectivity (pp. 79101). Newbury Park: Sage Publications.

Esiet, A. O. (2008). Sexuality education as a human right: Lessons from Nigeria. In A. Cornwall, S. Corrêa \& S. Jolly (Eds.), Development with a body: Sexuality, human rights and development (pp. 187-198). London: Zed Books.

Feinberg, L. (1996). Transgender warriors: Making history from Joan of Arc to Denis Rodman. Boston: Beacon Press.

Fine, M. (1994). Working the hyphens: Reinventing the self and other in qualitative research. In N. Denzin \& Y. Lincoln (Eds.), Handbook of qualitative research (pp. 7082). Thousand Oaks, CA: Sage Publications.

Foucault, M. (1972). The archaeology of knowledge (A. M. Sheridan Smith, Trans.). New York: Pantheon Books.

Foucault, M. (1978). The history of sexuality: An introduction (R. Hurley, Trans.). New York: Pantheon Books.

Four Arrows (aka Don Trent Jacobs) (2008). The authentic dissertation: Alternative ways of knowing research and representation. Oxon: Routledge.

Frank, A. (1995). The wounded storyteller. Chicago: University of Chicago Press.

Frühstück, S. (2003). Colonizing sex: Sexology and social control in modern Japan. Berkley: University of California Press.

Galvin, M. (1999). Queer poetics: Five modernist women writers. Westport, CT: Greenwood Press.

Gemmerli, T. (2009). Queering development - Incorporating sexuality: The problem of heteronormativity in the development paradigm. Retrieved 17 October 2010: http://www.ulandslaere.au.dk/Opgavestof/SampleStudentPapers/PaperCollection/Qu eeringDevelopment IncorporatingSexuality TobiasGemmerli.pdf

Gergen, M., \& Gergen, K. (2002). Ethnographic representation as relationship. In A. Bochner \& C. Ellis (Eds.), Ethnographically speaking: Autoethnography, literature and aesthetics (pp. 11-34). Walnut Creek, CA: AltaMira Press. 
Giddens, A. (1984). The constitution of society: Outline of the theory of structuration. Cambridge: Polity Press.

Gosine, A. (2004). Sex for pleasure, rights to participation, and alternatives to AIDS: Placing sexual minorities and/or dissidents in development. Brighton: Institute for Development Studies.

Gosine, A. (2006). 'Race, culture, power, sex, desire, love: Writing in 'Men who have sex with men". IDS Bulletin, 37(5), 27-33.

Gray, R., Ivonoffski, V., \& Sinding, C. (2002). Making a mess and spreading it around: Articulation of an approach to research-based theater. In A. Bochner \& C. Ellis (Eds.), Ethnographically speaking: Autoethnography, literature and aesthetics (pp. 57-75). Walnut Creek, CA: AltaMira Press.

Gust, A., Lovaas, K., \& Elia, J. (2003). Queer theory and communication: From disciplining queers to queering the discipline(s). Binghampton: Harrington Park Press.

Halberstam, J. (2004). Gender flex. In R. Swan (Ed.), Assume nothing (pp. 24-27). Grey Lynn: Boy Tiger Press.

Halpin, Z. (1989). Scientific objectivity and the concept of "the other". Women's Studies International Forum, 12(3), 285-294.

Hammers, C., \& Brown, A. D. (2004). Towards a feminist-queer alliance: A paradigmatic shift in the research process. Social Epistemology, 18(1), 85-101.

Hesse-Biber, S., \& Leavy, P. (2006). The practice of qualitative research. Thousand Oaks, CA: Sage Publications.

Hinojosa, C. (2009). Challenging an old (and false) dilemma: Economic (and sexual) justice revisited. Toward a vision of sexual and economic justice: www.barnard.edu/bcrw/justice/papers/hinojosa.pdf

Hoad, N. (1998). Tradition, modernity and human rights: An interrogation of contemporary gay and lesbian rights' claims in Southern African nationalist discourses. Development Update, 2(2), 32-43.

Hoggart, K., Lees, L., \& Davis, A. (2002). Close encounters: Interviews and focus groups. In K. Hoggart (Ed.), Researching human geography (pp. 201-250). London: Arnold.

hooks, b. (1990). Yearning: Race, gender and cultural politics. Boston: South End Press. hooks, b. (1993). Sisters of the yam: Black women and self-recovery. Boston: South End Press. 
hooks, b. (1996). Bone black: Memories of girlhood. New York: Henry Holt and Company. hooks, b. (1997). Wounds of passion: A writing life. New York: Henry Holt and Company. Hunt, P. (2008). Forward. In A. Cornwall, S. Corrêa \& S. Jolly (Eds.), Development with a body: Sexuality, human rights and development (pp. xi-xiv). London: Zed Books.

Ikkaracan, P., \& Jolly, S. (2007). Gender and sexuality: Overview report. Sussex: BRIDGE. Ivers, L. (2010). South-south collaboration in scale up of HIV care: Building capacity for care. AIDS, 24, 73-78.

Jackson, M. (1987). "Facts of life" or the eroticization of women's oppression? Sexology and the social construction of heterosexuality. In P. Caplan (Ed.), The cultural constructions of sexuality (pp. 52-81). London: Tavistock.

Jackson, P. (1997). Thai research on male homosexuality and transgenderism and the cultural limits of Foucaultian analysis. Journal of the History of Sexuality, 8(1), 52-85.

Jackson, P. (2000). Studies of Rates of Same-Sex Sexual Experience in Thailand. In P. Jackson \& G. Sullivan (Eds.), Lady boys, tom boys, rent boys: Male and female homosexualities in contemporary Thailand (pp. 28-59). Chiang Mai: Silkworm Books.

Jackson, P. (2001). Pre-gay, post-queer: Thai perspectives on proliferating gender/sex diversity in Asia. Journal of Sexuality, 40(3-4), 1-25.

Jackson, P. (2003). Performative genders, perverse desires: A bio-history of Thailand's samesex and transgender cultures. Intersections: Gender, History \& Culture in the Asian Context, (9). Retrieved from http://intersections.anu.edu.au/issue9/jackson.html Jackson, P. (2009). Global queering and global queer theory: Thai [trans]genders and [homo]sexualities in world history. Autrepart, 49, 15-30.

Jackson, P. (2010). The ambiguities of semicolonial power in Thailand. In P. Jackson \& R. Harrison (Eds.), The ambiguous Allure of the West (pp. 37-56). Hong Kong: Hong Kong University Press.

Jackson, P., \& Sullivan, G. (Eds.). (2000). Lady boys, tom boys, rent boys: Male and female homosexualities in contemporary Thailand. Chiang Mai: Silkworm Books.

Jackson, P., \& Sullivan, G. (2000). A panoply of roles: Sexual and gender diversity in contemporary Thailand: Introduction. In P. Jackson \& G. Sullivan (Eds.), Lady boys, tom 
boys, rent boys: Male and female homosexualities in contemporary Thailand (pp. 127). Chiang Mai: Silkworm Books.

Jolly, S. (2000a). Queering development: Exploring the links between same-sex sexualities, gender and development. Gender and Development, 8(1), 78-88.

Jolly, S. (2000b). What use is queer theory to development? Paper presented at the The IDS/Sussex University Seminar Series.

Kearns, R. (2005). Knowing seeing? Undertaking observational research. In I. Hay (Ed.), Qualitative research methods in human geography (2nd ed., pp. 192-206). Melbourne: Oxford University Press.

Kleitz, G. (2000). Why is development work so straight? Paper presented at the The Queering Development Seminar Series, The Institute of Development Studies, University of Sussex.

Kole, S. (2007). Globalizing queer? AIDS, homophobia and the politics of sexual identity in India. Global Health, 3(8), 1-16.

Leggo, C. (2004). The poet's corpus: Nine speculations. JCT: Journal of Curriculum Theorizing, 20(2), 65-86.

Leggo, C. (2006a). Attending to winter: A poetics of research. In W. Ashton \& D. Denton (Eds.), Spirituality, ethnography and teaching: Stories from within (pp. 140-155). New York: Peter Lang.

Leggo, C. (2006b). End of the line: A poet's postmodern musing on writing. English Teaching: Practice and Critique, 5(2), 69-92.

Lind, A., \& Share, J. (2003). Queering development: Institutionalized heterosexuality in development theory, practice and politics in Latin America. In K.-K. Bhavnani, J. Foran \& P. Kurian (Eds.), Feminist futures: Re-imagining women, culture and development (pp. 55-73). New York: Zed Press.

Lorde, A. (1980). The cancer journals. San Francisco: Aunt Lute Books.

Madison, S. (1999). Performing theory: Embodied writing. Text and Performance Quarterly 19, 107-124.

Manning, E. (2009). Queerly disrupting methodology. Paper presented at the The Celebrating Graduate Scholarship Conference, University of Victoria, Victoria, Canada. Mathuray, M. (2000). On the (African) national question: Sexuality and tradition. Paper presented at the Queering Development Seminar Series, University of Sussex. 
Mehta, M. (1991). Gender, development and culture. In T. Wallace \& C. March (Eds.), Changing perceptions: Writings on gender and development (pp. 286-288). Oxford: Oxfam.

Moore, D. (1999). The crucible of cultural politcs: Reworking "development" in Zimbabwe's eastern highlands. American Ethnologist, 26(3), 654-689.

Munt, S., \& Medhurst, A. (1997). Lesbian and gay studies: A critical introduction. London: Cassell.

Murray, A., \& Robinson, T. (1996). Minding your peers and queers: Female sex workers in the AIDS discourse in Australia and South-east Asia. Gender, Place \& Culture: A Journal of Feminist Geography, 3(1), 41-45.

Neilsen, L. (2008). Lyric inquiry. In J. G. Knowles \& A. L. Cole (Eds.), Handbook of the arts in qualitative research: Perspectives, methodologies, examples, and issues (pp. 93-102). Thousand Oaks, CA: Sage Publications.

Nguyen, V. (2005). Uses and pleasures: Sexual modernity, HIV/AIDS, and confessional technologies in a West African metropolis. In S. Adams \& V. Pigg (Eds.), Sex in development: Science, sexuality, and morality in global perspective (pp. 245-267). Durham: Duke University Press.

Nussbaum, M. (2000). Women and human development: The capabilities approach. Cambridge: Cambridge University Press.

Ojanen, T. (2009). Sexual/gender minorities in Thailand: Identities, challenges, and voluntary-sector counseling. Sexuality Research and Social Policy, 6(2), 4-34.

Ojanen, T. (2010). Mental health services and sexual/gender minority clients in Bangkok, Thailand: Views by service users and service providers. Unpublished Master's Thesis, Assumption University, Bangkok.

Overton, J., \& Story, D. (2004). Aid and partnerships: The effectiveness of relationships. Development Bulletin, 65, 41-45.

Parker, R., \& Aggleton, P. (1999). Introduction. In R. Parker \& P. Aggleton (Eds.), Culture, society and sexuality: A reader (pp. 1-9). Oxon: Routledge.

Parker, R., Barbosa, R., \& Aggleton, P. (Eds.). (2000). Framing the sexual subject: The politics of gender, sexuality, and power. Berkeley: University of California Press.

Parker, R., \& Gagnon, J. (1995). Concieving sexuality: Approaches to sex research in a postmodern world. New York: Routledge. 
Pavlenko, A. (2002). Narrative study: Whose story is it anyway? TESOL Quarterly, 36(2), 213218.

Pelias, R. (1999). Writing performance: Poeticizing the researcher's body. Carbondale: Southern Illinois University Press.

Pelias, R. (2002). For father and son: An ethnodrama with no catharsis. In A. Bochner \& C. Ellis (Eds.), Ethnographically speaking: Autoethnography, literature and aesthetics (pp. 35-43). Walnut Creek, CA: AltaMira Press.

Pelias, R. (2004). A methodology of the heart: Evoking academic and daily life. Walnut Creek, CA: AltaMira Press.

Pelias, R. (2006). Negotiating spirit. In W. Ashton \& D. Denton (Eds.), Spirituality, ethnography and teaching: Stories from within (pp. 17-29). New York: Peter Lang.

Petchesky, R. (2000). Sexual rights: Inventing a concept, mapping an international practice. In R. Parker, R. Barbosa \& P. Aggleton (Eds.), Framing sexual subject: The politics of gender, sexuality, and power (pp. 81-103). Berkley: University of California Press.

Pigg, S. (2005). Globalising the facts of life. In S. Adams \& V. Pigg (Eds.), Sex in development: Science, sexuality, and morality in global perspective (pp. 39-65). Durham: Duke University Press.

Pigg, S. (1992). Inventing social categories through place: Social representations and development in Nepal. Comparative Studies in Society and History, 34(3), 491-513.

Plummer, K. (1992). Modern homosexualities: Fragments of lesbian and gay experience. London: Routledge.

Plummer, K. (2005). Critical humanism and queer theory: Living with the tensions. In N. Denzin \& Y. Lincoln (Eds.), The Sage handbook of qualitative research (3rd ed., pp. 357373). Thousand Oaks, CA: Sage Publications.

Pryke, M. (2003). Situated audiences. In M. Pryke, G. Rose \& S. Whatmore (Eds.), Using social theory: Thinking through research (pp. 163-180). Thousand Oaks, CA: Sage Publications.

Rich, A. (1994). Blood, bread, and poetry: Selected prose. New York: W. W. Norton \& Company.

Richardson, L. (1992). The consequences of poetic representation: Writing the other, rewriting the self. In C. Ellis \& M. Flaherty (Eds.), Investigating subjectivity (pp. 125140). Newbury Park, CA: Sage Publications. 
Richardson, L. (1997). Fields of play: Constructing and academic life. New Brunswick, NJ: Rutgers University Press.

Richardson, L. (2000). Writing: A method of inquiry. In N. Denzin \& Y. Lincoln (Eds.), Handbook of qualitative research (2nd ed., pp. 923-949). Thousand Oaks, CA: Sage Publications.

Richardson, L. (2000). Skirting a pleated text. In E. St. Pierre \& W. Pillow (Eds.), Working the ruins: Feminist poststructural theory and methods in education (pp. 153-163). New York: Routledge.

Richardson, L. (2002). The metaphor is the message. In A. Bochner \& C. Ellis (Eds.), Ethnographically speaking: Autoethnography, literature and aesthetics (pp. 372-376). Walnut Creek, CA: AltaMira Press.

Rogers, D., Frellick, P., \& Babinski, L. (2002). Staging a study: Performing the personal and professional struggles of beginning teachers. In C. Bagley \& M. B. Cancienne (Eds.), Dancing the data (pp. 53-69). New York: Peter Lang.

Runeborg, A. (2008). Sexuality: A missing dimension in development. from Sida Department of Democracy and Social Development: http://www.sida.se/shared/isp/download.jsp?f=SIDA45003en Sexuality+A+Missing+D imension+in+Development webb.pdf\&a $=40003$

Rutherford, B., \& Nyamuda, R. (2000). Learning about power: Development and marginality in an adult literacy center for farm workers in Zimbabwe. American Ethnologist, 27(4), 839-854.

Samelius, L., \& Wagberg, E. (2005). Sexual orientation and gender identity issues in development: A study of Swedich policy and administration of lesbian, gay, bisexual and transgender issues in international development corperation: Sida Health Division.

Schostak, J., \& Schostak, J. (2008). Radical research. Oxon: Routledge.

Sedgwick, E. (1990). The epistemology of the closet. Berkley: University of California Press. Sen, A. (1999). Development as freedom. Oxford: Oxford University Press.

Singh, N. P. (2008). South-south cooperation: Another regional cooperative movement or a new path way for the sustained development of the third world? Paper presented at the ISA 49th Annual Convention (Bridging divides), San Francisco.

Sinnot, M. (2004). Toms and dees: Trangender identity and female same-sex relationships in Thailand. Honolulu: University of Hawai'i Press. 
Skelton, T. (2001). Cross-cultural research: Issues of pwer, positionality and 'race'. In M. Limb \& C. Dwyer (Eds.), Qualitative methodologies for geographers: Issues and debates (pp. 87-100). London: Hodder Arnold Publication.

Smith, L. T. (1999). Decolonizing methodologies: Research and indigenous peoples. Dunedin: University of Otago Press.

Sparkes, A. (2002). Telling tales in sport and physical activity: A qualitative journey. Champaign, IL: Human Kinetics.

Tan, M. L. (2000). AIDS, medicine, and moral panic in the Philippines. In R. Parker, R. Barbosa \& P. Aggleton (Eds.), Framing the sexual subject: The politics of gender, sexuality, and power (pp. 143-164). Berkley: University of California Press.

Tang, D. T. S. (2006). The research pendulum: Multiple roles and responsibilities as a researcher. Journal of Lesbian Studies, 10(3/4), 11-27.

Taylor, K., Durant, R., \& Boje, D. (2007). Telling the story, hearing the story: Narrative coconstruction and crisis research. American Communication Journal, 9(1). Retrieved from http://acjournal.org/holdings/vol9/spring/articles/co-construction.html

Thrift, N. (2003). Practising ethics. In M. Pryke, G. Rose \& S. Whatmore (Eds.), Using social theory: Thinking through research (pp. 105-121). Thousand Oaks, CA: Sage Publications.

Tsing, A. (2000). The global situation. Cultural Anthropology, 15(3), 327-360.

Vance, C. (Ed.). (1984). Pleasure and danger: Exploring female sexuality. Boston: Routledge \& Kegan Paul.

Wagle, T., \& Cantaffa, D. (2008). Working our hyphens: Exploring identity relations in qualitative research. Qualitative Inquiry, 14(1), 135-159.

Warner, M. (1993). Introduction. In M. Warner (Ed.), Fear of a queer planet: Queer politics and social theory (pp. vii-xxxi). Minneapolis: University of Minnesota Press.

Weeks, J. (1985). Sexuality and its discontents: Meanings, myths and modern sexualities. New York: Routledge.

Weems, M. (2001). I speak from the wound in my mouth. Unpublished doctoral dissertation, University of Illinois at Urbana-Champaign, Urbana-Champaign, IL.

Winter, S. (2006). Thai transgenders in focus: Demographics, transitions and identities. International Journal of Transgenderism, 9(1), 15-27.

Wittig, M. (1992). The straight mind and other essays. Boston: Beacon Press. 
Woolf, V. (1985). Moments of being: Unpublished autobiographical writings. New York: Harcourt Brace Jovanovich. 


\section{Re-searcher Biography}

JAMES BURFORD is a queer activist employed with the Otago University Students Association as queer support coordinator. His past work in the community development sector was with refugees and new migrants in the Canterbury region. He has a Bachelor of Arts in Political Science at Canterbury University. His academic interests are queering development, writing to heal, and que(e)r(y)ing higher education. Toward the end of writing this master's thesis he has been offered a PhD scholarship examining the experiences of queer students undertaking postgraduate re-search. 


\begin{tabular}{l|l}
\hline TO & James Burford \\
\hline COPY TO & Sara Kindon, Supervisor \\
\hline FROM & Dr Allison Kirkman, Convener, Human Ethics Committee \\
\hline DATE & April 24, 2009 \\
\hline PAGES & 1 \\
\hline & $\begin{array}{l}\text { Ethics Approval: No 16464, Developing sexual subjects; development } \\
\text { intervention into queer sexuality in Bangkok, Thailand. }\end{array}$ \\
\hline
\end{tabular}

Thank you for your application for ethical approval, which has now been considered by the Standing Committee of the Human Ethics Committee.

Your application has been approved from the above date and this approval continues until 28 February 2010. If your data collection is not completed by this date you should apply to the Human Ethics Committee for an extension to this approval.

Best wishes with the research.

\section{Allison Kirkman}

Convener 


\section{TE WHARE WĀNANGA O TE ŨPOKO O TE IKA A MĀUI

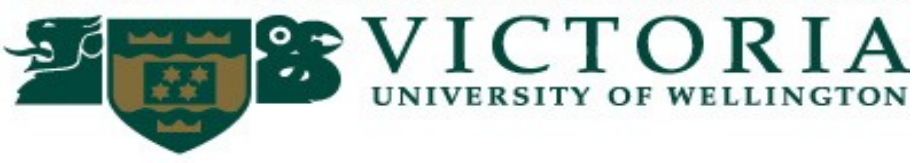 \\ Participant Information Sheet for Developing Sexual Subjects: Development Interventions into Queer Sexuality in Bangkok, Thailand.}

\section{[For 'program clients']}

Researcher: James Burford - School of Geography, Environment and Earth Sciences, Victoria University of Wellington, New Zealand

I am a Master's student in Development Studies at Victoria University of Wellington, New Zealand. As part of this degree I am undertaking research that will lead to a thesis. This research looks at development interventions into sexuality which target queer people/men who have sex with men (MSMs). The research will examine the discourses that operate through these interventions, and possible impacts that they have on the sexual meanings and practices of queer people in Bangkok. It is intended that the research will contribute to further understanding how development interventions engage with sexuality in Bangkok, and how this current engagement could be expanded to include a more multifaceted understanding of sexuality. The University has ethics approval which must be obtained for research involving human participants.

I am carrying out observations with organisations that target queer/MSM people in Bangkok. I will also interview staff or volunteers that work for these organisations and clients, people who use the services of this program, or obtain information from it. The observations will be of the interactions between staff and clients as they undertake their duties. I am also interviewing key informants, people who have done research into, have experience in organising, or deliver services to the different queer cultures of Bangkok.

Some of the interview questions deal with sensitive issues and you may decline to answer any question without reason. Should you feel the need to postpone or end the interview you may do so without question at any stage. Likewise if, for any reason, you decide after the completion of the interview that you do not want any of the information given to be used, let me know and I will destroy it or return it to you.

Your decision to take part, or not take part in this interview will have no impact on your treatment or participation in the programme.

The interview will take approximately 15 minutes and will be one-off, unless we agree at the time that a follow up interview would be beneficial. 
Interview responses will provide specific insights that will be combined with my observational and literature research to form the basis of my thesis. This interview will follow an informal format and will be strictly confidential. Any information you provide will not be able to be traced back to you and interview notes will be kept confidential. No other person beside my supervisor, Sara Kindon, and myself will see the interview notes. Notes will be destroyed two years following the completion of my thesis.

The thesis will be submitted for marking to the School of Geography, Environment and Earth Sciences and deposited in the University Library. A summary of the thesis may be presented at academic or professional conferences and it is intended that one or more articles will be submitted for publication in scholarly journals. In addition, an executive summary will be produced and be made available to all participants.

If you have any questions or would like to receive further information about my research, please contact me at 607 Jirapat Mansion, 35 Ratchaburi Road, Bang Sue, Thailand, or on 0874998015 or from the $7^{\text {th }}$ of July at my postal address in New Zealand, 24 b Silverstream Road Crofton Downs, Wellington 6035, New Zealand, phone: +644792254, email: burforiame@myvuw.ac.nz. You can contact my supervisor, Sara Kindon, at the Department of Geography, School of Geography, Environment and Earth Sciences, Faculty of Science, at Victoria University, P O Box 600, Wellington 6140, New Zealand, phone: +644636194, email: Sara.Kindon@vuw.ac.nz. 


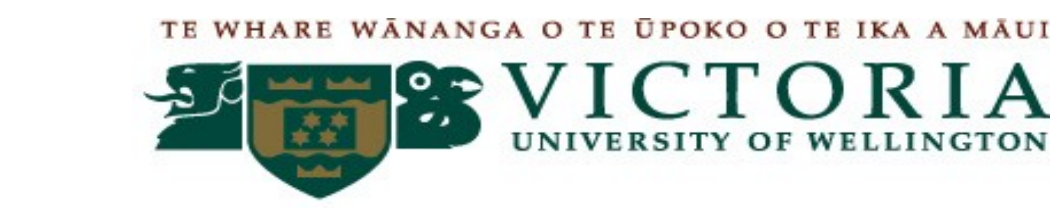

\title{
Participant Information Sheet for Developing Sexual Subjects: Development Interventions into Queer Sexuality in Bangkok, Thailand.
}

\section{[For 'program staff'/ key informants]}

\author{
Researcher: James Burford - School of Geography, Environment and Earth Sciences, Victoria \\ University of Wellington, New Zealand
}

I am a Master's student in Development Studies at Victoria University of Wellington, New Zealand. As part of this degree I am undertaking research that will lead to a thesis. This research looks at development interventions into sexuality which target queer people/men who have sex with men (MSMs). The research will examine the discourses that operate through these interventions, and possible impacts that they have on the sexual meanings and practices of queer people in Bangkok. It is intended that the research will contribute to further understanding how development interventions engage with sexuality in Bangkok, and how this current engagement could be expanded to include a more multifaceted understanding of sexuality. The university has ethics approval that must be obtained for research involving human participants.

I am carrying out observations with organisations that target queer/MSM people in Bangkok. I will also interview staff or volunteers that work for these organisations and clients, people who use the services of this program, or obtain information from it. The observations will be of the interactions between staff and clients as they undertake their duties. I am also interviewing key informants, people who have done research into, have experience in organising, or deliver services to the different queer cultures of Bangkok.

Some of the interview questions deal with sensitive issues and you may decline to answer any question without reason. Should you feel the need to postpone or end the interview you may do so without question at any stage. Likewise if, for any reason, you decide after the completion of the interview that you do not want any of the information given to be used, let me know and I will destroy it or return it to you.

The interview will take approximately 25 minutes and will be one-off, unless we agree at the time that a follow up interview would be beneficial.

Interview responses will provide specific insights that will be combined with my observational and literature research to form the basis of my thesis. This interview will follow a semi-structured format and will be tape recorded unless otherwise requested. You may request that any information you 
provide, including interview notes and tape recordings, will be kept confidential. If this is the case personal pseudonyms will be used for all identifiable information. You may choose the pseudonyms. You may also request to see my interview notes at the completion of the interview. No other person beside my supervisor, Sara Kindon, and myself will see the interview notes or hear the tape recordings. Notes will be destroyed, and tape recordings wiped, two years following the completion of my thesis. Interview transcripts will also be destroyed unless you request that they be returned to you.

The thesis will be submitted for marking to the School of Geography, Environment and Earth Sciences and deposited in the University Library. A summary of the thesis may be presented at academic or professional conferences and it is intended that one or more articles will be submitted for publication in scholarly journals. In addition, an executive summary will be produced and be made available to all participants.

If you have any questions or would like to receive further information about my research, please contact me at 607 Jirapat Mansion, 35 Ratchaburi Road, Bang Sue, Thailand, or on 0874998015 or from the $7^{\text {th }}$ of July at my postal address in New Zealand, 24 b Silverstream Road Crofton Downs, Wellington 6035, New Zealand, phone: +644792254, email: burforjame@myvuw.ac.nz. You can contact my supervisor, Sara Kindon, at the Department of Geography, School of Geography, Environment and Earth Sciences, Faculty of Science, at Victoria University, P O Box 600, Wellington 6140, New Zealand, phone: +644636194, email: Sara.Kindon@vuw.ac.nz. 


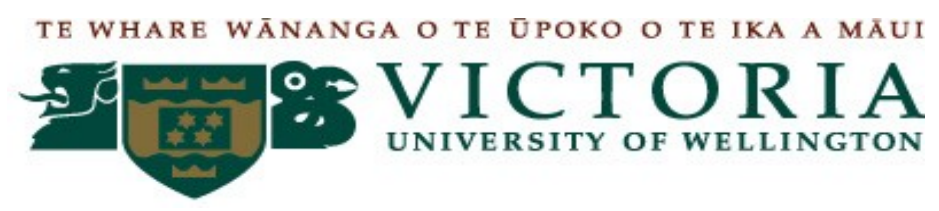

\section{Consent to Participation in Research on Development interventions into sexuality in Bangkok.}

\section{[For 'Program Staff/key informants']}

[Please tick the appropriate box]

Yes

No

\begin{tabular}{|l|l|l|}
\hline $\begin{array}{l}\text { "I have been given and have understood an explanation of this research } \\
\text { project. I have had an opportunity to ask questions and have them answered to } \\
\text { my satisfaction". }\end{array}$ & \\
\hline $\begin{array}{l}\text { "I understand that I may withdraw myself (or any information I have provided) } \\
\text { from this project (before data collection and analysis is complete) without } \\
\text { having to give reasons". }\end{array}$ & & \\
\hline $\begin{array}{l}\text { "I have been given the opportunity to request that specific responses be kept } \\
\text { confidential or not used. I understand that if I withdraw from the project, any } \\
\text { data I have provided will be destroyed". }\end{array}$ & & \\
\hline $\begin{array}{l}\text { "I understand that two years following the completion of the thesis the } \\
\text { information obtained will be destroyed". }\end{array}$ & \\
\hline $\begin{array}{l}\text { "I understand that the information I have provided will be used only for this } \\
\text { research project and academic articles/conference presentations arising from } \\
\text { it, and that any further use will require my written consent". }\end{array}$ & & \\
\hline $\begin{array}{l}\text { "I have been given the opportunity to request that my responses be included } \\
\text { with a pseudonym. I consent to the information or opinions being attributed to } \\
\text { me using the following pseudonym, }\end{array}$ & & \\
\hline $\begin{array}{l}\text { "I would like to receive an executive summary of this research when it is } \\
\text { completed". }\end{array}$ & & \\
\hline "I name of participant) _o take part in this research". & & \\
\hline
\end{tabular}

Signed:

Date: 


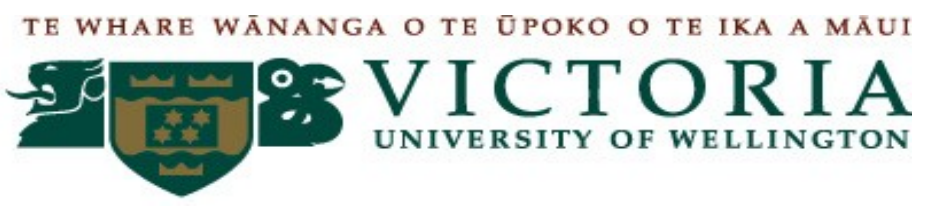

\section{Consent to Participation in Research on Development interventions into sexuality in Bangkok.}

\section{[For 'Program Clients']}

[Please tick the appropriate box]

Yes

No

\begin{tabular}{|l|l|l|}
\hline $\begin{array}{l}\text { "I have been given and have understood an explanation of this research } \\
\text { project. I have had an opportunity to ask questions and have them answered to } \\
\text { my satisfaction". }\end{array}$ & & \\
\hline $\begin{array}{l}\text { "I understand that I may withdraw myself (or any information I have provided) } \\
\text { from this project (before data collection and analysis is complete) without } \\
\text { having to give reasons". }\end{array}$ & & \\
\hline $\begin{array}{l}\text { "I understand that if I withdraw from the project, any data I have provided will } \\
\text { be destroyed". }\end{array}$ & \\
\hline $\begin{array}{l}\text { "I understand that two years following the completion of the thesis the } \\
\text { information obtained will be destroyed". }\end{array}$ & & \\
\hline $\begin{array}{l}\text { "I understand that the information I have provided will be used only for this } \\
\text { research project and academic articles/conference presentations arising from } \\
\text { it, and that any further use will require my written consent". }\end{array}$ & & \\
\hline $\begin{array}{l}\text { "I understand that all responses will be strictly confidential and any information } \\
\text { used will not be able to be attributed to me in any way". }\end{array}$ & & \\
\hline $\begin{array}{l}\text { "I would like to receive an executive summary of this research when it is } \\
\text { completed". }\end{array}$ & \\
\hline $\begin{array}{l}\text { "I (name of participant) } \\
\text { and to take part in this research". }\end{array}$ & \\
\hline
\end{tabular}

Signed:

Date: 


\section{Aide memoires:}

- Personal details:

o name,

o organization,

- age,

- place of birth (urban/rural),

- education,

- role in the organization,

- roles in previous organisations,

- Self identification (if possible) (gender, sex, sexuality).

- Organisational information:

o formation and history,

- collaboration with other organisations,

- targets for the organization- reasons targeted,

- excluded MSM groups or groups who tend not to use the services of the program, eg. class, age, ethnicity, drug users, sex workers, kàthoei.

- Programs run by the organization, how these were developed and by whom.

- Details of funding, what conditionalities are attached,

- Materials, how they were developed, is the organization satisfied with them, client feedback?

- Benefits and drawbacks of working with international donors/domestic donors.

- Organisations understanding of concepts around sex, gender, sexuality, how these are explained by staff and to clients, differences in Western/Thai conceptions, donor concepts.

- How are the messages of the organization framed, amoral, medical, scientific, Thaicultural, faith, pleasure.

- Sexual cultures changing in Bangkok?

- Role of interventions in contributing to change, positives and negatives.

- Awareness of concepts of sexual rights, what these could offer to the Thai context O

When possible I will also undertake informal interviews with clients/participants in the programs. The conversations with clients accessing the services of the projects are likely to be very short, the questions themselves need to be flexible, rather than specific.

\section{Clients:}

- Personal details:

○ name,

o age,

○ place of birth (urban/rural),

- education,

- self identification (if possible) (gender, sex, sexuality).

- Talk about the information/service they received and their perception of it.

- What did they learn, what do they agree/disagree with.

- Will the information they have accessed change their sexual habits or meanings. 


\section{Key informants}

Key informants are not attached to the programs I will be observing. They are people who have key knowledge about queer cultures/communities, and/or development interventions in Bangkok. They may be activists, researchers, journalists, staff of: donors, NGOs or government organisations. I will undertake semi-structured interviews with key informants.

- What is your full name?

- In what year were you born?

- Where were you born? (urban/rural)

- What is the full name of your organization, if any?

- What is your role within the organization?

- What (if any) organizations do you collaborate with?

- Which (if any) other organizations have you worked for?

- What is your educational background?

- Do you self-identify with any classification of sex, gender, sexuality? If so, could you please explain them for me.

- In what ways do concepts of sex/sexuality and gender differ in Thailand, compared to Western understandings?

- What organisations can you think of that are involved in interventions with MSM groups?

- Do you believe there is a need for organisations to intervene in MSMs? Why?

- What groups are targeted? Why?

- What impact may these interventions have? Positive? Negative? - Who is excluded, sex workers, kàthoei, drug users, ethnic groups, different class groups? Power within communities? Women/men?

- In your opinion are sexual identities fixed? Please explain the following as they are understood in a Thai context, kàthoei, phêet, gay, bisexual

- Are sexual cultures in Bangkok changing?

- If yes, why do you think these sexual cultures are changing? Are there any organisations that contribute to these changes? In what way?

- Do you believe that interventions are important in bringing about positive change?

- Can you think of any negative impacts of interventions such as these?

- What role may sexual rights play in a Thai/Bangkok context? 
Appendix Seven : Jacob Hale Rules for Non-Transsexuals Writing about Transsexuals, Transsexuality, Transsexualism, or Trans

1. Approach your topic with a sense of humility: you are not the experts about transsexuals, transsexuality, transsexualism, or trans Transsexuals are.

2. Interrogate your own subject position: the ways in which you have power that we don't (including powers of access, juridicial power, institutional power, material power, power of intelligible subjectivity), the ways in which this affects what you see and what you say, what your interests and stakes are in forming your initial interest, and what your interests and stakes are in what you see and say as you continue your work. (Here's what Bernie Hausman, p.vii, says about how her initial interest was formed: She had been reading about transvestism and ran across library material on transsexualism. "Now *that* was fascinating." Why? "The possibilities for understanding the construction of 'gender' through an analysis of transsexualism seemed enormous and there wasn't a lot of critical material out there." Remember that using those with less power within institutionalized, material and discursive structures as your meal ticket (retention, tenure, promotion) is objectionable to those so used.)

3. Beware of replicating the following discursive movement (which Sandy Stone articulates in "The Empire Strikes Back," and reminds us is familiar from other colonial discourses): Initial fascination with the exotic; denial of subjectivity, lack of access to dominant discourse; followed by a species of rehabilitation.

4. Don't erase our voices by ignoring what we say and write, through gross misrepresentation (as Hausman does to Sandy Stone and to Kate Bornstein), by denying us our academic credentials if we have them (as Hausman does to Sandy Stone), or by insisting that we must have academic credentials if we are to be taken seriously.

5. Be aware that our words are very often part of conversations we're having within our communities, and that we may be participating in overlapping conversations within multiple communities, e.g., our trans communities, our scholarly communities (both interdisciplinary ones and those that are disciplinarily bounded), feminist communities, queer communities, communities of color. Be aware of these conversations, our places within them, and our places within community and power structures. Otherwise, you won't understand our words.

6. Don't totalize us, don't represent us or our discourses as monolithic or univocal; look carefully at each use of 'the', and at plurals.

7. Don't uncritically quote non-transsexual "experts," e.g., Harry Benjamin, Robert Stoller, Leslie Lothstein, Janice Raymond, Virgina Prince, Marjorie Garber. Apply the same critical acumen to their writings as you would to anyone else. 
8. Start with the following as, minimally, a working hypothesis that you would be loathe to abandon: "Transsexual lives are lived, hence livable" (as Naomi Scheman put it in "Queering the Center by Centering the Queer").

9. When you're talking about male-to-female transsexual discourses, phenomena,experiences, lives, subjectivities, embodiments, etc., make that explicit and keep making it explicit throughout; stating it once or twice is not sufficient to undermine paradigmaticity. Don't toss in occasional references to female-to-male transsexual discourses, phenomena, experiences, lives, subjectivities, embodiments, etc., without asking what purposes those references serve you and whether or not those purposes are legitimate.

10. Be aware that if you judge us with reference to your political agenda (or agendas) taken as the measure or standard, especially without even asking if your agenda(s) might conflict with ours and might not automatically take precedence over ours, that it's equally legitimate (or illegitimate, as the case may be) for us to use our political agenda(s) as measures by which to judge you and your work.

11. Focus on: What does looking at transsexuals, transsexuality, transsexualism, or transsexual tell you about *yourself*, *not* what does it tell you about trans.

12. Ask yourself if you can travel in our trans worlds. If not, you probably don't get what we're talking about. Remember that we live most of our lives in nontranssexual worlds, so we probably do get what you're talking about.

13. Don't imagine that you can write about the trope of transsexuality, the figure of the transsexual, transsexual discourse/s, or transsexual subject positions without writing about transsexual subjectivities, lives, experiences, embodiments. Ask yourself: what relations hold between these categorial constructions, thus what implications hold between what you write about one and what you don't write about another.

14. Don't imagine that there is only one trope of transsexuality, only one figure of "the" transsexual, or only one transsexual discourse at any one temporal and cultural location.

15. If we attend to your work closely enough to engage in angry, detailed criticism, don't take this as a rejection, crankiness, disordered ranting and raving, or the effects of testosterone poisoning. It's a *gift*. (And it's praise: there must be something we value about you to bother to engage you, especially since such engagement is often painful, as well as time-consuming, for us.)

[source: http://sandystone.com/hale.rules.html ] 
Burford, J. (July, 2009) “Rainbow NGOs: Developing MSM Sexual Cultures and Communities in Bangkok, Thailand: Reflections from Fieldwork., New Zealand Asian Studies Society International Conference, Wellington, NZ

Burford, J. (November, 2009) "Developing 'MSM' in Bangkok- Complicating the Narrative". Sociology Association of Aotearoa New Zealand Conference, Palmerston North, NZ

Burford, J. (October, 2010) “Advocacy with Queer Young People: Reflections from research and practice", National Students Advocacy Conference, Dunedin, NZ

Burford, J. (Forthcoming- November, 2010) "De-facing my thesis? Queer Thoughts on Re-search and Writing" Contemporary Ethnography Across the Disciplines, Hamilton, NZ 